\title{
Task 3.5: Poison Resistant Catalyst Development and Testing
}

\author{
Final Topical Report \\ Design and Construction of the Alternative Fuels Field Test Unit \\ and Liquid Phase Methanol Feedstock and Catalyst Life Testing \\ at Eastman Chemical Company (Kingsport, TN)
}

Andrew W. Wang

Contractor

AIR PRODUCTS AND CHEMICALS, INC.

Allentown, PA 18195

March 1997

Prepared for the United States Department of Energy

Under Contract No. DE-FC22-95PC93052

NOTE: AIR PRODUCTS DOES NOT CONSIDER ANYTHING IN THIS REPORT TO BE CONFIDENTIAL OR PATENTABLE. 


\subsection{Introduction}

\subsection{Alternative Fuels Field Test Unit (AFFTU)}

The AFFTU is a portable laboratory designed specifically to provide on-site evaluation of potential feedstocks for processes that produce alternative fuels from indigenous raw materials such as coal, natural gas or environmentally disadvantaged carbonaceous feedstocks. Since conversion of these raw materials into feed gas streams can produce a variety of bulk gas compositions, which furthermore can contain a myriad of trace components, it is necessary to evaluate each new feedstock on an individual basis. While it is possible to prepare blended gas mixtures to simulate the bulk composition of a known feedstock, it is neither possible nor cost-effective to simulate adequately the variety of trace chemicals present in that feedstock -- some of which may not even be detected by routine analysis. Additionally, the transient composition of the gas during upsets or routine process changes may have an impact on the proposed process that is not foreseen in standard design. To address these concerns, the AFFTU was constructed with the following experimental capabilities:

1. A state-of-the-art gas chromatograph system to perform semi-continuous monitoring of both bulk composition and the concentration of key trace poisons down to one part per billion (ppb).

2. A 30-mL reactor system that can accept up to two feed streams from the customer, allowing a true life test with the actual gas projected for use in the proposed facility.

3. A manifold of four adsorbent beds, located upstream of the reactor, which permits the testing of adsorbents for the removal of contaminants from the feed stream. The effectiveness of these adsorbents may be evaluated either by analysis of the gas upstream and downstream of the bed (or at an intermediate point within the bed) or by observing the impact of the presence or absence of that bed on the actual stability of the catalyst activity.

To achieve portability, the AFFTU was constructed in a commercial 48-foot trailer. Roughly half of the trailer is dedicated as "office" space, and it contains three personal computers that serve as an interface to the process control and handles data acquisition and analysis. The other half houses the laboratory, which is highly automated and designed for unattended operation. When not in use at a customer's site, the AFFTU is located at Air Products' Iron Run research facility, where it becomes an effective extension of the Alternative Fuels research laboratories.

\subsection{Kingsport Testing}

A 260 ton-per-day Liquid-Phase Methanol (LPMEOH ${ }^{\mathrm{TM}}$ ) Plant has been constructed and commenced start-up in January 1997 at Eastman Chemicals' Kingsport, Tennessee facility as part of the Department of Energy's Clean Coal Technology program. The objective of this project is to "demonstrate the production of methanol using the LPMEOH ${ }^{\mathrm{TM}}$ process in conjunction with an integrated coal gasification facility." Design and construction of the plant is the responsibility of Air Products and Chemicals, Inc.. Start-up inaugurated a four-year demonstration period, under which Eastman Chemical Company will assume operation of the facility. 
A highly simplified flow sheet for the Kingsport $\mathrm{LPMEOH}^{\mathrm{TM}}$ facility is given in Figure 1. Three gas streams are available as feedstocks to the process: "balanced syngas" from Eastman's coal gasifiers, "makeup CO" from a cold box and " $\mathrm{H}_{2}$ makeup" from Eastman's existing methanol unit. The reactor will operate at $250^{\circ} \mathrm{C}$ and $750 \mathrm{psig}$. Downstream of the reactor, unreacted syngas will be separated from the products and roughly $90 \%$ of it will be recycled.

It is well known that the presence of even trace amounts of certain compounds in the feed gas to a methanol synthesis catalyst can cause unacceptable rates of catalyst deactivation. For this reason, extensive testing of the feed streams at Kingsport was performed during the project design phase. The results of this testing are summarized in Table 1; the full report is provided as Appendix 1. No known catalyst poisons were found in concentrations that would render the Eastman's feed streams unsuitable as feedstocks to a LPMEOH ${ }^{\mathrm{TM}}$ plant. Based on this work, an activated carbon guard bed (see Figure 1) was designed to protect the catalyst against possible contamination by iron or nickel carbonyl in the event of an upset in the gasifiers or syngas purification system.

Table 1 - Summary of Poisons Pretesting

\begin{tabular}{|l|l|l|}
\hline Component & Specification (ppmv) & $\begin{array}{l}\text { Measured Concentration } \\
\text { (ppmv) }\end{array}$ \\
\hline \hline Arsenic, as AsH $\mathrm{H}_{3}$ & 0.01 & 0.027 \\
\hline $\mathrm{Halogens}(\mathrm{Cl} \& \mathrm{~F})$ & 0.01 & $\sim 0$ \\
\hline $\mathrm{HCl}$ & 0.01 & $<1$ \\
\hline $\mathrm{Fe}(\mathrm{CO})_{5}$ & 0.01 & $<0.01$ \\
\hline $\mathrm{Ni}(\mathrm{CO})_{4}$ & 0.01 & $\leq 0.001$ \\
\hline Ammonia & 10 & $<0.023$ \\
\hline $\mathrm{HCN}$ & 0.01 & $<1$ \\
\hline Acetonitrile & $?$ & $<0.5$ \\
\hline $\mathrm{H}_{2} \mathrm{~S}$ (post Eastman guardbed) & $0.03^{*}$ & $0.035 \pm 0.024$ \\
\hline $\mathrm{COS}$ & $0.03^{*}$ & $<0.5$ \\
\hline
\end{tabular}

*[Note that the 30-ppb specification for COS and $\mathrm{H}_{2} \mathrm{~S}$ is an arbitrary division between $\mathrm{COS}$ and $\mathrm{H}_{2} \mathrm{~S}$; the true specification is $60 \mathrm{ppb}$ total sulfur.]

The results of the pre-testing of the Kingsport feed streams provided a sound basis for proceeding with the project and designing the guard bed. However, prudent engineering practice required the performance of additional on-site feedstock testing. This testing involved running a bench-scale $\mathrm{LPMEOH}^{\mathrm{TM}}$ reactor for one month using feed gas directly from Eastman's piping, while simultaneously monitoring the concentrations of key catalyst poisons. The following factors were involved in this decision:

- The pre-testing provided a picture of the average expected poisons levels in the three feed streams. It did not provide very much information on the frequency and magnitude of upsets or the poisons concentration excursions that might result. Therefore longer term monitoring of the key catalyst poisons would be valuable in confirming that the existing guard bed design was adequate. 
- In the case of a few of the potential catalyst poisons ( $\mathrm{HCN}$ and acetonitrile, for example), the testing method was not sufficiently sensitive to discern whether the concentration of those compounds met the specification. Furthermore, for many of the compounds, the specifications themselves represent judgments based on the best available information. Performing an actual life test using the syngas in question provides a reliable measurement of the true impact of these trace compounds on the stability of the catalyst.

- It is possible that an unknown poison is present, either continually or during upsets, which has a deleterious effect on the methanol synthesis catalyst.

- The construction of the Kingsport plant represents a leap both in terms of scale and feedstock source. It is therefore desirable to eliminate the feedstock as a possible variable by demonstrating stable LPMEOH ${ }^{\mathrm{TM}}$ reaction activity using Eastman's feed streams.

The AFFTU was taken to Kingsport in May 1996 for six weeks of on-site testing. As a result of this work, the assumption that the Eastman syngas is sufficiently poison-free to sustain stable catalyst activity was confirmed, and additional insights into the identity and concentrations of catalyst poisons in that feedstock were obtained. This report describes the AFFTU and the Kingsport testing.

\subsection{Objectives}

The AFFTU was designed to provide on-site testing of the quality of synthesis gas feeds for conversion to fuels via liquid phase technologies. The overall objective was to provide an accurate measure of the quality of the syngas via:

1. The capability to run the desired reaction for an extended period using the customer's synthesis gas as feed.

2. State-of-the-art trace gas analysis targeting specific, known catalyst poisons.

3. Highly automated data acquisition and storage.

4. Equipment and operating procedures designed with the safety of the operators and the equipment as the top priority.

The objective of the AFFTU/Kingsport project was to provide long-term testing of two of the three feed streams (i.e., the balanced syngas and makeup CO streams) for the Liquid Phase Methanol demonstration plant at Eastman Chemical Company (Kingsport, TN) for poisons that would cause faster than anticipated catalyst deactivation. Two forms of testing were employed: (1) a life test of the $\mathrm{LPMEOH}^{\mathrm{TM}}$ reaction in a 300-mL reactor using the actual feed streams and (2) semi-continuous analysis of those same feed streams using gas chromatographs equipped with detectors sensitive to targeted poisons. 


\subsection{Experimental Methods}

\subsection{Design of the AFFTU}

The AFFTU is a mobile laboratory housed in a tractor trailer. T. A. Dahl was responsible for the design and construction. The project was completed on time and on budget (see Appendix 3). Considerable cost savings were achieved by reusing large portions of the experimental apparatus from the similar system built for the proposed 1989 Clean Coal demonstration project at Beulah, North Dakota. The bulk of the cost of the current system went into upgrading the onboard gas analysis and data acquisition and control systems. These improvements permitted analysis of trace catalyst poisons down to the one part per billion levels. These improvements also permitted unattended data acquisition which allowed around-the-clock monitoring of gas concentrations.

The trailer is divided by a wall into two portions: an office area and a laboratory area. The office area houses three personal computers, a sink and counter, and most of the control and data acquisition electronics. The laboratory area houses all of the experimental apparatus and analytical equipment, tools and chemicals storage.

The utility requirements of the AFFTU are minimal, allowing for maximum flexibility in siting. The specific requirements are:

1. $480 \mathrm{~V}-3 \mathrm{Ph}-60 \mathrm{~Hz}$ electrical supply ( $75 \mathrm{kVA}, 90 \mathrm{~A}$ transformer)

2. Potable water

3. Instrument air: $150 \mathrm{psig}$

4. Instrument nitrogen: $150 \mathrm{psig}$

5. Municipal drain/sewer for sink

The experimental apparatus (Figures 2 through 11) consists of a feed manifold, adsorption (pretreatment) system and autoclave system. The feed manifold allows the blending of two feed streams (supplied by Eastman), as well as any of several cylinder gases ( $2 \%$ hydrogen in nitrogen is shown in Figure 2). Flows are controlled with mass flow controllers, MFC1 and MFC2. The adsorption system is designed to permit up to four adsorbent beds to be placed in series in the feed stream for selective removal of various catalyst poisons potentially present in the syngas. A compressor is available if adsorption at pressures greater than the supplied feed pressure is desired. A back-pressure regulator (BPR1) maintains the pressure in the adsorption system. The treated feed is sent to a $300-\mathrm{mL}$ stirred autoclave (Autoclave Engineers). This reactor is equipped with a gas-liquid separator, maintained at $145^{\circ} \mathrm{C}$, to return any entrained slurry to the reactor. Feed pressure to the reactor may be boosted using compressor COMP2; reactor pressure is set with regulator R5 and is maintained using BPR3. The flow rate is set by mass flow controller MFC3. Typically the flow rate set by MFC1 and MFC2 is least $10 \%$ above that of MFC3; this helps to eliminate any pulsations caused by the compressors, while guaranteeing that flow will be maintained. The excess feed vents through BPR2. The reactor effluent is vented through a wet test meter to obtain an accurate measurement of the reactor exit flow.

A list of the specific components of the AFFTU is provided as Appendix 2. 


\subsection{Onboard Gas Analysis}

Analysis of the gas compositions was performed by two Hewlett-Packard 6890 Gas Chromatographs (GCs). These GCs were configured for the specific analyses by Wasson.ECE Instrumentation, and the flow sheets are provided in Figure 12 (a) and (b). GC1 was dedicated to bulk gas analysis and was equipped with two detectors: a thermal conductivity detector (TCD) for analysis of hydrogen, carbon monoxide, carbon dioxide and nitrogen, and a flame ionization detector (FID) for hydrocarbons analysis (primarily methanol for the Kingsport work). GC2 was dedicated to analysis of ppb levels of four poisons: hydrogen sulfide and carbonyl sulfide using a Sulfur Chemiluminescence Detector (Sievers) and nickel and iron carbonyl using an Electron Capture Detector (Hewlett-Packard). The analysis of these metal carbonyls and sulfides was shown to be sensitive down to $1 \mathrm{ppb}$; that is, a clear and unambiguously integrable peak could be observed at that concentration. Calibration was performed using standards with considerably higher concentrations, and linearity of the detector response was assumed in order to interpolate to concentrations below those used for calibration. Examples of the chromatograms are given in Figure 12 (c) through (f). Details of the GC techniques are provided in Tables 2 and 3.

Table 2 - Gas Chromatograph \#1: Bulk Gas Analysis

\begin{tabular}{|c|c|c|c|}
\hline Detector & A: FID & B: TCD & C: TCD \\
\hline Components/Analysis & Hydrocarbons & $\mathrm{CO}, \mathrm{CO}_{2}, \mathrm{~N}_{2}$ & $\mathrm{H}_{2}$ \\
\hline Sample Size & $0.1 \mathrm{~mL}$ & $1.0 \mathrm{~mL}$ & $1.0 \mathrm{~mL}$ \\
\hline Carrier Gas & Helium & Helium & Nitrogen \\
\hline Detector Temp. & $250^{\circ} \mathrm{C}$ & $200^{\circ} \mathrm{C}$ & $50^{\circ} \mathrm{C}$ \\
\hline Injector Temp. & $200^{\circ} \mathrm{C}$ & $200^{\circ} \mathrm{C}$ & Not Applicable \\
\hline Columns & $\begin{array}{l}\# 1 \text { ) } 0.53 \mathrm{~mm} \times 9 \mathrm{~cm} \\
\text { ?Wasson KC5 capillary } \\
\text { \#2) } 0.53 \mathrm{~mm} \times 50 \mathrm{~m} \\
\text { Wasson KC5 capillary }\end{array}$ & $\begin{array}{c}\text { \#3) } 1 / 16 \text { in. } x 8 \mathrm{ft} \\
\text { Wasson } \mathrm{Km} 1(80 / 100) \\
\text { \#4) } 1 / 16 \text { in. } \mathrm{x} 10 \mathrm{ft} \\
\text { Wasson } \mathrm{Km} 2 \mathrm{~S} \\
(80 / 100)\end{array}$ & $\begin{array}{c}\text { \#5a) } 1 / 8 \text { in. } x 6 \mathrm{ft} \\
\text { Wasson } \mathrm{K} 1(80 / 100) \\
\text { \#5b) } 1 / 8 \text { in. } \mathrm{x} 7 \mathrm{ft} \\
\text { Wasson } \mathrm{K} 2(80 / 100) \\
\text { \#6) } 1 / 8 \text { in. } \mathrm{x} 2 \mathrm{ft} \\
\text { Wasson } \mathrm{K} 2(80 / 100) \\
\text { \#7) } 1 / 8 \text { in. } \mathrm{x} 2 \mathrm{ft} \\
\text { Wasson } \mathrm{K} 2(80 / 100)\end{array}$ \\
\hline Temp. Program & $85^{\circ} \mathrm{C}$ Isothermal & & \\
\hline Valve Program & $\begin{array}{l}0.01 \mathrm{~min} \\
0.05 \mathrm{~min} \\
0.05 \mathrm{~min} \\
0.75 \mathrm{~min} \\
0.75 \mathrm{~min} \\
2.30 \mathrm{~min} \\
2.90 \mathrm{~min} \\
4.00 \mathrm{~min} \\
5.00 \mathrm{~min}\end{array}$ & $\begin{array}{l}\text { Valve } 2 \mathrm{ON} \\
\text { Valve } 1 \mathrm{ON} \\
\text { Valve } 7 \mathrm{ON} \\
\text { Valve } 3 \mathrm{ON} \\
\text { Valve } 7 \mathrm{OFF} \\
\text { Valve } 1 \mathrm{OFF} \\
\text { Valve } 4 \mathrm{ON} \\
\text { Valve } 2 \mathrm{OFF} \\
\text { Valve } 3 \mathrm{OFF}\end{array}$ & \\
\hline
\end{tabular}




\begin{tabular}{|l|l|l|l|} 
& $5.50 \mathrm{~min}$ & Valve 4 OFF & \\
\hline
\end{tabular}


Table 3 - Gas Chromatograph \#3: Poisons Analysis

\begin{tabular}{|c|c|c|}
\hline Detector & $\begin{array}{c}\text { A: Hewlett-Packard } \\
\text { Electron Capture } \\
\text { Detector }\end{array}$ & $\begin{array}{l}\text { B: Sievers Instruments, Inc. Sulfur } \\
\text { Chemiluminescence Detector }\end{array}$ \\
\hline Components/Analysis & $\mathrm{Fe}(\mathrm{CO})_{5}, \mathrm{Ni}(\mathrm{CO})_{4}$ & $\mathrm{COS}, \mathrm{H}_{2} \mathrm{~S}$ \\
\hline Sample Size & $1.0 \mathrm{~mL}$ & $1.0 \mathrm{~mL}$ \\
\hline Carrier Gas & Nitrogen & Helium \\
\hline Detector Temp. & $150^{\circ} \mathrm{C}$ & Not Applicable \\
\hline Injector Temp. & $100^{\circ} \mathrm{C}$ & Not Applicable \\
\hline Columns & $\begin{array}{c}\text { \#3) } 1 / 8 \text { in. } \mathrm{x} 10 \mathrm{ft} \\
\text { 10\% Squalane on } \\
\text { Chromosorb W-AW } \\
(100 / 120)\end{array}$ & $\begin{array}{l}\text { \#1) } 1 / 8 \text { in. x } 30 \text { in. } \\
\text { Wasson K20 (80/100) } \\
\text { \#2) } 1 / 8 \text { in. x } 30 \text { in. } \\
\text { Wasson K20 (80/100) }\end{array}$ \\
\hline Temp. Program & $50^{\circ} \mathrm{C}$ Isothermal & \\
\hline Valve Program & $\begin{array}{l}0.01 \mathrm{~min} \\
0.05 \mathrm{~min} \\
4.00 \mathrm{~min} \\
4.00 \mathrm{~min}\end{array}$ & $\begin{array}{l}\text { Valve } 2 \mathrm{ON} \\
\text { Valve } 1 \mathrm{ON} \\
\text { Valve } 2 \mathrm{OFF} \\
\text { Valve } 1 \mathrm{OFF}\end{array}$ \\
\hline
\end{tabular}

\subsection{Feed Streams}

Eastman's "balanced syngas" stream was connected to the AFFTU primary feed; the company's "makeup CO" stream was connected to the secondary feed. For most of the AFFTU experiments at Kingsport, a feed mixture of $75 \%$ balanced syngas and $25 \%$ makeup $\mathrm{CO}$ was used. This corresponded to the condition in the demonstration plan that used the highest quantity of makeup CO. This case was chosen since our objective was not to mimic the final plant design, but rather to evaluate the poisons concentrations for both streams.

\subsection{Adsorption System Design and Operating Conditions}

The adsorption system (see Figures 2 and 6) consists of five beds -- four operating beds and a fifth bed filled with alumina which is used to decompose toxic metal carbonyls desorbed from the other four beds during regeneration. A detailed drawing of one of these beds is given in Figure 11. Each bed is approximately 12 inches long and 0.65 inches inside diameter. Four-foot-long beds are also available, but were not used in the Kingsport testing. Sampling ports are located at three intermediate positions along the bed.

The choice of adsorbents and their position in the pretreatment sequence (Table 4) was based on results from our laboratory and the previous Field Test Unit work in Beulah, ND. ${ }^{2,10}$ 
Table 4 - Adsorbents Used for Kingsport Testing

\begin{tabular}{|c|c|c|c|c|}
\hline Bed & Adsorbent & $\begin{array}{c}\text { Target } \\
\text { Contaminant }\end{array}$ & Weight & Temp. \\
\hline 1 & Ground S3-86 & $\mathrm{H}_{2} \mathrm{~S}, \mathrm{COS}$ & $80.71 \mathrm{~g}$ & Room \\
\hline 2 & LZY-52 & $\mathrm{Ni}(\mathrm{CO})_{4}$ & $36 \mathrm{~g}$ & Room \\
\hline 3 & BPL Carbon & $\mathrm{Fe}(\mathrm{CO})_{5}, \mathrm{Ni}(\mathrm{CO})_{4}$ & $29.14 \mathrm{~g}$ & Room \\
\hline 4 & UCI G-132D & $\mathrm{AsH}_{3}$ & $69.53 \mathrm{~g}$ & $40^{\circ} \mathrm{C}$ \\
\hline 5 & Alumina & Decomp. Carbonyls & $42.8 \mathrm{~g}$ & $250^{\circ} \mathrm{C}$ \\
\hline
\end{tabular}

Bed \#1 was packed with the same type of catalyst as was used in the reactor, BASF S3-86. To avoid introducing any undue pressure drop associated with a fine powder, pelletized S3-86 was selected and coarsely ground to the range 35-100 mesh.

The intended adsorbent for Bed \#2 was Linde LZY-72, a hydrogen-exchanged zeolite Y. Previous experimentation at Air Products had shown this material to be an effective and partially regenerable sorbent for nickel carbonyl. ${ }^{2}$ However, Linde had no LZY-72 available, so it was agreed that LZY-52, a sodium-exchanged $\mathrm{Y}$, would be tested instead.

The BPL carbon used in Bed \#3 is a commercially available microporous carbon from Calgon. This is the same material that will be used in the actual guard bed being installed in the Kingsport $\mathrm{LPMEOH}^{\mathrm{TM}}$ Demonstration Facility. A smaller extrudate (12×30 mesh) was used in the AFFTU to avoid channeling problems in the bed. This carbon is known to be an effective adsorbent for metal carbonyls and a variety of other trace components; however, it is not expected to be useful for the removal of sulfides.

G-132D, an arsine removal material from UCI, is a mixed copper and zinc oxide that removes arsine via reaction with $\mathrm{CuO}$, forming copper arsenide. To improve the rate of this reaction, the bed was maintained slightly above room temperature in accordance with the manufacturer's recommendations.

The metal carbonyls were decomposed on a bed of Kaiser A-201 alumina heated to $250^{\circ} \mathrm{C}$. The function of the alumina is primarily to provide a high surface area on which the decomposition can occur.

\subsection{Safety Considerations}

The AFFTU was subjected to Air Products' Process Hazards Review protocol. This protocol reviews the equipment and procedures in terms of chemical hygiene/exposure, strategies to handle potential hazards, risk minimization, required training and personal protective equipment, operability and acceptable design practices. An Operational Readiness Inspection (ORI) at Air Products verified that the equipment had been constructed in accordance with the Hazards Review and that all alarms and safety interlocks were calibrated and functioning properly. Details of the design were supplied to Eastman for their review. Once the AFFTU was installed at Kingsport, a second ORI was performed by a combined team of Air Products and Eastman personnel. Minor changes in the tie-in tubing that connected the AFFTU to Eastman's syngas headers were implemented as a result. 


\section{Results}

\subsection{Preliminary AFFTU Tests (Run 14987-1)}

A preliminary test ("Shakedown Run") of the AFFTU systems was performed at Air Products' Iron Run facility (Fogelsville, PA) on April 10-26, 1996. This provided an opportunity to de-bug the data acquisition and control systems, as well as verify that all of the experimental components were functioning properly.

The shakedown run used powdered BASF S3-86 catalyst in the methanol synthesis reactor, employing Texaco-type gas from a tube trailer as feed. Our standard laboratory conditions were used. The resulting product stream concentrations were in line with our experience (Table 5).

Table 5 - Shakedown Run Summary

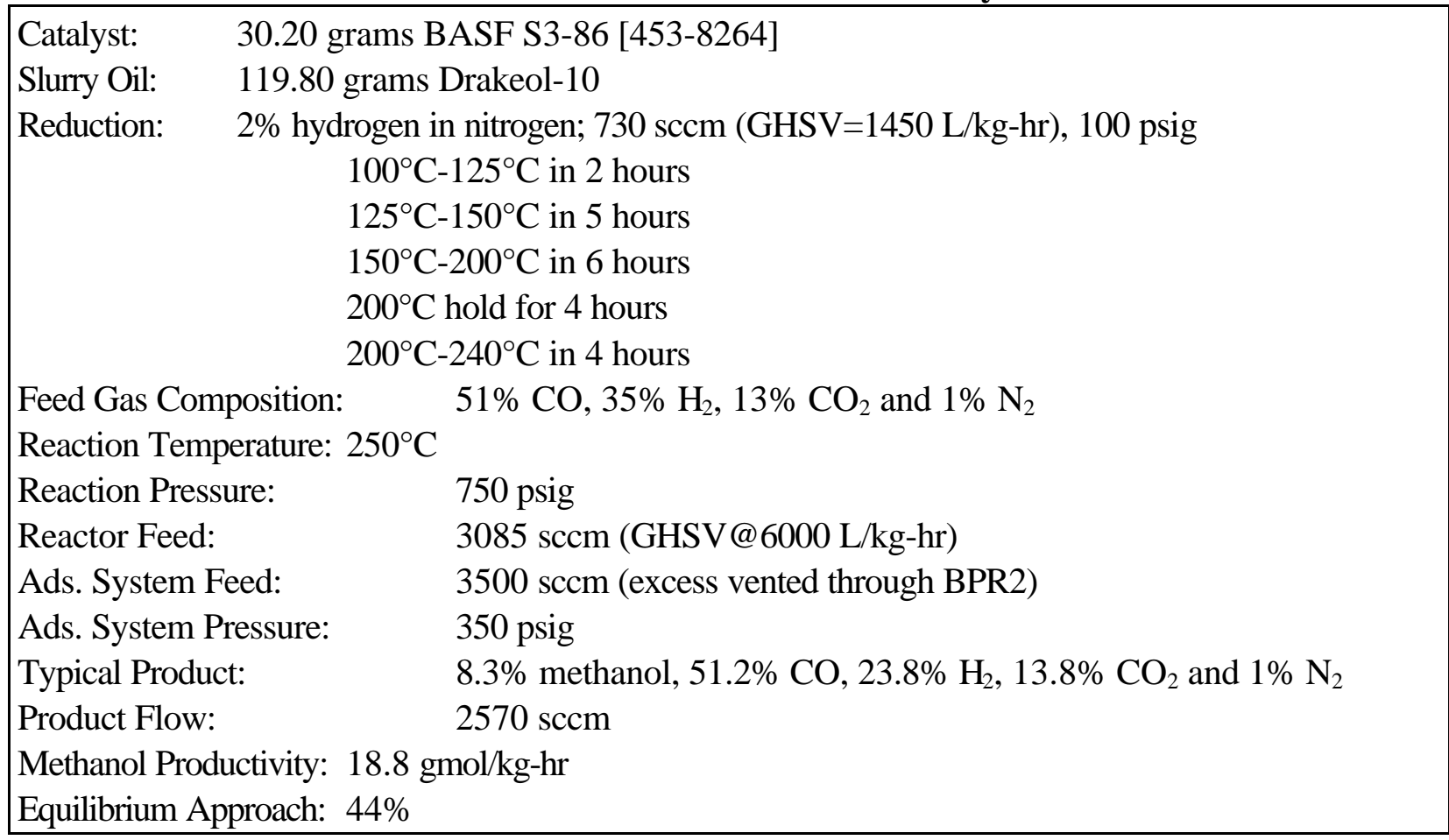

The four adsorption beds were loaded with the same adsorbents that were eventually used for the Kingsport test (Beds 1-3 were reloaded at the beginning of the Kingsport run). All four beds were kept on line through the entire shakedown run.

The shakedown run yielded the following results:

- The capability of the equipment to sustain an active, stable LPMEOH ${ }^{\mathrm{TM}}$ reaction was demonstrated.

- The GC methods were reproducible, and accurate analyses were achieved.

- Several critical problems with the data acquisition software surfaced during the shakedown run. These were corrected, allowing unattended data acquisition to be achieved. Particularly useful was the ability to change sampling ports automatically and to sample from those ports at predetermined times. 
- The presence of 10-15 ppm of iron carbonyl and $14 \mathrm{ppb}$ of COS in the tube trailer gas was observed. This underscores the importance of our current procedure for pretreating the gas for our laboratory operations by passing it through a bed of adsorbent carbon.

- The progressive breakthrough of iron carbonyl through Beds \#1 and \#2 was observed.

\subsection{Kingsport Testing (Run 14987-27)}

The conditions used in the Kingsport run are given in Table 6, and the chronology of the run is provided in Table 7.

Table 6 - Kingsport Run Summary

\begin{tabular}{|ll|}
\hline Catalyst: & 30.02 grams BASF S3-86 [453-8264] \\
Slurry Oil: & 120.12 grams Drakeol-10 \\
Reduction: & $2 \%$ hydrogen in nitrogen; 754 sccm (GHSV@ 1500 L/kg-hr), 100 psig \\
& $100^{\circ} \mathrm{C}-125^{\circ} \mathrm{C}$ in 2 hours \\
& $125^{\circ} \mathrm{C}-150^{\circ} \mathrm{C}$ in 5 hours \\
& $150^{\circ} \mathrm{C}-200^{\circ} \mathrm{C}$ in 6 hours \\
& $200^{\circ} \mathrm{C}$ hold for 4 hours \\
& $200^{\circ} \mathrm{C}-240^{\circ} \mathrm{C}$ in 4 hours
\end{tabular}


Table 7 - Chronology of Kingsport Run

\begin{tabular}{|l|c|c|c|}
\hline \multicolumn{1}{|c|}{ Event } & Date \& Time & Time Onstream* & Days of Operation*** \\
\hline Beginning of Run & $5 / 151440$ & 0 & -0.35 \\
\hline Bed \#4 Dropped & $5 / 20830$ & 114 & 4.4 \\
\hline Bed \#2 Dropped & $5 / 21930$ & 139 & 5.44 \\
\hline Bed \#1 Dropped & $5 / 221000$ & 163 & 6.56 \\
\hline Bed \#3 Dropped & $5 / 261500$ & 264 & 10.67 \\
\hline First Gasifier Outage & $5 / 301430$ & 360 & 14.65 \\
\hline Restored & $5 / 31400$ & 360 & 15.21 \\
\hline Second Gasifier Outage & $6 / 6730$ & 503 & 21.36 \\
\hline Restored & $6 / 101000$ & 503 & 25.47 \\
\hline Run Terminated & $6 / 171700$ & 678 & 32.76 \\
\hline
\end{tabular}

*The cumulative time (in hours) of exposure of the catalyst to feed gas.

**The number of days since the beginning of the experiment. The negative value at the beginning results from differing definitions of when the experiment began. Continuous syngas poisons monitoring ("Days of Operation") began several hours after the point we adopted as the basis for our "Time Onstream" datum.

\subsubsection{Poisons Monitoring Results}

\section{Summary}

Four materials that are known to poison the S3-86 methanol catalyst were observed during at least portions of the testing period: iron carbonyl, nickel carbonyl, hydrogen sulfide and carbonyl sulfide. No other compounds (other than the bulk components of the feed and product streams) were observed with either the Electron Capture Detector or the Sulfur Chemiluminescence Detector. The packed bed of BASF S3-86 methanol synthesis catalyst was effective for the removal of $<20 \mathrm{ppb}$ iron carbonyl, $<3$ ppb hydrogen sulfide and $<20 \mathrm{ppb}$ carbonyl sulfide, but was saturated rapidly by the $10-200 \mathrm{ppb}$ nickel carbonyl initially present in the feed stream. The activated carbon bed (Calgon BPL) was effective for the removal of both iron and nickel carbonyl and the trace hydrogen sulfide in the feed. Carbonyl sulfide was not removed by the BPL carbon. The nickel carbonyl was clearly demonstrated to be an artifact of the fresh tie-in tubing between Eastman's piping and the AFFTU. Most, if not all, of the iron carbonyl was likely also an artifact of the tie-in. The sulfides are believed to be inherent in Eastman's syngas.

\subsubsection{Carbonyl Sulfide}

Carbonyl sulfide was observed throughout the testing period. The concentration typically remained between 7 and $15 \mathrm{ppb}$. During days 1-5, this concentration fluctuated according to a 24-hour cycle, as did the metal carbonyls, reaching a maximum value in the late afternoon. After day 5, these fluctuations disappeared. No satisfactory explanation as to why this component should initially fluctuate regularly in concentration and then later achieve a comparatively steady concentration has been found.

Tripling the flow rate of fresh feed into the AFFTU on day 10 had no effect on the feed concentration of COS, which did not diminish over the course of the testing period. These observations suggest that the COS is truly present in the Eastman syngas. 
In the middle of the testing period, Eastman's gasifiers were off for four days (days 22-25). When syngas generation was restored, a significant COS excursion was observed, beginning with a concentration of $190 \mathrm{ppb}$ and falling gradually to $30 \mathrm{ppb}$ over a 10-hour period (see Figure 14). Restoration of gasifier function after an earlier, briefer outage (days 14-15) did not result in such an excursion. The ephemeral nature of these excursions demonstrates the need for long-term on-site testing.

When all four guard beds were in place, the COS was largely removed by Bed \#1 (S3-86). Roughly $0.5 \mathrm{ppb}$ of COS passed through this bed, and this level of COS continued essentially unattenuated through the remaining three beds. The sequential removal of Beds 4 and 2 obviously had little impact on the COS concentrations elsewhere in the system. Just prior to the removal of Bed \#1 (day 6), samples were taken from the intermediate sampling port 3 in. from the feed end of Bed \#1. The concentration was found to be $0.4-0.5 \mathrm{ppb}$, the same as the exit concentration, indicating that the COS adsorption front had not penetrated one quarter of the way through the S3-86 bed. Removal of Bed \#1 left only the BPL carbon bed in place. Feed concentrations of COS of 8-14 ppb passed basically unchanged through this bed.

The presence of (typically) 5-20 ppb COS in our mixture of $75 \%$ balanced syngas and $25 \%$ makeup $\mathrm{CO}$ was unexpected based on the pre-testing results, which had indicated that most of the 10-60 ppb total sulfur in the balanced syngas was in the form of $\mathrm{H}_{2} \mathrm{~S}$. However, as discussed in Section 4.2.3, the reactor data show that at these levels, COS does not significantly affect catalyst stability.

\subsubsection{Hydrogen Sulfide}

Analysis of ppb levels of hydrogen sulfide is difficult due to the tendency of $\mathrm{H}_{2} \mathrm{~S}$ to react with process tubing. This reaction is reversible; therefore saturating the tubing walls with sulfide ("pickling") is, at best, a temporary solution. Our approach was to use sulfide-resistant silico-steel tubing for as much of the analytical lines as practical and to attempt to maintain the system in a "pickled" state. The fact that no hydrogen sulfide was initially observed at Kingsport (see Figure 15) and that eventually $\mathrm{H}_{2} \mathrm{~S}$ was observed approaching a level of roughly 3-4 ppb suggests that the system was initially not pickled, and gradually approached a pickled state, which permitted $\mathrm{H}_{2} \mathrm{~S}$ to reach the sulfur detector. We need to consider not only the analytical tubing, but also the entire length of fresh stainless steel used to tie the AFFTU to Eastman's syngas headers.

On day 9, catalyst poisons analysis was interrupted for 4 hours while calibration of the metal carbonyls detector was performed. During this period, $\mathrm{H}_{2} \mathrm{~S}$-free carbonyl standard was directed through the analytical system, and the pickling was lost. When the feedstock analysis was resumed later that day, no $\mathrm{H}_{2} \mathrm{~S}$ was detected. This underscores the difficulty of the $\mathrm{ppb} \mathrm{H}_{2} \mathrm{~S}$ analysis. $\mathrm{H}_{2} \mathrm{~S}$ concentrations in the range of 1-3 ppb were observed intermittently thereafter, through the second gasifier outage (day 21). 
After the second outage, hydrogen sulfide was detected fairly rapidly and leveled off in a concentration range of 2.5-6 ppb, spiking once to $29 \mathrm{ppb}$. It appears that the actual concentration of hydrogen sulfide in the Eastman syngas after the second outage was somewhat higher than during the previous portion of the run.

To summarize, in spite of the analytical challenges, we are comfortable that the actual hydrogen sulfide concentration in the Eastman gas was generally in the 2-4 ppb range prior to the second gasifier outage and in the 2.5-6 ppb range after it. These results are notably different from the pre-testing report (Table 1), which specified 10-60 ppb of total sulfur, essentially completely in the form of hydrogen sulfide. ${ }^{3}$

There are several possible explanations for this discrepancy:

1. The pre-test for hydrogen sulfide also detected COS.

2. Hydrogen sulfide is converted to COS in the AFFTU tie-in and/or analytical tubing.

3. The amount of hydrogen sulfide in Eastman's gas can vary considerably.

The trace amounts of hydrogen sulfide we detected in the trailer feed were readily removed by Bed \#1, the crushed S3-86 pellets. When this bed was removed, the BPL carbon likewise was successful in removing all traces of hydrogen sulfide from the reactor feed. This is attributed to the low inlet $\mathrm{H}_{2} \mathrm{~S}$ concentration, since previous work has shown that BPL carbon is not a particularly effective material for $\mathrm{H}_{2} \mathrm{~S}$ removal. ${ }^{4}$

\subsubsection{Nickel Carbonyl}

Nickel carbonyl was observed in the trailer feed over much of the six weeks of work in Kingsport. Both the iron and nickel carbonyl levels demonstrated a strong 24-hour cycle that followed ambient temperature (Figure 16a). ${ }^{5}$ The highest concentrations were almost always observed in late afternoon and were typically five times higher than the minimum concentrations. This observation is consistent with the kinetically limited formation of these poisons as the syngas flows through iron- and nickel-containing process lines and equipment. It has been shown that the formation of both of these catalyst poisons is reasonably sensitive to temperature in this temperature range. ${ }^{6}$ This correlation is clearly seen in Figure $16 c$.

The presence of nickel carbonyl in the AFFTU feed was shown to be an artifact of the tie-in between Eastman's piping and the AFFTU. This conclusion is based on the following observations:

1. Nickel carbonyl concentrations, initially in the $100-300 \mathrm{ppb}$ range, eventually dwindled to undetectably low levels. This is consistent with the progressive removal of nickel from the source of the artifact (valve lubricant, for example).

2. Tripling the flow rate of gas through the tie-in tubing (on day 10 and thereafter) caused an immediate drop in the nickel carbonyl concentration (to undetectable levels; see Figure 16a16c). Because day 10 was comparatively cool, the concentration of nickel carbonyl before the flow rate was tripled was already quite low. By the end of day 11, the concentration of nickel carbonyl was similar to that before the tripling of the flow. However, the ambient temperature on that day was considerably higher; in Figure 16c, this temperature difference is accounted for, and the impact of tripling the flow is more clearly seen. 
3. Temporarily stopping the flow caused a buildup in nickel carbonyl in the tie-in line, indicating that this poison is formed there. This was clearly observed when flow was resumed on three occasions: first, during the initial testing of the gas (before the period shown in Figure 13); second, during the restart after the first gasifier outage (day 15); and finally after the second gasifier outage, when nickel carbonyl was briefly observed long after it had disappeared from normal onstream sampling.

The comparatively high concentrations of nickel carbonyl observed when syngas was first fed to the trailer rapidly saturated Bed \#1 (S3-86). Three days later, nickel carbonyl broke through Bed \#2 (LZY-52). Bed \#3 (BPL carbon) was also found to be effective in removing all of the 5-60 ppb of nickel carbonyl still present in the AFFTU feed over the following eight days until this bed was taken out.

\subsubsection{Iron Carbonyl}

Iron carbonyl was observed throughout the six weeks of testing. Concentrations were generally in the range of 4-20 ppb before the flow through the tie-in was tripled, and 1-4 ppb when tripled flow was used (see Figures 13 and 16a-c). This change in concentration leads to the hypothesis that the presence of iron carbonyl is an artifact of the tie-in and not representative of the Eastman syngas itself. This hypothesis is supported by the observation, already described for nickel carbonyl, that particularly high iron carbonyl levels were measured whenever flow was restarted through the tie-in lines, indicating that this material accumulates when flow is stopped. However, two observations prevent us from stating definitively that all the iron carbonyl was an artifact. First, unlike nickel carbonyl, the concentration of iron carbonyl remained steady throughout the run. This means that if iron carbonyl was being generated in the tie-in tubing, the source of iron was not as limited as that of nickel. Second, the instantaneous drop in iron carbonyl concentration upon tripling of the feed was only $35 \%$ (from 5.1 to $3.3 \mathrm{ppb}$ ), quite far from a proportional decrease. This certainly could be explained by the fact that increasing the flow rate in the tie-in tubing results in a higher rate of iron carbonyl formation, either because of improved mass transfer to/from the tubing wall ${ }^{7}$ or because of LeChâtelier's principle (per Equation 1). In the limiting case in which the formation of iron carbonyl was extremely fast, an equilibrium concentration of iron carbonyl would be expected, regardless of the flow rate through the tie-in lines. Nevertheless, the other limiting case, in which the rate of iron carbonyl formation is very slow, must also be considered. In this case, tripling the flow rate should result in a proportional decrease in the part of the overall measured iron carbonyl concentration that is an artifact. Under this assumption, $2.5 \mathrm{ppb}$ of the iron carbonyl must be present in Eastman's syngas upstream of the tie-in lines.

$$
5 \mathrm{CO}+\mathrm{Fe} \Leftrightarrow \mathrm{Fe}(\mathrm{CO})_{5} \quad \text { (Equation 1) }
$$

Iron carbonyl was strongly adsorbed by S3-86. During the first 6 days of operation, the S3-86 adsorbent bed (Bed \#1) was in place, and no iron carbonyl was found to penetrate even 3 in. into the 12-in. bed. 


\subsubsection{Methanol Productivity Results}

\subsubsection{General Comments}

The overall productivity history of the life test is shown in Figure 17. The FID was recalibrated at 260 hours on stream, resulting in the two curves shown.

The data were analyzed by our standard reaction model. The results of this analysis and all the measured bulk gas data are given in Appendix 5. Fugacities were estimated with Air Products' proprietary thermodynamics package, which uses the modified Redlich-Kwong equation of state. The resulting $\mathrm{k}_{\mathrm{M}}$ history is given in Figure 18.

During the initial 50 hours on stream, fairly rapid loss of catalytic activity was observed. This is typical behavior for methanol production runs using this catalyst. After this initial period, activity decline was gradual and fairly steady. Several abrupt productivity losses (for example, at roughly 370, 390, 500, 540 and 660 hours on stream) are not reflected in the $\mathrm{k}_{\mathrm{M}}$ because, as explained in the following section, these productivity fluctuations were due to changes in the feed $\mathrm{CO}_{2}$ content and not to changes in the actual activity of the catalyst.

\subsubsection{Carbon Dioxide Effects}

The results given in Figures 18 and 19 show convincingly that many of the irregularities in reactor methanol productivity observed over the course of the life test were due to fluctuations in the $\mathrm{CO}_{2}$ content of Eastman's syngas stream. This kinetic model not only takes into account the dependence of the methanol synthesis rate on the fugacities of $\mathrm{CO}$ and $\mathrm{H}_{2}$, but also contains a correction term that accounts for the dependency on $\mathrm{CO}_{2}$. When the $\mathrm{k}_{\mathrm{M}}$ from this model is plotted as a function of time on stream, many of the productivity fluctuations are smoothed out. The most obvious example of this is the loss in productivity observed after the second gasifier outage. It is apparent that the catalyst did not deactivate appreciably during the four days of the outage; rather, it was low $\mathrm{CO}_{2}$ concentrations in the post-outage syngas that were responsible for the low productivity.

The reason that these comparatively small fluctuations in $\mathrm{CO}_{2}$ concentration have an unusually large impact on the reactor productivity is that although the rate is essentially independent of $\mathrm{CO}_{2}$ level at $\mathrm{CO}_{2}$ concentrations above $7 \%$, below $5 \% \mathrm{CO}_{2}$ the rate decreases rapidly with falling $\mathrm{CO}_{2}$ levels. Fortunately, even if these fluctuations are typical, they should not have a significant impact on the performance of the Kingsport plant, since the recycle is expected to raise the reactor product $\mathrm{CO}_{2}$ levels to the $7-10 \%$ range. For a few of the planned test cases in the demonstration plan, recycle ratios may be sufficiently low to cause these variations in $\mathrm{CO}_{2}$ to have an reasonable impact. The concentration of $\mathrm{CO}_{2}$ in Eastman's feed and, particularly, in the reactor effluent, must be taken into account when the performance of the Kingsport plant is evaluated.

\subsubsection{Analysis of Deactivation Rates}

Past experimentation in the laboratory using syngas free of contaminants provided the basis for evaluating the stability of the methanol synthesis activity. This data are given in Table 8 . 
Table 8 - Typical Clean-Feed LPMEOH ${ }^{\mathrm{mM}}$ Activity and Stability

\begin{tabular}{|c|c|c|c|c|c|}
\hline Gas Type & $\mathbf{C O}$ & $\mathbf{H}_{\mathbf{2}}$ & $\mathbf{C O}_{\mathbf{2}}$ & $\mathbf{k}_{\mathbf{M}}$ Deactivation Rate & Productivity Deactivation Rate \\
\hline "Shell" & 66 & 30 & 3 & $-0.042 \% / \mathrm{hr}$ & $-0.0039 \% / \mathrm{hr}$ \\
\hline "Texaco" & 51 & 35 & 13 & $-0.045 \% / \mathrm{hr}$ & $-0.019 \% / \mathrm{hr}$ \\
\hline "Eastman" & 39 & 50 & 9 & $-0.053 \% / \mathrm{hr}$ & $-0.024 \% / \mathrm{hr}$ \\
\hline
\end{tabular}

Figure 20 shows the slopes (obtained by linear regression) of various portions of the productivity history. Because the change in carbon dioxide concentration after the second gasifier outage caused a significant drop in productivity, several cases that ignore the data after this point were considered. For the same reason, the rate constant data were more useful in evaluating the stability of the catalyst. This analysis is given in Figure 21; the data from Figures 20 and 21 are summarized in Table 9. A comparison of these results with the baseline data in Table 8 leads to the conclusion that the Eastman syngas did not contain any compounds that adversely affected the stability of the methanol synthesis catalyst when compared to operation using laboratory syngas. Note that the feed mixture used in the Kingsport testing $\left(42 \% \mathrm{CO}, 55 \% \mathrm{H}_{2}\right.$ and $\left.2 \% \mathrm{CO}_{2}\right)$ was not identical to any of the standard mixes shown in Table 8. However, the interpretation of the results of the testing was straightforward because the observed deactivation rates were lower than any of the baseline cases given in Table 8 . The lone exception to this was the productivity loss during the period after the last guard bed was removed $(0.035 \% / \mathrm{hr})$. The rate constant declined $0.038 \% / \mathrm{hr}$ during that period, showing that the catalyst was at least as stable as the baseline cases and that the apparently higher productivity deactivation rate was due to changes in the feed gas composition.

Table 9 - Kingsport Test Stability Data

\begin{tabular}{|c|c|c|c|}
\hline Description & Period & $\mathbf{k}_{\mathbf{M}}$ Deactivation Rate & $\begin{array}{c}\text { Productivity } \\
\text { Deactivation Rate }\end{array}$ \\
\hline Whole Test & 0-672 Hours & $-0.038 \% / \mathrm{hr}$ & \\
\hline No Guard Beds & $264-672$ Hours & $-0.038 \% / \mathrm{hr}$ & $-0.035 \% / \mathrm{hr}$ \\
\hline COS Exposure & $163-264$ Hours & $-0.001 \% / \mathrm{hr}$ & $+0.014 \% / \mathrm{hr}$ \\
\hline After Initial Drop & $50-672$ Hours & $-0.031 \% / \mathrm{hr}$ & \\
\hline $\begin{array}{c}\text { No Guard Beds and } \\
\text { Before Second Outage }\end{array}$ & $264-500$ Hours & & $-0.017 \% / \mathrm{hr}$ \\
\hline $\begin{array}{c}\text { After Initial Drop and } \\
\text { Before Second Outage }\end{array}$ & $50-500$ Hours & & $-0.011 \% / \mathrm{hr}$ \\
\hline
\end{tabular}

One unexpected finding in the poisons analysis was the presence of 5-20 ppb of carbonyl sulfide in the trailer feed. As a consequence of this observation, the period of time in which the AFFTU was operated with Bed \#3 alone was extended. This bed, which contained BPL carbon, selectively removes metal carbonyls, but allows carbonyl sulfide to pass through. Extending this stage to 100 hours permitted an assessment of the stability of the catalyst in the presence of 5-20 ppb COS without introducing any ambiguities due to the presence of iron and nickel carbonyl. As can be seen in Figures 20 and 21, the reaction was very stable during this period; in fact, the slope of the productivity was actually positive during this time. The $\mathrm{k}_{\mathrm{M}}$ data show that the true activity did diminish very slightly and 
that the productivity increase was a reflection of the increasing $\mathrm{CO}_{2}$ content of the feed over this time frame. We conclude that COS at these levels does not have a measurable impact on the stability of the S3-86. ${ }^{8}$

\subsubsection{Analytical Results}

At the end of the life test, the four guard beds were purged individually with nitrogen for 15 minutes each. Bed \#1 received an additional post-treatment: overnight passivation with $2 \%$ oxygen in nitrogen to reoxidize the copper. After these treatments, samples were taken from each end (feed and product) of the four guard beds.

The post-reaction slurry was removed from the autoclave, and a total of 92 grams was recovered. Since a few grams were lost during the transfer, a good estimate is that 95 grams of the original 150 grams of slurry remained in the autoclave at the end of the reaction. Separate weights of oil and catalyst were not measured; however, it is likely that most of the lost weight was due to oil losses. ${ }^{9}$ The slurry was allowed to settle, the oil was then decanted and the remaining catalyst was washed with cyclohexane.

Samples of the spent slurry oil and catalyst, together with samples from the top and bottom of each adsorbent bed, were sent to Air Products' analytical group. The desired outcomes of this analysis were to:

- Assess any physical or chemical changes that may have occurred to the catalyst that could help determine the nature of the gradual deactivation over the course of the experiment or the more abrupt deactivation seen during the second gasifier outage.

- Determine whether degradation of the Drakeol-10 slurry oil could be responsible for the gradual loss of methanol productivity.

- Provide additional information on the distribution of adsorbed poisons on the adsorbent beds and the utility of those beds for the removal of specific poisons.

\subsubsection{Analysis of Spent Oil}

A sample of the spent oil was analyzed by infrared, Raman and UV/Vis spectroscopy. A sample of fresh oil and a sample of oil from a 435-hour run previously performed in the laboratory were also analyzed for comparison.

The results (Figures 22-24) showed that the three oils were essentially identical under both infrared and Raman spectroscopy. The UV/Vis spectra, which are more sensitive to unsaturation, clearly show the growth of peaks in the 200-300 nm region. These peaks are indicative of unsaturation or conjugated unsaturation. Thus it appears that although the oil remained basically unchanged throughout the run, there was some development of unsaturation, presumably through cracking of the hydrocarbon chains. Another possibility is that small amounts of unsaturated hydrocarbons were formed as by-products of

the methanol synthesis reaction, and traces of these remained in the oil. In either case, it seems unlikely that this small amount of change in the slurry medium could have caused the gradual deactivation of the S3-86. 


\subsubsection{XRD Analysis of Spent Catalyst}

$\mathrm{X}$-Ray Diffraction analysis of the spent catalyst was carried out to determine whether the crystallite size of the copper had grown appreciably during the run. During the two Great Plains (Beulah, ND) Coal Gas tests, a relationship was noted between deactivation of the S3-86 and crystallite growth. ${ }^{10}$ The first test showed significant deactivation, and the $\mathrm{Cu}$ crystallites grew from an initial size of roughly $100 \AA$ to $400 \AA$ over the 550-hour run. In the second trial, stable activity was seen, and the final $\mathrm{Cu}$ crystallite size was $140 \AA$ ( 400 hours on stream). Thus, it appears that the deactivation of the catalyst can be correlated with, though not necessarily attributed to, the growth of the copper crystallites.

The diffraction pattern for the spent catalyst sample is shown in Figure 25. Peaks for $\mathrm{Cu}$ and $\mathrm{ZnO}$, as well as a third phase (perhaps $\mathrm{CuO}$ ), were observed. The crystallite size of copper was calculated to be $179.4(+/-3.5) \AA ̊$ using the Scherrer equation with alumina as an external standard.

The general conclusion in comparing the Kingsport catalyst to the one from Great Plains is that roughly twice as much crystallite growth was observed over twice as long a run. It is consistent that both runs underwent comparatively slow deactivation, while the Great Plains run, which deactivated quickly, also showed much faster copper crystallite growth.

\subsubsection{Elemental Analysis of Spent Catalyst and Guard Beds}

All of these samples were subjected to elemental analysis by ICP-AES (Inductively Coupled Plasma Atomic Emission Spectroscopy) and/or ETA-AAS (Electrothermal Atomization Atomic Adsorption Spectroscopy). The complete report from F. A. Lucrezi is given in Appendix 4 and is summarized below in Table 10, which also includes information about the amount of time on stream each bed experienced.

Table 10 - Elemental Analysis of Catalyst and Guard Bed Samples (in ppm)

\begin{tabular}{|c|c|c|c|c|c|c|}
\hline Sample & Iron & Nickel & Arsenic & Sulfur & Chloride & $\begin{array}{l}\text { Onstream } \\
\text { Time, hrs }\end{array}$ \\
\hline Catalyst & $172[408]^{*}$ & 58 [408] & $184[408]$ & $<=660$ [509] & 5570 [678] & 678 \\
\hline S3-86 Feed & 118 [163] & $<10[163]$ & $<100[163]$ & $<=360[163]$ & $<=740[163]$ & 163 \\
\hline S3-86 Product & 88 & $<10$ & $<50$ & $<=170$ & $<=360$ & \\
\hline LZY-52 Feed & $242[0]$ & $<=19$ [262] & $<50$ [139] & $<=330[0]$ & $<=810$ [?] & 139 \\
\hline $\begin{array}{l}\text { LZY-52 } \\
\text { Product }\end{array}$ & 261 & $<=22$ & $<50$ & $<=130$ & $<=650$ & \\
\hline BPL Feed & $4390[101]$ & $120[262]$ & $299[264]$ & $4960[101]$ & $1050[101+]$ & 264 \\
\hline BPL Product & 4480 & 39 & $<50$ & 3740 & $<=740$ & \\
\hline G132D Feed & $1240[0]$ & $<=20[0]$ & $<50[0]$ & $<=420[0]$ & $<=360[?]$ & 114 \\
\hline G132D Product & 1190 & $<=24$ & $<50$ & $<=390$ & $<=750$ & \\
\hline
\end{tabular}

*Numbers in [ ]s indicate the number of hours which that bed was exposed to levels of each contaminant roughly equal to that present in the raw feed gas.

The following comments and observations apply: 
- When Bed \#1 was taken out of the feed stream, iron carbonyl was not detected even 3 in. into it. The baseline iron content of S3-86 was typically $70 \mathrm{ppm}$. The feed end iron level of $118 \mathrm{ppm}$ was consistent with the average exposure of 12 ppb over a 163 -hour period.

- The BPL carbon, which was very effective in removing iron carbonyl, contained such a high background level of iron that the gradient of adsorbed iron carbonyl was not observed.

- Adsorption of nickel carbonyl onto the S3-86 bed was not observed, consistent with the rapid breakthrough of this component. However, $58 \mathrm{ppm}$ of nickel was found on the S3-86 from the slurry. It may be that the reaction of $\mathrm{Ni}(\mathrm{CO})_{4}$ with $\mathrm{S} 3-86$ is slow at room temperature, but not at $250^{\circ} \mathrm{C}$.

- A clear nickel gradient was observed on the BPL carbon, which showed excellent ability to remove this poison.

- The presence of arsenic, which was anticipated based on the preliminary feedstock testing, was confirmed. Only the BPL carbon showed a clear affinity for this component. The G-132D, although designed for arsine removal, was downstream of the BPL carbon and was taken out of the feed stream first; it was therefore never exposed to this compound. The higher loading was observed at the feed end of the BPL bed (299 ppm) compared with the S3-86 in the slurry and in Bed \#1, in spite of the greater exposure of both of these samples to arsenic. This observation reinforces the hypothesis that the S3-86 is not a particularly active arsenic scavenger.

- Assuming that all the arsenic entering the carbon bed was captured by the first 20 grams of adsorbent, one obtains an estimated average arsenic concentration of $40 \mathrm{ppb}$ in the syngas mixture. This is comparable to the pre-guardbed value of $27 \mathrm{ppb}$ reported in the preliminary gas testing. The expected low levels of arsine were therefore confirmed and the guard bed should be able to remove them. Furthermore, when all the guard beds were removed, this level of arsine did not lead to an observable increase in the rate of catalyst deactivation.

- The sulfur data were consistent with our GC observations. The fact that sulfur was obviously adsorbed onto Bed \#2, in spite of the fact that this bed was never exposed to the full feed levels of COS, substantiates the observation (made via GC) that Bed \#1 was not $100 \%$ effective in removing COS.

- The most striking information provided by the analysis was the high chloride concentration measured on the post-slurry catalyst $(0.56 \%)$. In spite of this, stable catalyst activity was observed over the course of the life test; therefore, we concluded that this loading of chloride does not measurably impact the catalyst's performance. The comparatively low levels seen on the S3-86 from Bed \#1 indicate that the high concentration found on the catalyst in the reactor is not a baseline level. Both Beds \#1 and \#3 appear to have had some affinity for the chloride; however, it appears that the S386 in the slurry at $250^{\circ} \mathrm{C}$ was a much more effective sink for this contaminant. Regarding chloride, the preliminary report (Appendix 1) states "No additional amount detected on spent catalyst surface 
vs. fresh catalyst. No further analysis performed", and supported this observation with FT-IR data indicating $<1 \mathrm{ppm}$ chlorine. However, the catalyst limit was given as $0.01 \mathrm{ppm}$. A rough estimate of the average chloride content of the feed gas mixture based on the final loading and 678 hours of total exposure was $0.88 \mathrm{ppm}$. It is certainly possible that this reflects one or more excursions in the chloride content and that the average value is not meaningful.

\subsection{Conclusions}

1. The AFFTU was constructed on schedule and at the budgeted cost.

2. The capabilities of the AFFTU to perform on-site evaluation of catalyst performance and stability coupled with state-of-the-art gas chromatography for ppb level analysis of sulfides and metal carbonyls were demonstrated.

3. Stable LPMEOH ${ }^{\mathrm{TM}}$ catalyst activity was demonstrated over a 28-day life test using the actual syngas feed that will be used at the Kingsport LPMEOH ${ }^{\mathrm{TM}}$ Demonstration facility. During the final 420 hours of the test, the syngas was fed to the reactor without any pretreatment; the stable catalyst activity observed during this period confirmed that no catalyst poisons were present in the syngas at sufficient concentrations to measurably impact the catalyst performance.

4. Onboard gas analysis revealed the presence of iron and nickel carbonyl, hydrogen sulfide and carbonyl sulfide in the AFFTU feed. The nickel carbonyl was shown to be an artifact of the tie-in tubing; the iron carbonyl was also at least partially, if not totally, an artifact. All four compounds were present at levels comfortably below the specifications set by Air Products' process engineering.

5. Chemical analysis of the spent catalyst and guard beds revealed the presence of arsenic and chloride. Neither of these was present in high enough concentrations to measurably increase the rate of catalyst deactivation.

6. When Eastman's gasifiers were restarted after a shutdown, levels of both trace poisons and the bulk gases increased significantly from the steady-state level. It has been recommended for plant operation that these analyses be performed before the $\mathrm{LPMEOH}^{\mathrm{T}}$ reactor is placed back on stream after an upset.

7. The carbon dioxide concentration in Eastman's syngas was found to fluctuate in the range of 1 to $2 \%$. In the once-through design of the AFFTU reactor system, these fluctuations resulted in obvious changes in methanol productivity. The recycle stream in the actual LPMEOH ${ }^{\mathrm{TM}}$ demonstration plant will keep carbon dioxide levels high enough that these fluctuations should not have any impact.

Overall, the design and fabrication of the AFFTU was very successful. In addition to meeting the technical requirements and the constraints of schedule and cost, the AFFTU design was approved by 
both Air Products' and Eastman's safety teams. During the work at Kingsport, the AFFTU proved to be a safe and easily operated laboratory and also provided a comfortable working environment. An obvious improvement in operability compared with the previous Field Test Trailer was seen, a result of the improved analytical and data handling equipment. 
The Kingsport testing was likewise a success and provided positive results. This testing confirmed that the Eastman syngas meets process engineering's specifications and is capable of being used as a feed to the LPMEOH ${ }^{\mathrm{TM}}$ reaction with no measurable decrease in catalyst stability compared with laboratory data. Further insights were gained into the nature of the poisons in the Eastman syngas and the possibility of potential concentration excursions with gasifier restart.

\subsection{Recommendations}

Several recommendations were made to Air Products' process engineering group as a result of this work. The confirmation that Eastman's syngas yielded stable catalyst activity substantiated the decision to design the plant with a single carbon guard bed to handle traces of metal carbonyls that might be present during upsets. Two other recommendations were to:

1. Monitor poisons and bulk gas concentrations before putting the LPMEOH ${ }^{\mathrm{TM}}$ Demonstration Facility back on stream after gasifier outages.

2. Scrutinize the data collected during the four-year demonstration plan to ensure that carbon dioxide fluctuations do not impact the data, leading to false conclusions.

\subsection{Current Status of the AFFTU}

The AFFTU has been returned to Air Products' Iron Run site in Fogelsville, PA, where it serves as an extension of the Alternative Fuels II research facilities. This equipment remains available for use in evaluating future Liquid Phase Technology sites, providing analytical or start-up support for existing facilities or for qualifying new catalysts using on-site syngas.

\subsection{Acknowledgments}

G. M. Muraro, B. A. Toseland and X. D. Peng each spent a week on site at Kingsport, providing backup to T. A. Dahl and assistance and/or guidance with the experimental work. From our Process Engineering group, V. E. Stein, B. L. Bhatt and C. M. Chen provided valuable technical suggestions and guidance. Barry Street of Eastman Chemical was of inestimable help in making arrangements for the installation of the AFFTU and in supporting the project while the AFFTU was on site. 
${ }^{1}$ Estimating Scope Report, Kingsport Liquid Phase Methanol Demonstration Facility, Rev. 0 (1 August 1994).

2 "Liquid phase methanol LaPorte PDU: Modification, operation, and support studies. Task 3.4, Adsorbent evaluation for removal of catalyst poisons from synthesis gas.", Topical Report No. DOE/PC/90005-T34, (28 September 1990).

3 This pre-testing sulfide data was provided by Eastman's analytical group. They measure the concentration of hydrogen sulfide using an online technique involving reaction with lead acetate (Tracor Atlas Lead Acetate Tape/Reflectance); they also periodically measured the concentration of $\mathrm{H}_{2} \mathrm{~S}$ when the sample was first passed over a catalyst to convert all sulfur to $\mathrm{H}_{2} \mathrm{~S}$. Because there was little or no difference between these two measurements, they concluded that most of the sulfur was present as $\mathrm{H}_{2} \mathrm{~S}$.

${ }^{4}$ R. J. Grant, M. Manes and S. B. Smith, "Adsorption of Normal Paraffins and Sulfur Compounds on Activated Carbon", AIChe Journal, 8(3) (1962).

${ }^{5}$ The temperature data presented in Figure 16 was recorded using a thermocouple located inside the AFFTU; the external temperature was not recorded. However this temperature does reflect the external temperature although the amplitude of the temperature fluctuations is not as large.

${ }^{6}$ (a) R. L. Montgomery, "Engineering-Support Services for the DOE/GRI Coal-Gasification Research Program: Metal-Carbonyl Formation in Coal-Gasification Processes", (April 1981). (b) H. Inouye and J. H. DeVan, "Formation of Iron Carbonyl Between a 1/2 Pct Mo Steel and High-Pressure Gases Containing Carbon Monoxide", J. Materials for Energy Systems, 52(1), (1979). Reference (b) also gives data showing the reduced nickel carbonyl concentrations which result from increasing flow rate through an experimental system.

${ }^{7}$ The flow in the tie-in tubing, both before and after tripling of the flow, is laminar. The Reynolds number is estimated to be 250 and 750 for the respective cases.

${ }^{8}$ The fact that the slope of the $\mathrm{k}_{\mathrm{M}}$ data was less negative during the period when COS was present than during the time immediately before, when no known poisons were permitted to reach the catalyst, should not be interpreted as an indication that COS stabilizes the catalyst activity! In fact, this results from (a) data scatter and the relatively small number of points acquired, (b) inability of the model to completely account for changes in $\mathrm{CO}_{2}$ and (c) residual impact of the initial hyperactivity/deactivation which appears to persist well beyond the initial 50 hours on stream.

${ }^{9}$ The subsequent run in the AFFTU (Run 14987-54, also a LPMEOH ${ }^{\mathrm{TM}}$ experiment) showed a similar weight loss. After this run, the temperature of the gas-liquid separator was lowered from $145^{\circ} \mathrm{C}$ to $140^{\circ} \mathrm{C}$ and much better oil retention was observed.

10 "Liquid phase methanol LaPorte process development unit: Modification, operation, and support studies. Task 3.8, Catalyst poisons field demonstration.”, Topical Report No. DOE/PC/90005-T38, (9 Nov 1990). 
Appendix 1: Summary of Kingsport Pretesting

Methanol Feed Contaminants: Summary of Analytical Results (rev. 4/28/95)

\begin{tabular}{|c|c|c|c|c|c|c|c|c|}
\hline Component & $\begin{array}{l}\text { Catalyst } \\
\text { Limit } \\
\text { (ppmv) }\end{array}$ & Analytical Method Used & $\begin{array}{l}\text { Sampling } \\
\text { Technique }\end{array}$ & $\begin{array}{c}\text { Sample } \\
\text { Date }\end{array}$ & $\begin{array}{c}\text { ppmv in } \\
\text { Syngas Feed, } \\
\text { pre-G.Bed }\end{array}$ & $\begin{array}{l}\text { ppmv in } \\
\text { CO } \\
\text { Makeup }\end{array}$ & $\begin{array}{c}\text { ppmv in } \\
\mathrm{H}_{2} \\
\text { Makeup }\end{array}$ & Comments \\
\hline \multirow[t]{2}{*}{ Acetylene } & \multirow[t]{2}{*}{ 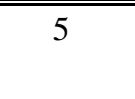 } & GC-FID & Offline gas & $8 / 5 / 94$ & $<0.5$ (Note 2$)$ & $<0.5($ Note 2$)$ & $<0.5$ (Note 2$)$ & \\
\hline & & GC-FID & Offline gas & 2/94 & $<1$ (Note 2) & $<1$ (Note 2) & $<1$ (Note 2) & \\
\hline \multirow[t]{3}{*}{ Arsenic, as $\mathrm{AsH}_{3}$} & \multirow[t]{3}{*}{$0.01 ?$} & HGA-AAS & Charcoal tube & $8 / 5 / 94$ & 0.027 & $<0.001$ & $<0.001$ & \multirow[t]{3}{*}{ Eastman syngas guard bed } \\
\hline & & ICP-AES & Acid scrub & $4 / 94$ & $<0.04$ & N/A & $<0.04$ & \\
\hline & & TOF-SIMS & Spent catalyst & 1993 & \multicolumn{3}{|c|}{$\begin{array}{l}\text { Significant amount of } \mathrm{AsO}_{2}^{-} \text {detected on spent } \\
\text { catalyst surface vs. fresh catalyst. }\end{array}$} & \\
\hline $\begin{array}{l}\text { Halogens } \\
(\mathrm{Cl} \& \mathrm{~F})\end{array}$ & 0.01 & TOF-SIMS & Spent catalyst & 1993 & \multicolumn{3}{|c|}{$\begin{array}{l}\text { No additional amount detected on spent catalyst } \\
\text { surface vs. fresh catalyst. No further analysis } \\
\text { performed. }\end{array}$} & \\
\hline $\mathrm{HCl}$ & & FT-IR & Offline gas & $2 / 94$ & $<1$ & $<1$ & $<1$ & \\
\hline \multirow[t]{5}{*}{ Iron, as $\mathrm{Fe}(\mathrm{CO})_{5}$} & \multirow[t]{5}{*}{0.01} & ICP-AES & Acid scrub & $12 / 94$ & $<0.01$ & $<0.01$ & $<0.01$ & \multirow[t]{5}{*}{ APCI guard bed for upset } \\
\hline & & F-AAS & Offline gas & $8 / 5 / 94$ & $<0.01$ & $<0.01$ & $<0.01$ & \\
\hline & & ICP-AES & Acid scrub & $4 / 94$ & $<0.025$ & N/A & $<0.025$ & \\
\hline & & F-AAS & Charcoal tube & $8 / 5 / 94$ & $<0.05$ & $<0.04$ & $<0.07$ & \\
\hline & & TOF-SIMS & Spent catalyst & 1993 & \multicolumn{3}{|c|}{$\begin{array}{l}\text { Slightly more } \mathrm{Fe}^{+} \text {detected on spent catalyst } \\
\text { surface vs. fresh catalyst. }\end{array}$} & \\
\hline \multirow[t]{4}{*}{ Nickel, as $\mathrm{Ni}(\mathrm{CO})_{4}$} & \multirow[t]{4}{*}{0.01} & ICP-AES & Charcoal tube & $8 / 5 / 94$ & $\leq 0.001$ & $<0.001$ & $<0.002$ & \multirow[t]{4}{*}{ APCI guard bed for upset } \\
\hline & & ICP-AES & Acid scrub & $12 / 94$ & $<0.01$ & $<0.01$ & $<0.01$ & \\
\hline & & ICP-AES & Acid scrub & $4 / 94$ & $<0.025$ & N/A & $<0.025$ & \\
\hline & & TOF-SIMS & Spent catalyst & 1993 & \multicolumn{3}{|c|}{$\begin{array}{l}\text { No additional amount of } \mathrm{Ni}^{+} \text {detected on spent } \\
\text { catalyst surface vs. fresh catalyst. }\end{array}$} & \\
\hline \multirow{3}{*}{$\begin{array}{l}\text { Nitrogen compounc } \\
\text { Ammonia }\end{array}$} & \multirow{3}{*}{10} & & & & & & & \\
\hline & & ion chromatography & Acid scrub & 3/94 & $<0.23$ & N/A & $<0.23$ & \\
\hline & & FT-IR & Offline gas & $2 / 94$ & $<1$ & $<1$ & $<1$ & \\
\hline \multirow[t]{3}{*}{$\mathrm{HCN}$} & \multirow[t]{3}{*}{0.01} & FT-IR & Offline gas & $2 / 94$ & $<1$ & $<1$ & $<1$ & \multirow{3}{*}{$\begin{array}{l}\text { Need more sensitive analysis } \\
\text { and/or portable test trailer. }\end{array}$} \\
\hline & & ion chromatography & Caustic scrub & $3 / 94$ & $<5$ & $<2.5$ & $<7.5$ & \\
\hline & & TOF-SIMS & Spent catalyst & 1993 & \multicolumn{3}{|c|}{$\begin{array}{l}\text { No additional amount of } \mathrm{CN}^{-} \text {detected on spent } \\
\text { catalyst surface vs. fresh catalyst. }\end{array}$} & \\
\hline
\end{tabular}




\begin{tabular}{|c|c|c|c|c|c|c|c|c|}
\hline Component & $\begin{array}{c}\text { Catalyst } \\
\text { Limit } \\
\text { (ppmv) } \\
\end{array}$ & Analytical Method Used & $\begin{array}{l}\text { Sampling } \\
\text { Technique } \\
\end{array}$ & $\begin{array}{c}\text { Sample } \\
\text { Date } \\
\end{array}$ & $\begin{array}{c}\text { ppmv in } \\
\text { Syngas Feed, } \\
\text { pre-G.Bed } \\
\end{array}$ & $\begin{array}{c}\text { ppmv in } \\
\text { CO } \\
\text { Makeup } \\
\end{array}$ & $\begin{array}{c}\text { ppmv in } \\
\mathbf{H}_{2} \\
\text { Makeup } \\
\end{array}$ & Comments \\
\hline \multirow{3}{*}{ Amines } & & $\overline{~ G C-N P D}$ & Offline gas & $8 / 5 / 94$ & $<0.5$ & $<0.5$ & $\begin{array}{l}<0.5 \\
\end{array}$ & \\
\hline & & GC-FID & Offline gas & 2/94 & $<0.5$ & $<0.5$ & $<0.5$ & \\
\hline & & TOF-SIMS & Spent catalyst & 1993 & \multicolumn{3}{|c|}{$\begin{array}{l}\text { Increased amount of amine-type species detected } \\
\text { on spent catalyst surface vs. fresh catalyst. }\end{array}$} & \\
\hline \multirow[t]{2}{*}{ Acetonitrile } & $?$ & GC-FID & Offline gas & $8 / 5 / 94$ & $<1$ & $<1$ & $<1$ & Technical risk. See HCN. \\
\hline & & GC-FID & Offline gas & $2 / 94$ & $<0.5$ & $<0.5$ & $<0.5$ & \\
\hline \multirow[t]{2}{*}{$\mathrm{NO}_{\mathrm{x}}$} & 0.1 & FT-IR & Offline gas & $2 / 94$ & $<1$ & $<1$ & $<1$ & \\
\hline & & TOF-SIMS & Spent catalyst & 1993 & \multicolumn{3}{|c|}{$\begin{array}{l}\text { No additional amount of } \mathrm{NO}_{3}{ }^{-} \text {detected on spent } \\
\text { catalyst surface vs. fresh catalyst. (Note } 2 \text { ) }\end{array}$} & \\
\hline \multirow[t]{2}{*}{ Oxygen } & 1500 & trace $\mathrm{O} 2$ analyzer & Online gas & $1 / 95$ & 100 to 200 & N/A & N/A & \\
\hline & & GC-TCD & Offline gas & $8 / 5 / 94$ & 4000 & 800 & 71400 & $\begin{array}{l}\text { Levels in syngas \& } \mathrm{H} 2 \text { makeup } \\
\text { unusually high \& may be in errs }\end{array}$ \\
\hline Sulfur, total & 0.06 & TOF-SIMS & Spent catalyst & 1993 & \multicolumn{3}{|c|}{$\begin{array}{l}\text { No additional amount of } \mathrm{SO}_{3}{ }^{-} \text {detected on spent } \\
\text { catalyst surface vs. fresh catalyst. }\end{array}$} & \\
\hline \multirow[t]{2}{*}{$\begin{array}{l}\mathrm{H}_{2} \mathrm{~S} \\
\text { (pre-Guard Bed) }\end{array}$} & & $\begin{array}{l}\text { Tracor Atlas lead-acetate } \\
\text { tape/reflectance }\end{array}$ & Online gas & $\begin{array}{l}3 / 2 / 94 \text { to } \\
8 / 10 / 94\end{array}$ & $0.061 \pm 0.031$ & Note 2 & Note 2 & \\
\hline & & ion chromatography & Caustic scrub & $3 / 94$ & $<4$ & $<2$ & $<6$ & \\
\hline $\begin{array}{l}\mathrm{H}_{2} \mathrm{~S} \\
\text { (post-Guard Bed) }\end{array}$ & 0.03 & $\begin{array}{l}\text { Tracor Atlas lead-acetate } \\
\text { tape/reflectance }\end{array}$ & Offline gas & $\begin{array}{l}3 / 2 / 94 \text { to } \\
8 / 10 / 94\end{array}$ & $0.035 \pm 0.024$ & Note 2 & Note 2 & Eastman syngas guard bed. \\
\hline $\mathrm{COS}$ & 0.03 & GC-FPD & Offline gas & $8 / 5 / 94$ & $<0.5$ & $<0.5$ (Note 2$)$ & $<0.5$ (Note 2$)$ & $\begin{array}{l}\text { EMN data shows that nearly all } \\
\text { sulfur is in form of H2S. EMN } \\
\text { guard bed will not remove COS } \\
\text { ambient temp. }\end{array}$ \\
\hline \multirow{2}{*}{$\begin{array}{l}\text { Unsat. hydrocarbons } \\
\text { (olefins, aromatics) }\end{array}$} & 300 & GC-FID & Offline gas & $8 / 5 / 94$ & $<1$ & $<1$ & $<1$ & \\
\hline & & GC-FID & Offline gas & $2 / 94$ & $<1$ & $<1$ & $<1.8$ & \\
\hline
\end{tabular}




\begin{tabular}{|c|c|c|c|c|c|c|c|c|}
\hline Component & $\begin{array}{c}\text { Catalyst } \\
\text { Limit } \\
\text { (ppmv) } \\
\end{array}$ & Analytical Method Used & $\begin{array}{l}\text { Sampling } \\
\text { Technique } \\
\end{array}$ & $\begin{array}{c}\text { Sample } \\
\text { Date }\end{array}$ & $\begin{array}{c}\text { ppmv in } \\
\text { Syngas Feed, } \\
\text { pre-G.Bed }\end{array}$ & $\begin{array}{c}\text { ppmv in } \\
\text { CO } \\
\text { Makeup } \\
\end{array}$ & $\begin{array}{c}\text { ppmv in } \\
\mathbf{H}_{2} \\
\text { Makeup } \\
\end{array}$ & Comments \\
\hline \multirow[t]{2}{*}{ Antimony } & & ICP-AES & Acid scrub & $12 / 94$ & $<0.025$ & $<0.025$ & $<0.025$ & \\
\hline & & ICP-AES & Acid scrub & $4 / 94$ & $<0.025$ & N/A & $<0.025$ & \\
\hline Barium & & TOF-SIMS & Spent catalyst & 1993 & \multicolumn{3}{|c|}{ None detected on spent catalyst surface. } & \\
\hline \multirow[t]{3}{*}{ Beryllium } & & ICP-AES & Acid scrub & $12 / 94$ & $<0.025$ & $<0.025$ & $<0.025$ & \\
\hline & & ICP-AES & Acid scrub & 4/94 & $<0.025$ & N/A & $<0.025$ & \\
\hline & & TOF-SIMS & Spent catalyst & 1993 & \multicolumn{3}{|c|}{ None detected on spent catalyst surface. } & \\
\hline Boron & & TOF-SIMS & Spent catalyst & 1993 & \multicolumn{4}{|c|}{ None detected on spent catalyst surface. } \\
\hline Cadmium & & N/A & & & & & & \\
\hline Calcium & & TOF-SIMS & Spent catalyst & 1993 & \multicolumn{3}{|c|}{$\begin{array}{l}\text { Slightly more detected on spent catalyst surface } \\
\text { vs. fresh catalyst. }\end{array}$} & \\
\hline \multirow[t]{2}{*}{ Chromium } & & ICP-AES & Acid scrub & 4/94 & $<0.025$ & N/A & N/A & \\
\hline & & TOF-SIMS & Spent catalyst & 1993 & \multicolumn{3}{|c|}{ None detected on spent catalyst surface. } & \\
\hline Cobalt & & TOF-SIMS & Spent catalyst & 1993 & \multicolumn{3}{|c|}{ None detected on spent catalyst surface. } & \\
\hline Lead & & N/A & & & & & & \\
\hline Manganese & & N/A & & & & & & \\
\hline \multirow[t]{2}{*}{ Mercury } & & Cold Vapor AAS & Acid scrub & $12 / 94$ & $<0.01$ & $<0.01$ & $<0.01$ & \\
\hline & & Cold Vapor AAS & Acid scrub & $4 / 94$ & $<0.025$ & N/A & $<0.025$ & \\
\hline Phosphorus & & N/A & & & & & & \\
\hline Potassium & absent & TOF-SIMS & Spent catalyst & 1993 & \multicolumn{3}{|c|}{$\begin{array}{l}\text { Slightly more detected on spent catalyst surface } \\
\text { vs. fresh catalyst. }\end{array}$} & \\
\hline Radionuclides & & N/A & & & & & & \\
\hline \multirow[t]{3}{*}{ Selenium } & & ICP-AES & Acid scrub & $12 / 94$ & $<0.15$ & $<0.15$ & $<0.15$ & \\
\hline & & ICP-AES & Acid scrub & 4/94 & $<0.15$ & N/A & $<0.15$ & \\
\hline & & TOF-SIMS & Spent catalyst & 1993 & \multicolumn{3}{|c|}{ None detected on spent catalyst surface. } & \\
\hline
\end{tabular}




\begin{tabular}{|c|c|c|c|c|c|c|c|c|}
\hline Component & $\begin{array}{c}\text { Catalyst } \\
\text { Limit } \\
\text { (ppmv) } \\
\end{array}$ & Analytical Method Used & $\begin{array}{l}\text { Sampling } \\
\text { Technique } \\
\end{array}$ & $\begin{array}{c}\text { Sample } \\
\text { Date } \\
\end{array}$ & $\begin{array}{c}\text { ppmv in } \\
\text { Syngas Feed, } \\
\text { pre-G.Bed }\end{array}$ & $\begin{array}{c}\text { ppmv in } \\
\text { CO } \\
\text { Makeup } \\
\end{array}$ & $\begin{array}{c}\text { ppmv in } \\
\mathbf{H}_{2} \\
\text { Makeup } \\
\end{array}$ & Comments \\
\hline Silver & & TOF-SIMS & Spent catalyst & 1993 & \multicolumn{4}{|c|}{ None detected on spent catalyst surface. } \\
\hline Sodium & absent & TOF-SIMS & Spent catalyst & 1993 & \multicolumn{4}{|c|}{$\begin{array}{l}\text { Slightly more detected on spent catalyst surface } \\
\text { vs. fresh catalyst. }\end{array}$} \\
\hline Thallium & & TOF-SIMS & Spent catalyst & 1993 & \multicolumn{4}{|c|}{ None detected on spent catalyst surface. } \\
\hline Vanadium & absent & ICP-AES & Acid scrub & $12 / 94$ & $<0.025$ & $<0.025$ & $<0.025$ & \\
\hline
\end{tabular}

Notes:

1. In general, the lower detectable limit is dependent on the amount of gas sampled, the sampling procedure, the final analytical instrument, and the amount of interfering species. The notation " $<\mathrm{X}$ " is used to indicate that the analyte was not detected at the lower detectable limit of X.

2. Not expected to be present and no further analysis performed.

\section{Abbreviations:}

N/A: Not Analyzed

F-AAS: Flame Atomic Absorption Spectroscopy

FT-IR: Fourier Transform - Infrared Spectroscopy

GC-FID: Gas Chromatography - Flame Ionization Detector

GC-FPD: Gas Chromatography - Flame Photometric Detector

GC-NPD: Gas Chromatography - Nitrogen-Phosphorus Detector

GC-TCD: Gas Chromatography - Thermal Conductivity Detector

HGA-AAS: Heated Graphite Atomization Atomic Absorption Spectroscopy

ICP-AES: Inductively Coupled Plasma Atomic Emission Spectroscopy

TOF-SIMS: Time-of-Flight Secondary Ion Mass Spectrometry 
Appendix 2: AFFTU Parts \& Components List

\begin{tabular}{|c|c|c|c|c|c|c|}
\hline Comp. & Part No./Supplier & Type & Pressure & Temp ${ }^{\circ} \mathrm{C}$ & Seals & Location \\
\hline $\mathrm{V}(\mathrm{M} 1) 1$ & SS-1KS6/Whitey & Shutoff & 3000 & 21 & & Dock 3 \\
\hline V1 & SS-43S6/Whitey & Ball Valve & 3000 & 65 & TFE & $1^{\circ}$ Feed \\
\hline $\mathrm{V} 2$ & SS-1KS4/Whitey & Shutoff & 3000 & 93 & KEL-F & $1^{\circ}$ Feed \\
\hline V3 & SS-43S6/Whitey & Ball & 3000 & 65 & TFE & $1^{\circ} \mathrm{Feed}$ \\
\hline V4 & SS-43S6/Whitey & Ball & 3000 & 65 & TFE & $1^{\circ}$ Feed \\
\hline V5 & SS-1KS4/Whitey & Shutoff & 3000 & 93 & KEL-F & $1^{\circ}$ Feed \\
\hline V7 & SS-1KS4/Whitey & Shutoff & 3000 & 93 & KEL-F & $1^{\circ}$ Feed \\
\hline v8 & SS-1KS4/Whitey & Shutoff & 3000 & 93 & KEL-F & $1^{\circ}$ Feed \\
\hline v9 & SS-43S6/Whitey & Ball & 3000 & 65 & TFE & $1^{\circ}$ Feed \\
\hline V10 & SS-1KS4/Whitey & Shutoff & 3000 & 93 & KEL-F & $1^{\circ}$ Feed \\
\hline V11 & SS-1KS4/Whitey & Shutoff & 3000 & 93 & KEL-F & $1^{\circ}$ Feed \\
\hline V12 & SS-4P4T/Nupro & Plug & 3000 & 204 & Viton & $1^{\circ}$ Feed \\
\hline V13 & SS-4P4T/Nupro & Plug & 3000 & 204 & Viton & $1^{\circ}$ Feed \\
\hline V16 & SS-1VS4/Whitey & Shutoff & 3000 & 232 & TFE & Adsorption \\
\hline V17 & SS-4P4T/Nupro & Plug & 3000 & 204 & Viton & Adsorption \\
\hline V18 & SS-ORS2/Whitey & Regulating & 3000 & 232 & TFE & Adsorption \\
\hline V19 & SS-4P4T/Nupro & Plug & 3000 & 204 & Viton & Adsorption \\
\hline V20 & 6V-71B4TG/Autoclave & Shutoff & 11500 & 316 & Teflon Glass & Adsorption \\
\hline $\mathrm{v} 21$ & SS-1VS4/Whitey & Shutoff & 3000 & 232 & TFE & Adsorption \\
\hline v22 & SS-4P4T/Nupro & Plug & 3000 & 204 & Viton & Adsorption \\
\hline V23 & SS-ORS2/Whitey & Regulating & 3000 & 232 & TFE & Adsorption \\
\hline V24 & SS-4P4T/Nupro & Plug & 3000 & 204 & Viton & Adsorption \\
\hline V25 & 6V-71B4TG/Autoclave & Shutoff & 11500 & 316 & Teflon Glass & Adsorption \\
\hline V26 & SS-1VS4/Whitey & Shutoff & 3000 & 232 & TFE & Adsorption \\
\hline V27 & SS-4P4T/Nupro & Plug & 3000 & 204 & Viton & Adsorption \\
\hline $\mathrm{v} 28$ & SS-ORS2/Whitey & Regulating & 3000 & 232 & TFE & Adsorption \\
\hline V29 & SS-4P4T/Nupro & Plug & 3000 & 204 & Viton & Adsorption \\
\hline v32 & SS-4P4T/Nupro & Plug & 3000 & 204 & Viton & Adsorption \\
\hline V33 & SS-ORS2/Whitey & Regulating & 3000 & 232 & TFE & Adsorption \\
\hline V34 & SS-ORS2/Whitey & Regulating & 3000 & 232 & TFE & Adsorption \\
\hline V35 & SS-ORS2/Whitey & Regulating & 3000 & 232 & TFE & Adsorption \\
\hline
\end{tabular}




\begin{tabular}{|c|c|c|c|c|c|c|}
\hline Comp. & Part No./Supplier & Type & Pressure & Temp ${ }^{\circ} \mathrm{C}$ & Seals & Location \\
\hline V36 & SS-4P4T/Nupro & Plug & 3000 & 204 & Viton & Adsorption \\
\hline V37 & SS-4P4T/Nupro & Plug & 3000 & 204 & Viton & Adsorption \\
\hline V38 & SS-4P4T/Nupro & Plug & 3000 & 204 & Viton & Adsorption \\
\hline V39 & SS-1KS4/Whitey & Shutoff & 3000 & 93 & KEL-F & Adsorption \\
\hline V40 & SS-1KS6/4/Whitey & Shutoff & 3000 & 93 & KEL-F & Reduction \\
\hline V41 & SS-1KS6/4/Whitey & Shutoff & 3000 & 93 & KEL-F & Reduction \\
\hline V42 & SS-OKS2/Whitey & Shutoff & 3000 & 93 & KEL-F & Reduction \\
\hline V43 & SS-OKS2/Whitey & Shutoff & 3000 & 93 & KEL-F & Reduction \\
\hline V44 & SS-OKS2/Whitey & Shutoff & 3000 & 93 & KEL-F & Reduction \\
\hline V45 & SS-ORS2/Whitey & Regulating & 3000 & 232 & TFE & Trailer \\
\hline V46 & SS-ORS2/Whitey & Regulating & 3000 & 232 & TFE & Trailer \\
\hline V47 & SS-ORS2/Whitey & Regulating & 3000 & 232 & TFE & Trailer \\
\hline V48 & SS-ORS2/Whitey & Regulating & 3000 & 232 & TFE & Trailer \\
\hline V49 & SS1S4/Whitey & Vee & 3000 & 232 & TFE & Adsorption \\
\hline V52 & SS-OKS2/Whitey & Shutoff & 3000 & 93 & KEL-F & $2^{\circ}$ Feed \\
\hline V52A & SS-OKS2/Whitey & Shutoff & 3000 & 93 & KEL-F & $2^{\circ}$ Feed \\
\hline V53 & SS-1KS4/Whitey & Shutoff & 3000 & 93 & KEL-F & Autoclave \\
\hline V54 & SS-4P4T/Nupro & Plug & 3000 & 204 & Viton & Autoclave \\
\hline V55 & SS-1KS4/Whitey & Shutoff & 3000 & 93 & KEL-F & Autoclave \\
\hline V56 & SS-1KS4/Whitey & Shutoff & 3000 & 93 & KEL-F & Autoclave \\
\hline V57 & SS-1KS4/Whitey & Shutoff & 3000 & 93 & KEL-F & Autoclave \\
\hline V58 & SS-4P4T/Nupro & Plug & 3000 & 204 & Viton & Autoclave \\
\hline V59 & SS-4P4T/Nupro & Plug & 3000 & 204 & Viton & Autoclave \\
\hline V60 & SS-1KS4/Whitey & Shutoff & 3000 & 93 & KEL-F & Autoclave \\
\hline V61 & SS-1KS4/Whitey & Shutoff & 3000 & 93 & KEL-F & Autoclave \\
\hline V62 & SS-2P4T/Nupro & Plug & 3000 & 204 & Viton & Autoclave \\
\hline V63 & SS-OKS2/Whitey & Shutoff & 3000 & 93 & KEL-F & Autoclave \\
\hline V64 & SS-OKS2/Whitey & Shutoff & 3000 & 93 & KEL-F & Autoclave \\
\hline V67 & SS-1KS4/Whitey & Shutoff & 3000 & 93 & KEL-F & Autoclave \\
\hline V68 & SS-OKS2/Whitey & Shutoff & 3000 & 93 & KEL-F & Autoclave \\
\hline V69 & SS-1VS4/Whitey & Shutoff & 3000 & 232 & $\mathrm{TFE}$ & Autoclave \\
\hline V70 & SS-OKS2/Whitey & Shutoff & 3000 & 93 & KEL-F & Reduction \\
\hline V70A & SS-OKS2/Whitey & Shutoff & 3000 & 93 & KEL-F & Autoclave \\
\hline
\end{tabular}




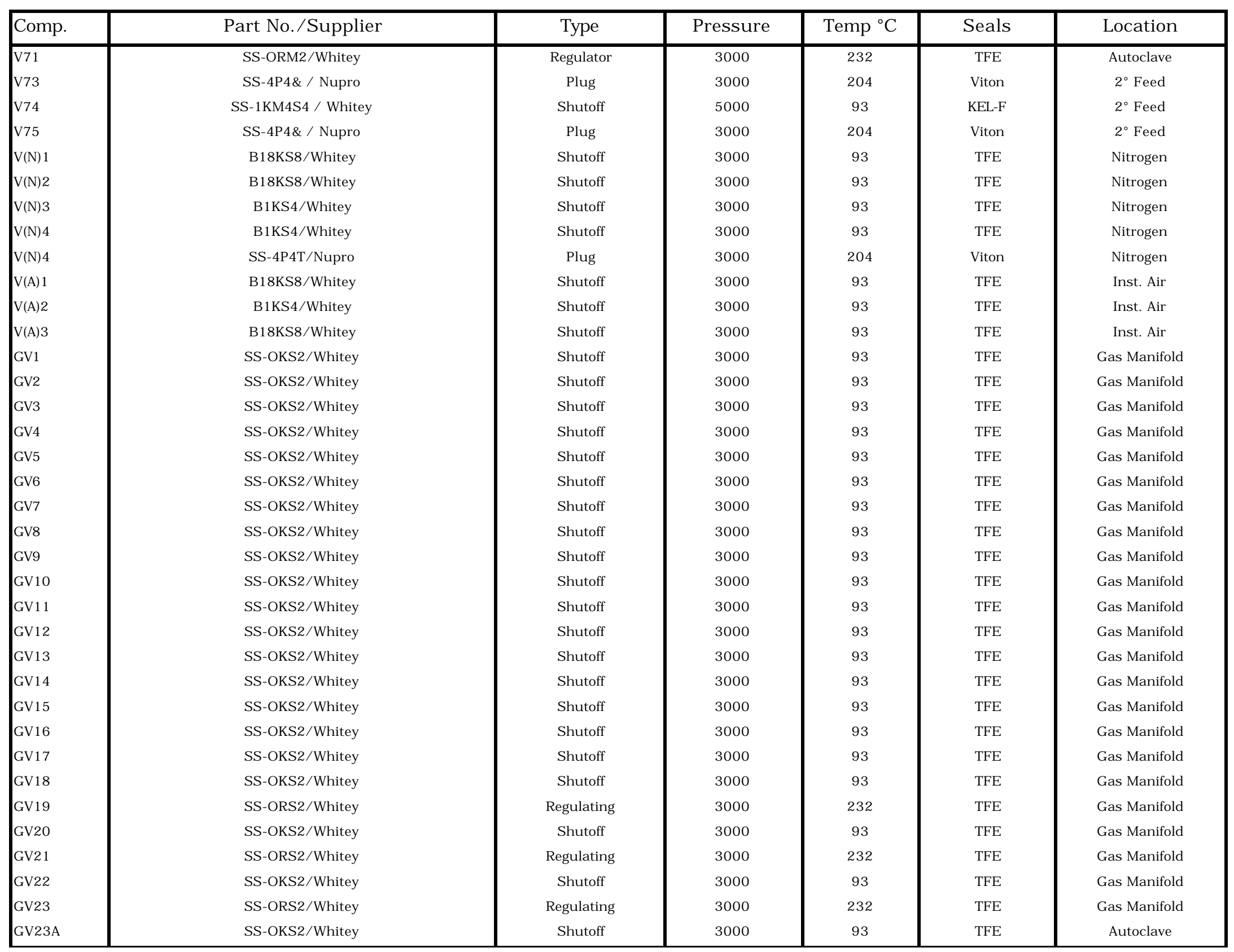




\begin{tabular}{|c|c|c|c|c|c|c|}
\hline Comp. & Part No./Supplier & Type & Pressure & Temp ${ }^{\circ} \mathrm{C}$ & Seals & Location \\
\hline GV24 & SS-ORS2/Whitey & Regulating & 3000 & 232 & TFE & Gas Manifold \\
\hline GV25 & SS-OKS2/Whitey & Shutoff & 3000 & 93 & TFE & Gas Manifold \\
\hline GV26 & SS-1KS4/Whitey & Shutoff & 3000 & 93 & Kel-F & Gas Manifold \\
\hline P1 & QM 0-2000/McDaniel Controls Inc. & ss & 2000 & & & $1^{\circ} \mathrm{Feed}$ \\
\hline P2 & QM 0-2000/McDaniel Controls Inc. & ss & 2000 & & & $1^{\circ}$ Feed \\
\hline P3 & QM 0-2000/McDaniel Controls Inc. & ss & 2000 & & & $1^{\circ}$ Feed \\
\hline $\mathrm{P} 4$ & GM 0-2000/McDaniel Controls Inc. & ss & 2000 & & & $1^{\circ} \mathrm{Feed}$ \\
\hline P5 & QM 0-2000/McDaniel Controls Inc. & ss & 2000 & & & $1^{\circ}$ Feed \\
\hline P6 & QM 0-2000/McDaniel Controls Inc. & ss & 2000 & & & $1^{\circ} \mathrm{Feed}$ \\
\hline P7 & KMP AB 1207/McDaniel Controls Inc. & ss & 2000 & & & $1^{\circ} \mathrm{Feed}$ \\
\hline P8 & & ss & 2000 & & & $1^{\circ} \mathrm{Feed}$ \\
\hline P9 & QM 0-2000/McDaniel Controls Inc. & ss & 2000 & & & Adsorption \\
\hline P10 & QM 0-2000/McDaniel Controls Inc. & ss & 2000 & & & Adsorption \\
\hline P11 & 3M 0-2000/McDaniel Controls Inc. & ss & 2000 & & & Adsorption \\
\hline $\mathrm{P} 12$ & QM 0-2000/McDaniel Controls Inc. & ss & 2000 & & & Adsorption \\
\hline $\mathrm{P} 13$ & QM 0-2000/McDaniel Controls Inc. & ss & 2000 & & & Adsorption \\
\hline P14 & GM 0-2000/McDaniel Controls Inc. & ss & 2000 & & & Adsorption \\
\hline P15 & QM 0-2000/McDaniel Controls Inc. & ss & 2000 & & & Adsorption \\
\hline P16 & QM 0-2000/McDaniel Controls Inc. & ss & 2000 & & & Adsorption \\
\hline P17 & KMP AB 429/McDaniel Controls Inc. & ss & 3000 & & & Reduction \\
\hline P18 & McDaniel Controls Inc. & ss & 2000 & & & Reduction \\
\hline P19 & US Gauge & & $0-3000$ & & & $2^{\circ}$ Feed \\
\hline $\mathrm{P} 20$ & US Gauge & & $0-3000$ & & & $2^{\circ}$ Feed \\
\hline $\mathrm{P} 21$ & 232.30/Wika & F. Flange & 2000 & 21 & & Autoclave \\
\hline $\mathrm{P} 22$ & 232.30/Wika & F. Flange & 2000 & 21 & & Autoclave \\
\hline P23 & KMU/McDaniel Controls & U-Clamp & 2000 & 21 & & Autoclave \\
\hline P24 & KMU/McDaniel Controls & U-Clamp & 2000 & 21 & & Autoclave \\
\hline P25 & QM McDaniel Controls & & 2000 & 21 & & Autoclave \\
\hline P26 & QM McDaniel Controls & & 2000 & 21 & & Autoclave \\
\hline P27 & QM McDaniel Controls & & 2000 & 21 & & Autoclave \\
\hline P28 & GM McDaniel Controls & & 2000 & 21 & & Autoclave \\
\hline P29 & & & 30 & 21 & & Autoclave \\
\hline P30 & & & & & & $2^{\circ}$ Feed \\
\hline $\mathrm{P}(\mathrm{N}) 1$ & Wika $316 \mathrm{SS}$ & & $0-200$ & & & Nitrogen \\
\hline $\mathrm{P}(\mathrm{N}) 2$ & Wika 316 SS & & $0-200$ & & & Nitrogen \\
\hline $\mathrm{P}(\mathrm{A}) 1$ & US Gauge & & $0-160$ & & & Inst. Air \\
\hline
\end{tabular}




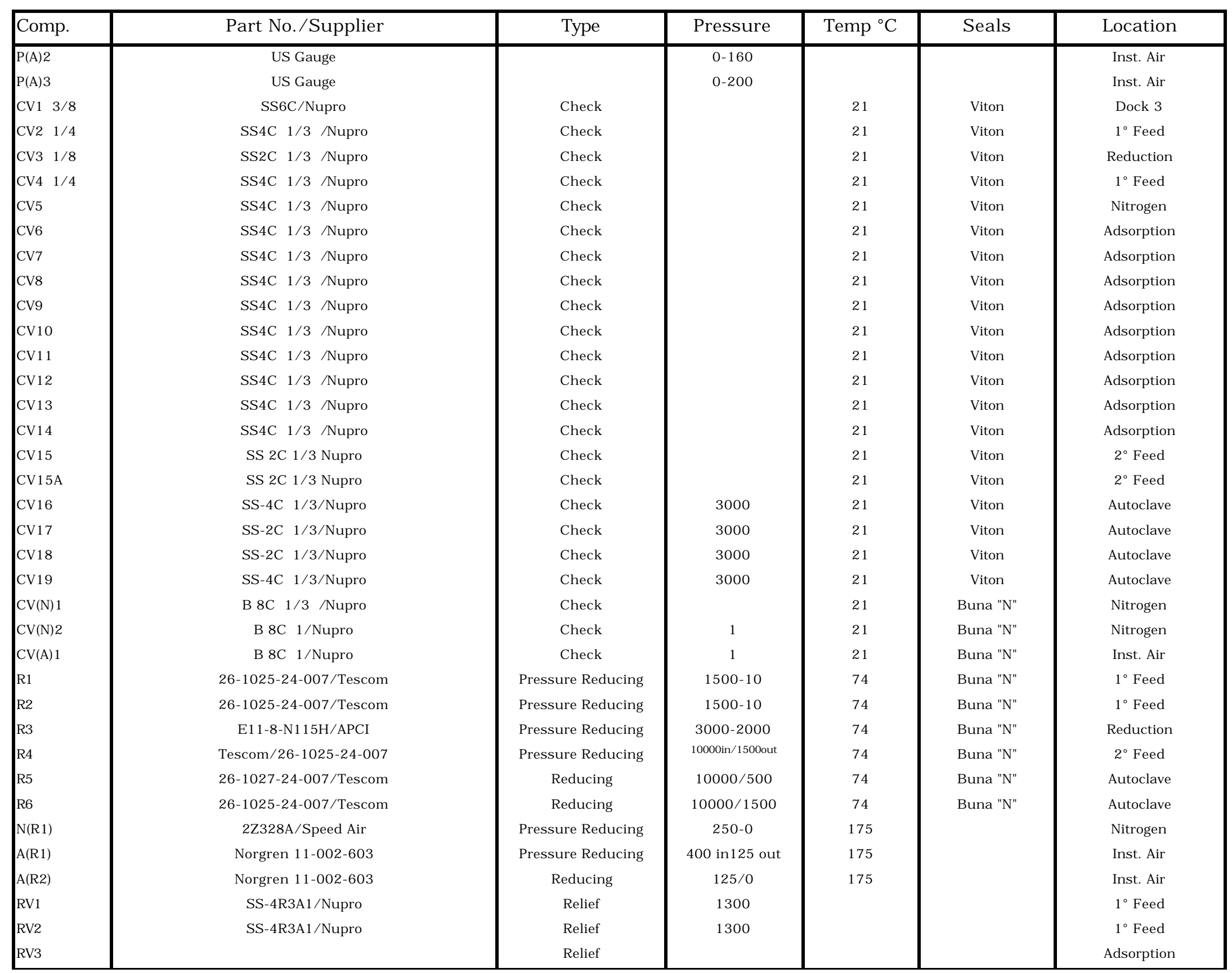




\begin{tabular}{|c|c|c|c|c|c|c|}
\hline Comp. & Part No./Supplier & Type & Pressure & Temp ${ }^{\circ} \mathrm{C}$ & Seals & Location \\
\hline RV4 & SS-4R3A1/Nupro & Relief & 1300 & & & Reduction \\
\hline RV5 & SS-4R3A1/Nupro & Relief & $1300 \mathrm{set}$ & $70^{\circ} \mathrm{F}$ & & $2^{\circ}$ Feed \\
\hline RV6 & SS-4R3A1/Nupro & Relief & $1700 \mathrm{set}$ & 121 & Viton & Autoclave \\
\hline RV7 & SS-4R3A1/Nupro & Relief & 1300 & 121 & Viton & Autoclave \\
\hline RV8 & SS-4R3A1/Nupro & Relief & 1300 & 121 & Viton & Autoclave \\
\hline RV9 & SS-4CPA4-3/Nupro & Relief & 5 & 149 & Buna "N" & Autoclave \\
\hline $\mathrm{N}(\mathrm{RV}) 1$ & SS-4CPA2 150/Nupro & Relief & 200 & & & Nitrogen \\
\hline $\mathrm{A}(\mathrm{RV}) 1$ & B 4CPA2 150/Nupro & Relief & $100 ?$ & & & Inst. Air \\
\hline GRV1 & SS-4CPA2-50 & Relief & 100 & & & Gas Manifold \\
\hline GRV2 & SS-4CPA2-50 & Relief & 100 & & & Gas Manifold \\
\hline GRV3 & SS-4CPA2-50 & Relief & 100 & & & Gas Manifold \\
\hline GRV4 & SS-4CPA2-50 & Relief & 100 & & & Gas Manifold \\
\hline GRV5 & SS-4CA-50/Nupro & Relief & 100 & & & Gas Manifold \\
\hline GRV6 & SS-4R3A1/Nupro & Relief & 1700 & & & Gas Manifold \\
\hline GRV8 & SS-2C-10/Nupro & Relief & 10 & & & Gas Manifold \\
\hline $\mathrm{F}(\mathrm{A}) 1$ & 2E764A/Speed Air & & 150 & 52 & Buna "N" & Inst. Air \\
\hline $\mathrm{F} 1$ & SS-6F-90/Nupro & Filter & 2500 & 482 & Silver Plated 316SS & $1^{\circ}$ Feed \\
\hline $\mathrm{F} 2$ & SS-4TF-2/Nupro & Filter & 6000 & 482 & & $1^{\circ} \mathrm{Feed}$ \\
\hline F3 & SS-2F-7/Nupro & Filter & 3000 & 21 & $316 \mathrm{sS}$ & $2^{\circ}$ Feed \\
\hline F4 & SS-4F-90/Nupro & Filter & 3000 & 900 & $316 \mathrm{sS}$ & Autoclave \\
\hline F5 & SS-2F-7/Nupro & Filter & 3000 & 900 & $316 \mathrm{sS}$ & Autoclave \\
\hline $\mathrm{S} 1 \mathrm{~A}$ & 8262A2 15/Stainless Asco & Normally Closed & 2200 & 104 & Buna "N" & $1^{\circ}$ Feed \\
\hline $\mathrm{S} 1 \mathrm{~B}$ & 8262A215/Stainless Asco & Normally Closed & 2200 & 104 & Buna "N" & $1^{\circ}$ Feed \\
\hline $\mathrm{S} 2 \mathrm{~A}$ & 8262A215/Stainless Asco & Normally Closed & 2200 & 104 & Buna "N" & $2^{\circ}$ Feed \\
\hline S2B & 8262A215/Stainless Asco & Normally Closed & 2200 & 104 & Buna "N" & $2^{\circ}$ Feed \\
\hline S3 & 8262A215/Stainless Asco & Normally Closed & 2200 & 104 & Buna "N" & $1^{\circ}$ Feed \\
\hline S4 & $8262 \mathrm{~A} 215 /$ Asco & Normally Closed & 2200 & 104 & Buna "N" & $2^{\circ}$ Feed \\
\hline S5 & 8262A215/Asco & Normally Closed & 2200 & 104 & Buna "N" & Autoclave \\
\hline $\mathrm{S}(\mathrm{A}) 1$ & $8262 \mathrm{C} 232 /$ Brass Asco & Normally Closed & 2200 & 104 & Buna "N" & Inst. Air \\
\hline $\mathrm{S}(\mathrm{G}) 2$ & $82 \mathrm{C} 2 \mathrm{C} 98 / \mathrm{Asco}$ & Normally Shut & 1900 & 60 & SS & GC System \\
\hline PS1 & J6-612 303 SS/United Electric & Presure Switch & 5000 & & & $1^{\circ}$ Feed \\
\hline PS2 & J6-612303SS/United Electric & Pressure Switch & 5000 , set 1600 & & & Autoclave \\
\hline GP1 & JPN/McDaniel Controls Inc. & SS & $0-3000$ & & & Gas Manifold \\
\hline
\end{tabular}




\begin{tabular}{|c|c|c|c|c|c|c|}
\hline Comp. & Part No./Supplier & Type & Pressure & Temp ${ }^{\circ} \mathrm{C}$ & Seals & Location \\
\hline GP2 & JPF/McDaniel Controls Inc. & SS & 200 & & & Gas Manifold \\
\hline GP3 & JPN/McDaniel Controls Inc. & ss & 3000 & & & Gas Manifold \\
\hline GP4 & JPF/McDaniel Controls Inc. & SS & 200 & & & Gas Manifold \\
\hline GP5 & JPN/McDaniel Controls Inc. & SS & 3000 & & & Gas Manifold \\
\hline GP6 & JPF/McDaniel Controls Inc. & SS & 200 & & & Gas Manifold \\
\hline GP7 & JPN/McDaniel Controls Inc. & SS & 3000 & & & Gas Manifold \\
\hline GP8 & JPF/McDaniel Controls Inc. & SS & 200 & & & Gas Manifold \\
\hline GP9 & KNP AB1129/McDaniel Controls Inc. & SS & 3000 & & & Gas Manifold \\
\hline GP10 & McDaniel Controls Inc. & SS & 200 & & & Gas Manifold \\
\hline GP11 & KNP AB1129/McDaniel Controls Inc. & SS & 3000 & & & Gas Manifold \\
\hline GP12 & McDaniel Controls Inc. & SS & 200 & & & Gas Manifold \\
\hline GP13 & KNP AB1 129/McDaniel Controls Inc. & SS & 3000 & & & Gas Manifold \\
\hline GP14 & McDaniel Controls Inc. & SS & 200 & & & Gas Manifold \\
\hline GR1 & E12-JN145D/APCI & Pressure Reducing & & & KEL-F/Teflon & Gas Manifold \\
\hline GR2 & E12-JN145D/APCI & Pressure Reducing & & & KEL-F/Teflon & Gas Manifold \\
\hline GR4 & E12-JN145D/APCI & Pressure Reducing & & & KEL-F/Teflon & Gas Manifold \\
\hline GR5 & CRR2 15-9014-1/Circle Seal & Pressure Reducing & $3000 / 180$ & & & Gas Manifold \\
\hline GR6 & CRR2 15-9014-1/Circle Seal & Pressure Reducing & $3000 / 180$ & & & Gas Manifold \\
\hline GR7 & CRR2 15-9014-1/Circle Seal & Pressure Reducing & $3000 / 200$ & & & Gas Manifold \\
\hline $\mathrm{C} 1$ & 304L-HDF8-1gal/Whitey & Sample Cylinder & 1800 & 21 & $316 \mathrm{SS}$ & $1^{\circ}$ Feed \\
\hline $\mathrm{C} 2$ & 304L-HDF8-1gal/Whitey & Sample Cylinder & 1800 & 21 & $316 \mathrm{sS}$ & Autoclave \\
\hline $\mathrm{C} 3$ & 304L-HDF8-1gal/Whitey & Sample Cylinder & 1800 & 21 & $316 \mathrm{SS}$ & Autoclave \\
\hline $\mathrm{C} 4$ & 304L-HDF2-1 liter/Whitey & Sample Cylinder & 1800 & 21 & $316 \mathrm{SS}$ & Autoclave \\
\hline C5 & 304L-DHF4-150cc/Whitey & Sample Cylinder & 1800 & 21 & $316 \mathrm{SS}$ & Gas Manifold \\
\hline $\mathrm{C} 6$ & 304L-HDF4-500cc/Whitey & Sample Cylinder & 1800 & 21 & $316 \mathrm{SS}$ & Autoclave \\
\hline BPR1 & 26-1725-24-043/Tescom & Back Pressure & $10-1500$ & 75 & Teflon & Adsorption \\
\hline BPR2 & 26-1727-24-043/Tescom & Back Pressure & $10 / 500$ & 74 & Buna "N" & Autoclave \\
\hline BPR3 & 26-1725-24-043/Tescom & Back Pressure & $10 / 1500$ & 74 & Buna "N" & Autoclave \\
\hline $\mathrm{RD} 1$ & A232/Fike & Rupture Disk & 2036 & 200 & $316 \mathrm{SS}$ & Autoclave \\
\hline$G(N V) 3$ & SS-2SG/Nupro & Fine Metering Valve & 2000 & 204 & Viton & GC System \\
\hline $\mathrm{G}(\mathrm{NV}) 4$ & SS-2SG/Nupro & Fine Metering Valve & 2000 & 204 & Viton & GC System \\
\hline EFV1 & EFV-125-S PSO KZ/Chem-Tec Equ. & XS FLow Valve & & & & $1^{\circ}$ Feed \\
\hline EFV2 & EFV-125-S PSO KZ/Chem-Tec Equ. & XS FLow Valve & & & & $2^{\circ}$ Feed \\
\hline
\end{tabular}




\begin{tabular}{|l|c|c|c|c|c|c|}
\hline Comp. & Part No./Supplier & Type & Pressure & Temp ${ }^{\circ} \mathrm{C}$ & Seals & Location \\
\hline EFV3 & 6L-E4AB / Nupro & XS Flow Valve & 3000 & & & Gas Manifold \\
PT9 & WIKA & P-Transducer & & & Adsorption \\
PT14 & WIKA & P-Transducer & & & WTM\#1 \\
PT27 & WIKA & P-Transducer & & & Autoclave \\
PT28 & WIKA & P-Transducer & & & Autoclave \\
PT29 & WIKA & P-Transducer & & & WTM\#2 \\
\hline
\end{tabular}


Appendix 3: AFFTU Budget

\begin{tabular}{|c|c|c|c|c|}
\hline \multirow{2}{*}{\multicolumn{2}{|c|}{ Trailer }} & \multirow[t]{2}{*}{ Vendor } & \multirow{2}{*}{$\begin{array}{c}\text { Budget } \\
\$ 48,314.00\end{array}$} & \multirow{2}{*}{$\begin{array}{c}\text { Actual } \\
\$ 61,526.67\end{array}$} \\
\hline & & & & \\
\hline & Trailer & & $\$ 9,000.00$ & $\$ 7,500.00$ \\
\hline & Inspection & & incl. & $\$ 1,500.00$ \\
\hline & Conversion & & $\$ 39,314.00$ & $\$ 15,414.00$ \\
\hline & Floor & Bastian & incl. & $\$ 1,000.00$ \\
\hline & Delivery & & incl. & $\$ 75.00$ \\
\hline & Ventilation, etc. & H. T. Lyons & incl. & $\$ 25,489.00$ \\
\hline & Counters & Seislove & incl. & $\$ 930.00$ \\
\hline & E. Door, etc. & APCI & incl. & $\$ 1,645.00$ \\
\hline \multirow[t]{4}{*}[1]{} & Steps\&Tie-Down & H. T. Lyons & $\$ 0.00$ & $\$ 6,910.00$ \\
\hline & Comp. Tables & & $\$ 0.00$ & $\$ 300.00$ \\
\hline & GC Stand & & incl. & $\$ 450.07$ \\
\hline & Water Util. & Granger & incl. & $\$ 313.60$ \\
\hline
\end{tabular}

\begin{tabular}{|c|c|c|c|}
\hline GC System & & $\$ 100,675.00$ & $\$ 101,569.80$ \\
\hline 2 @ HP6890 GCs & Hewlett-Packard & $\$ 34,350.00$ & $\$ 32,870.00$ \\
\hline HP Detectors & Hewlett-Packard & incl. & incl. \\
\hline Packed Inlets & Hewlett-Packard & incl. & incl. \\
\hline Capillary & Hewlett-Packard & incl. & incl. \\
\hline SCD & Sievers & $\$ 17,900.00$ & $\$ 18,299.00$ \\
\hline GC System Integ. & Wasson/ECE & $\$ 31,980.00$ & $\$ 31,980.00$ \\
\hline TurboChrom & Perkin-Elmer & $\$ 9,645.00$ & $\$ 9,880.00$ \\
\hline Tubing & Supelco & $\$ 200.00$ & $\$ 420.00$ \\
\hline AT-1 Cap. Col. & Alltech & $\$ 0.00$ & $\$ 657.00$ \\
\hline Cables & Hewlett-Packard & $\$ 0.00$ & $\$ 463.80$ \\
\hline APCI Support & APCI & $\$ 6,800.00$ & $\$ 7,000.00$ \\
\hline
\end{tabular}

\begin{tabular}{|c|c|c|c|}
\hline \multicolumn{2}{|c|}{ Equipment \& Control } & $\$ 110,000.00$ & $\$ 90,061.70$ \\
\hline [2] PLC \& Software & Allen-Bradley & $\$ 60,000.00$ & $\$ 27,977.00$ \\
\hline Wiring (PLC) & APCI & incl. & $\$ 3,920.00$ \\
\hline Wiring (Gen'l) & APCI & $\$ 22,758.00$ & $\$ 23,693.00$ \\
\hline Programming & APCI & $\$ 18,000.00$ & $\$ 21,600.00$ \\
\hline P_Transducers & WIKA & incl. & $\$ 2,162.70$ \\
\hline Encoders & Gurley & incl. & $\$ 818.00$ \\
\hline Valco Repairs & Valco & $\$ 500.00$ & $\$ 644.00$ \\
\hline Thermocouples & & $\$ 221.65$ & $\$ 230.00$ \\
\hline Valves \&Fittings & $\mathrm{AV} \& \mathrm{~F}$ & incl. & $\$ 3,500.00$ \\
\hline Supplies/Gases & APCI & incl. & $\$ 2,000.00$ \\
\hline Visual Basic & Stream Int'1 & $\$ 0.00$ & $\$ 100.00$ \\
\hline Regulators & Tescom & $\$ 0.00$ & $\$ 3,417.00$ \\
\hline
\end{tabular}

TOTALS

$\$ 258,989.00 \quad \$ 253,158.17$

[1] Not in original scope. Township inspector required permanent stairs and additional tie-downs before issuing an occupancy permit.

[2] The budgeted $\$ 60,000$ was an early estimate, and included any additional hardware and supplies which might be necessary for the automation of the data acquisition and process control. 
Appendix 5: Kingsport Data \& Rate Analysis

\begin{tabular}{|c|c|c|c|c|c|c|c|c|c|c|c|c|c|c|}
\hline Pt & $\operatorname{Tos}(h \mathbf{r})$ & $P(p$ sig $)$ & $T(C)$ & $\begin{array}{c}\operatorname{sccm} \\
\text { Vin }\end{array}$ & $\begin{array}{l}\text { sccm } \\
\text { Vout }\end{array}$ & Feed $\mathrm{CO} 2$ & H2 & $\mathbf{C M}$ & CD & N2 & $\begin{array}{c}\text { Methanol } \\
\text { L1 }\end{array}$ & $\begin{array}{c}\text { Synth. } \\
\text { Equil } \\
\text { Approach } \\
(\%)\end{array}$ & $\begin{array}{c}\text { MeOH } \\
\text { Equiv } \\
\text { rate } \\
\text { (gmol/kg-hr) }\end{array}$ & $\begin{array}{c}\text { MEOH } \\
\text { rate } \\
\text { const }\end{array}$ \\
\hline $\mathrm{A}$ & 2.83 & 751.4 & 250 & 2996 & 2335 & 1.517 & 38.25 & 44.162 & 2.475 & 0.89 & 12.5294 & 30.63 & 26.09 & 2.39 \\
\hline B & 6.58 & 752 & 249 & 2996 & 2348 & 1.499 & 39.599 & 44.919 & 2.357 & 0.751 & 12.4759 & 26.78 & 26.12 & 2.25 \\
\hline $\mathrm{C}$ & 10.5 & 752.6 & 250 & 2996 & 2375 & 1.483 & 39.902 & 45.272 & 2.25 & 0.742 & 12.322 & 27.00 & 26.10 & 2.29 \\
\hline $\mathrm{D}$ & 19.33 & 751.8 & 250 & 2996 & 2378 & 1.525 & 39.983 & 45.021 & 2.271 & 0.737 & 12.1278 & 26.71 & 25.72 & 2.24 \\
\hline $\mathrm{E}$ & 25.5 & 750 & 250 & 2996 & 2420 & 1.483 & 40.358 & 45.131 & 2.121 & 0.727 & 11.3376 & 24.69 & 24.47 & 2.13 \\
\hline $\mathrm{F}$ & 31.5 & 750 & 249 & 2996 & 2432 & 1.528 & 40.552 & 45.216 & 2.103 & 0.718 & 11.1045 & 22.90 & 24.08 & 2.05 \\
\hline G & 37.5 & 750.8 & 249 & 2996 & 2435 & 1.535 & 40.739 & 45.003 & 2.131 & 0.715 & 11.3469 & 23.22 & 24.64 & 2.09 \\
\hline G B & 43.5 & 746.4 & 250 & 2996 & 2450 & 1.561 & 40.843 & 44.972 & 2.125 & 0.71 & 11.1288 & 24.04 & 24.31 & 2.10 \\
\hline $\mathrm{H}$ & 49.5 & 744.6 & 250 & 2996 & 2475 & 1.538 & 41.174 & 44.973 & 2.003 & 0.707 & 10.6137 & 22.75 & 23.42 & 2.04 \\
\hline $\mathrm{J}$ & 52.13 & 744.8 & 249 & 2996 & 2488 & 1.538 & 40.85 & 44.934 & 1.994 & 0.702 & 10.3492 & 21.58 & 22.96 & 1.98 \\
\hline $\mathrm{K}$ & 58.13 & 746 & 250 & 2996 & 2475 & 1.493 & 41.338 & 44.868 & 2.018 & 0.7 & 10.6223 & 22.55 & 23.44 & 2.02 \\
\hline $\mathrm{L}$ & 64.13 & 746.6 & 249 & 2996 & 2470 & 1.547 & 41.248 & 44.77 & 2.075 & 0.725 & 10.6503 & 21.73 & 23.46 & 1.98 \\
\hline $\mathrm{M}$ & 70.17 & 746.6 & 249 & 2996 & 2499 & 1.475 & 41.847 & 44.621 & 1.969 & 0.747 & 10.3935 & 20.72 & 23.16 & 1.96 \\
\hline $\mathrm{N}$ & 76.13 & 744.6 & 250 & 2996 & 2510 & 1.479 & 41.765 & 44.541 & 1.948 & 0.696 & 10.4569 & 22.03 & 23.40 & 2.03 \\
\hline $\mathrm{o}$ & 82.13 & 751.2 & 250 & 2996 & 2485 & 1.605 & 41.158 & 44.957 & 2.119 & 0.697 & 10.4448 & 22.00 & 23.14 & 1.92 \\
\hline$P$ & 88.13 & 752.8 & 249 & 2996 & 2482 & 1.65 & 41.044 & 44.86 & 2.194 & 0.7 & 10.7406 & 21.67 & 23.77 & 1.94 \\
\hline 3 & 94.13 & 751.2 & 250 & 2996 & 2510 & 1.545 & 41.58 & 44.773 & 2.068 & 0.703 & 10.4932 & 21.75 & 23.49 & 1.96 \\
\hline $\mathrm{R}$ & 100.13 & 752 & 249 & 2996 & 2535 & 1.55 & 41.809 & 44.766 & 2.039 & 0.703 & 10.1299 & 19.87 & 22.90 & 1.87 \\
\hline $\mathrm{s}$ & 106.13 & 751.6 & 249 & 2996 & 2521 & 1.551 & 41.555 & 44.951 & 2.074 & 0.7 & 10.107 & 20.00 & 22.72 & 1.85 \\
\hline $\mathrm{T}$ & 112.13 & 752 & 249 & 2996 & 2521 & 1.582 & 41.58 & 44.571 & 2.095 & 1.074 & 10.1787 & 20.29 & 22.88 & 1.86 \\
\hline $\bar{U}$ & 118.13 & 750.6 & 249 & 2996 & 2550 & 1.616 & 41.426 & 45.075 & 2.126 & 0.776 & 10.0911 & 20.10 & 22.95 & 1.85 \\
\hline $\mathrm{v}$ & 124.13 & 749.4 & 249 & 2996 & 2557.76 & 1.602 & 42.063 & 44.668 & 1.996 & 0.7 & 9.7547 & 19.13 & 22.25 & 1.82 \\
\hline $\mathrm{w}$ & 130.88 & 750.4 & 249 & 2996 & 2543.76 & 1.551 & 41.433 & 44.72 & 2.028 & 1.117 & 9.8618 & 19.86 & 22.37 & 1.85 \\
\hline $\mathrm{x}$ & 136.23 & 751.6 & 249 & 2996 & 2544.84 & 1.591 & 41.7 & 44.583 & 2.068 & 0.698 & 10.128 & 20.07 & 22.98 & 1.87 \\
\hline $\mathrm{Y}$ & 142.25 & 749.4 & 250 & 2996 & 2555.94 & 1.62 & 41.43 & 45.08 & 2.13 & 0.78 & 10.0543 & 21.00 & 22.92 & 1.87 \\
\hline $\begin{array}{ll}z \\
\end{array}$ & 148.13 & 750.4 & 249 & 2996 & 2550 & 1.525 & 41.894 & 44.546 & 1.988 & 0.693 & 9.8234 & 19.41 & 22.34 & 1.84 \\
\hline A A & 154.13 & 750.4 & 249 & 2996 & 2551 & 1.566 & 41.661 & 44.746 & 2.027 & 0.698 & 10.0807 & 20.02 & 22.93 & 1.89 \\
\hline A B & 160.13 & 752 & 250 & 2996 & 2545 & 1.57 & 41.471 & 44.775 & 2.035 & 0.7 & 10.2312 & 21.30 & 23.22 & 1.94 \\
\hline AC & 166.13 & 747.6 & 250 & 2996 & 2546 & 1.545 & 41.652 & 45.098 & 2.01 & 0.697 & 9.9283985 & 20.64 & 22.54 & 1.88 \\
\hline A D & 172.25 & 747.6 & 249 & 2996 & 2510 & 1.56 & 43.273 & 41.786 & 2.068 & 0.568 & 9.8081937 & 19.57 & 21.95 & 1.78 \\
\hline $\mathrm{AE}$ & 178.25 & 750.8 & 249 & 2996 & 2520 & 1.615 & 42.875 & 41.944 & 2.12 & 0.702 & 10.113966 & 20.25 & 22.73 & 1.84 \\
\hline AF & 184.25 & 751.2 & 249 & 2996 & 2520 & 1.66 & 42.907 & 41.968 & 2.175 & 0.74 & 10.386034 & 20.70 & 23.34 & 1.88 \\
\hline A G & 190.25 & 750.8 & 249 & 3200 & 2559 & 1.634 & 43.348 & 41.95 & 2.275 & 0.675 & 10.074767 & 19.74 & 22.99 & 1.78 \\
\hline A H & 196.25 & 746 & 250 & 3200 & 2599.06 & 1.602 & 43.805 & 41.36 & 2.09 & 0.668 & 9.8389199 & 20.34 & 22.80 & 1.86 \\
\hline
\end{tabular}




\begin{tabular}{|c|c|c|c|c|c|c|c|c|c|c|c|c|c|c|}
\hline Pt & $\operatorname{Tos}(h \mathbf{r})$ & $P($ psig $)$ & $T(C)$ & $\begin{array}{c}\operatorname{sccm} \\
\operatorname{vin}\end{array}$ & $\begin{array}{l}\operatorname{sccm} \\
\text { Vout }\end{array}$ & Feed $\mathrm{CO} 2$ & H2 & $\mathbf{C M}$ & CD & N2 & $\begin{array}{c}\text { Methanol } \\
\quad \text { L1 }\end{array}$ & $\begin{array}{c}\text { Synth. } \\
\text { Equil } \\
\text { Approach } \\
(\%)\end{array}$ & $\begin{array}{c}\text { MeOH } \\
\text { Equiv } \\
\text { rate } \\
\text { (gmol/kg-hr) }\end{array}$ & $\begin{array}{l}\text { MEOH } \\
\text { rate } \\
\text { const }\end{array}$ \\
\hline A I & 202.25 & 750 & 249 & 3200 & 2551.63 & 1.638 & 43.491 & 41.856 & 2.116 & 0.672 & 9.9554935 & 19.49 & 22.65 & 1.81 \\
\hline$\overline{\mathrm{AJ}}$ & 208.25 & 750 & 249 & 3150 & 2547.61 & 1.678 & 43.538 & 41.735 & 2.165 & 0.665 & 10.124209 & 19.82 & 23.00 & 1.82 \\
\hline A K & 214.25 & 745.8 & 250 & 3150 & 2572.8 & 1.643 & 44.385 & 41.328 & 2.135 & 0.698 & 9.9261639 & 20.03 & 22.77 & 1.81 \\
\hline $\mathrm{AL}$ & 220.25 & 744.4 & 249 & 3150 & 2586 & 1.64 & 44.338 & 41.403 & 2.123 & 0.8 & 9.640689 & 18.72 & 22.23 & 1.75 \\
\hline A M & 226.25 & 746.2 & 249 & 3150 & 2557 & 1.675 & 44.125 & 41.693 & 2.138 & 0.75 & 9.9320298 & 19.20 & 22.65 & 1.79 \\
\hline AN & 232.25 & 745 & 250 & 3150 & 2565.6 & 1.678 & 44.005 & 41.835 & 2.163 & 0.715 & 9.8860335 & 20.08 & 22.62 & 1.80 \\
\hline$\overline{\mathrm{AO}}$ & 244.25 & 746.4 & 249 & 3200 & 2570 & 1.65 & 44.13 & 41.47 & 2.13 & 0.69 & 10.06797 & 19.54 & 23.07 & 1.83 \\
\hline A P & 250.25 & 746.2 & 249 & 3200 & 2560.83 & 1.63 & 43.86 & 41.96 & 2.26 & 0.76 & 10.232123 & 19.85 & 23.37 & 1.81 \\
\hline A $Q$ & 256.25 & 745.6 & 249 & 3200 & 2554.23 & 1.69 & 43.64 & 41.51 & 2.17 & 0.8 & 10.124302 & 20.10 & 23.06 & 1.84 \\
\hline $\mathrm{AR}$ & 263 & 744.4 & 250 & 3200 & 2560.21 & 1.663 & 43.447 & 41.5 & 2.151 & 0.679 & 10.13622 & 21.29 & 23.14 & 1.89 \\
\hline A $S$ & 268 & 745.6 & 249 & 3150 & 2576 & 1.554 & 43.883 & 41.778 & 2.077 & 0.675 & 9.9088454 & 19.35 & 22.76 & 1.83 \\
\hline$\overline{\mathrm{AT}}$ & 274 & 745.4 & 249 & 3200 & 2569 & 1.629 & 44.306 & 41.599 & 2.104 & 0.68 & 10.171788 & 19.57 & 23.30 & 1.86 \\
\hline $\mathrm{AU}$ & 280 & 745 & 249 & 3200 & 2580 & 1.673 & 44.165 & 41.558 & 2.138 & 0.68 & 10.131937 & 19.66 & 23.31 & 1.85 \\
\hline $\mathrm{AV}$ & 286.25 & 742.6 & 250 & 3175 & 2581.33 & 1.628 & 43.82 & 41.8 & 2.12 & 0.675 & 9.8120112 & 20.26 & 22.59 & 1.83 \\
\hline $\mathrm{Aw}$ & 292.25 & 743.8 & 249 & 3200 & 2596.03 & 1.614 & 44.083 & 41.795 & 2.068 & 0.673 & 9.6428305 & 18.78 & 22.32 & 1.78 \\
\hline $\mathrm{AX}$ & 298.25 & 744.4 & 250 & 3100 & 2543 & 1.598 & 43.838 & 41.578 & 2.062 & 0.669 & 9.7678771 & 20.16 & 22.15 & 1.81 \\
\hline$\overline{\mathrm{AY}}$ & 304.25 & 744.6 & 250 & 3150 & 2580.46 & 1.616 & 43.456 & 41.833 & 2.096 & 0.668 & 9.8213222 & 20.47 & 22.60 & 1.85 \\
\hline A $Z$ & 310.25 & 746 & 250 & 3150 & 2580.38 & 1.8 & 43.408 & 41.869 & 2.088 & 0.931 & 9.6478585 & 20.09 & 22.20 & 1.81 \\
\hline B A & 316.25 & 746.4 & 249 & 3200 & 2582.23 & 1.913 & 43.1 & 41.683 & 2.423 & 0.675 & 9.8332402 & 19.89 & 22.64 & 1.72 \\
\hline В В & 322.88 & 746.2 & 249 & 3200 & 2599.72 & 1.74 & 43.19 & 41.68 & 2.28 & 0.67 & 9.939013 & 20.02 & 23.04 & 1.80 \\
\hline $\mathrm{BC}$ & 328.25 & 746 & 250 & 3175 & 2577.14 & 1.78 & 43.49 & 41.51 & 2.27 & 0.67 & 9.9775605 & 20.83 & 22.93 & 1.81 \\
\hline$\overline{\mathrm{BD}}$ & 335.25 & 746.2 & 249 & 3200 & 2604.5 & 1.651 & 43.716 & 41.79 & 2.146 & 0.673 & 9.798324 & 19.25 & 22.76 & 1.80 \\
\hline B E & 340.25 & 746 & 249 & 3200 & 2603.26 & 1.666 & 43.815 & 41.709 & 2.185 & 0.668 & 9.5140596 & 18.68 & 22.09 & 1.72 \\
\hline B F & 347.25 & 746.8 & 249 & 3200 & 2587.57 & 1.73 & 43.78 & 41.5 & 2.2 & 0.67 & 9.7743017 & 19.25 & 22.55 & 1.77 \\
\hline B G & 352.25 & 747.2 & 249 & 3200 & 2584.11 & 1.74 & 43.13 & 42.13 & 2.21 & 0.67 & 9.7439479 & 19.44 & 22.45 & 1.76 \\
\hline $\mathrm{BH}$ & 358 & 747.2 & 249 & 3125 & 2578.39 & 1.722 & 43.464 & 42.056 & 2.268 & 0.79 & 9.7219739 & 19.15 & 22.35 & 1.72 \\
\hline BI & 365.5 & 754.2 & 250 & 3100 & 2525.98 & 1.9 & 41.98 & 42.51 & 2.59 & 0.75 & 10.381471 & 22.07 & 23.38 & 1.77 \\
\hline B J & 368.5 & 750.8 & 249 & 3157.74 & 2533.16 & 1.995 & 42.549 & 42.112 & 2.558 & 0.698 & 10.158473 & 20.54 & 22.95 & 1.71 \\
\hline B K & 374.5 & 753.2 & 249 & 3157.74 & 2528.56 & 1.97 & 42.59 & 42.217 & 2.53 & 0.679 & 10.330074 & 20.64 & 23.29 & 1.74 \\
\hline B L & 380.5 & 752 & 250 & 3157.74 & 2530.39 & 1.8 & 43.123 & 42.208 & 2.348 & 0.67 & 10.472253 & 21.42 & 23.63 & 1.84 \\
\hline B M & 386.5 & 747.6 & 250 & 3157.74 & 2542.21 & 1.785 & 43.352 & 42.313 & 2.325 & 0.676 & 10.130912 & 20.75 & 22.97 & 1.78 \\
\hline$\overline{\mathrm{BN}}$ & 392.5 & 746.2 & 249 & 3157.74 & 2591.66 & 1.51 & 44.11 & 42.5 & 1.96 & 0.67 & 9.2147114 & 17.54 & 21.30 & $\overline{1.71}$ \\
\hline Во & 398.5 & 746.6 & 249 & 3157.74 & 2582.43 & 1.54 & 43.67 & 42.92 & 1.96 & 0.7 & 9.2710428 & 17.80 & 21.35 & 1.72 \\
\hline В Р & 404.5 & 747.4 & 249 & 3157.74 & 2579.22 & 1.58 & 43.71 & 42.6 & 2.01 & 0.66 & 9.6867784 & 18.62 & 22.28 & 1.79 \\
\hline
\end{tabular}




\begin{tabular}{|c|c|c|c|c|c|c|c|c|c|c|c|c|c|c|}
\hline Pt & $\operatorname{Tos}(h \mathbf{r})$ & $P(p$ sig $)$ & $T(C)$ & $\begin{array}{c}\operatorname{sccm} \\
\operatorname{Vin}\end{array}$ & $\begin{array}{l}\text { sccm } \\
\text { Vout }\end{array}$ & Feed $\mathrm{CO} 2$ & H2 & $\mathbf{C M}$ & CD & N2 & $\begin{array}{c}\text { Methanol } \\
\text { L1 }\end{array}$ & $\begin{array}{c}\text { Synth. } \\
\text { Equil } \\
\text { Approach } \\
(\%)\end{array}$ & $\begin{array}{c}\text { MeOH } \\
\text { Equiv } \\
\text { rate } \\
\text { (gmol/kg-hr) }\end{array}$ & $\begin{array}{c}\text { MEOH } \\
\text { rate } \\
\text { const }\end{array}$ \\
\hline B 9 & 410.5 & 746.6 & 250 & 3157.74 & 2586.54 & 1.564 & 44.069 & 42.158 & 2.038 & 0.669 & 9.5512104 & 19.14 & 22.03 & 1.77 \\
\hline B R & 416.5 & 746.8 & 249 & 3157.74 & 2602.82 & 1.525 & 43.818 & 42.529 & 1.934 & 0.667 & 9.2391061 & 17.77 & 21.44 & 1.74 \\
\hline BS & 422.5 & 746.8 & 250 & 3157.74 & 2589.29 & 1.559 & 43.6 & 42.598 & 1.971 & 0.851 & 9.355959 & 18.96 & 21.60 & 1.77 \\
\hline B T & 429.5 & 747 & 249 & 3157.74 & 2597.2 & 1.568 & 43.66 & 42.462 & 1.988 & 0.674 & 9.5247672 & 18.44 & 22.06 & 1.78 \\
\hline $\mathrm{BU}$ & 435.5 & 746.8 & 250 & 3157.74 & 2598.7 & 1.583 & 43.656 & 42.399 & 2.012 & 0.67 & 9.6479516 & 19.56 & 22.36 & 1.82 \\
\hline $\mathrm{BV}$ & 441.5 & 747.8 & 249 & 3157.74 & 2595.55 & 1.52 & 43.56 & 42.69 & 1.93 & 0.66 & 9.0759777 & 17.56 & 21.01 & 1.70 \\
\hline B W & 447.5 & 747.8 & 249 & 3157.74 & 2595.55 & 1.59 & 43.88 & 42.28 & 1.94 & 0.66 & 9.2984171 & 17.89 & 21.52 & 1.75 \\
\hline $\mathrm{BX}$ & 453.5 & 747.8 & 249 & 3157.74 & 2595.55 & 1.61 & 43.6 & 42.19 & 2.04 & 0.66 & 9.5315642 & 18.58 & 22.06 & 1.77 \\
\hline $\mathrm{BY}$ & 459.5 & 747 & 249 & 3157.74 & 2612.98 & 1.602 & 43.403 & 42.588 & 2.054 & 0.663 & 9.4280261 & 18.42 & 21.97 & 1.75 \\
\hline B Z & 465.5 & 747 & 249 & 3157.74 & 2580.5 & 1.63 & 44.43 & 41.78 & 2.057 & 0.66 & 9.4713222 & 18.02 & 21.79 & 1.71 \\
\hline $\mathrm{CA}$ & 471.5 & 747 & 249 & 3157.74 & 2602.05 & 1.63 & 44.31 & 41.85 & 2.04 & 0.67 & 9.5597765 & 18.25 & 22.18 & 1.76 \\
\hline $\mathrm{C} \mathrm{B}$ & 477.5 & 747 & 249 & 3157.74 & 2593.78 & 1.86 & 43.41 & 42.17 & 2.3 & 0.67 & 9.9770019 & 19.62 & 23.08 & 1.78 \\
\hline $\mathrm{C} \mathrm{C}$ & 483.5 & 747 & 249 & 3157.74 & 2593.78 & 1.77 & 43.68 & 42.43 & 2.24 & 0.67 & 9.6507449 & 18.67 & 22.32 & 1.71 \\
\hline $\mathrm{CD}$ & 489.5 & 746 & 249 & 3157.74 & 2601.47 & 1.72 & 43.724 & 42.533 & 2.172 & 0.694 & 9.2459032 & 17.90 & 21.45 & 1.65 \\
\hline $\mathrm{CE}$ & 495.5 & 745.8 & 249 & 3157.74 & 2587.01 & 1.752 & 43.515 & 42.618 & 2.207 & 0.694 & 9.5255121 & 18.56 & 21.97 & 1.70 \\
\hline $\mathrm{CF}$ & 501.5 & 745.8 & 249 & 3157.74 & 2588.56 & 1.746 & 43.666 & 42.479 & 2.179 & 0.693 & 9.755959 & 18.92 & 22.52 & 1.76 \\
\hline $\mathrm{CG}$ & 512.18 & 750.4 & 249 & 3177.8 & 2657.28 & 1.498 & 44.076 & 41.675 & 1.672 & 1.699 & 8.2960894 & 16.08 & 19.66 & 1.68 \\
\hline $\mathrm{CH}$ & 517.93 & 750.4 & 249 & 3177.8 & 2658.1 & 1.207 & 44.116 & 43.191 & 1.577 & 0.71 & 8.388175 & 15.59 & 19.88 & 1.71 \\
\hline $\mathrm{CI}$ & 523.15 & 750.4 & 249 & 3177.8 & 2651.1 & 1.261 & 44.195 & 43.032 & 1.588 & 0.693 & 8.4371508 & 15.68 & 19.95 & 1.72 \\
\hline $\mathrm{CJ}$ & 529.43 & 750 & 249 & 3178.14 & 2656.54 & 1.32 & 43.84 & 43.51 & 1.57 & 0.68 & 8.2091248 & 15.36 & 19.45 & 1.68 \\
\hline $\mathrm{C} \mathrm{K}$ & 535.18 & 750.4 & 249 & 3178.14 & 2673.85 & 1.22 & 43.75 & 43.582 & 1.57 & 0.67 & 8.0706704 & 15.13 & 19.24 & 1.66 \\
\hline $\mathrm{CL}$ & 541 & 750 & 249 & 3178.14 & 2664.9 & 1.324 & 44.157 & 43.341 & 1.574 & 0.662 & 8.1631285 & 15.12 & 19.40 & 1.66 \\
\hline $\mathrm{CM}$ & 547.2 & 750.8 & 249 & 3178.14 & 2645.72 & 1.497 & 43.817 & 42.908 & 1.891 & 0.664 & 8.7420857 & 16.52 & 20.62 & 1.65 \\
\hline $\mathrm{CN}$ & 553 & 750.4 & 250 & 3178.14 & 2636.31 & 1.572 & 44.097 & 42.554 & 1.932 & 0.673 & 8.8115456 & 17.34 & 20.71 & 1.66 \\
\hline $\mathrm{CO}$ & 559.48 & 750.8 & 249 & 3178.14 & 2630.57 & 1.822 & 44.015 & 42.279 & 2.16 & 0.677 & 8.7879888 & 16.70 & 20.61 & 1.55 \\
\hline $\mathrm{CP}$ & 565.23 & 750.8 & 249 & 3178.14 & 2623.31 & 1.762 & 44.014 & 42.086 & 2.25 & 0.688 & 8.9565177 & 17.08 & 20.95 & 1.56 \\
\hline $\mathrm{CO}$ & 571.25 & 751.6 & 249 & 3178.14 & 2625.18 & 1.915 & 44.116 & 41.975 & 2.219 & 0.681 & 8.9468343 & 16.99 & 20.94 & 1.56 \\
\hline $\mathrm{CR}$ & 577.27 & 750 & 249 & 3178.14 & 2630.04 & 1.77 & 44.075 & 42.164 & 2.221 & 0.68 & 8.8798883 & 16.90 & 20.83 & 1.56 \\
\hline $\mathrm{cs}$ & 583.27 & 747.2 & 249 & 3178.14 & 2634.56 & 2 & 43.62 & 42.42 & 2.45 & 0.66 & 8.6972998 & 16.94 & 20.43 & 1.47 \\
\hline $\mathrm{CT}$ & 589.55 & 749.6 & 249 & 3178.14 & 2633.59 & 1.74 & 44.69 & 42.08 & 2.04 & 0.66 & 8.6136872 & 16.04 & 20.23 & 1.55 \\
\hline $\mathrm{Cu}$ & 595.03 & 750.2 & 250 & 3178.14 & 2632.17 & 1.81 & 43.87 & 42.31 & 2.25 & 0.67 & 8.8231844 & 17.65 & 20.71 & 1.55 \\
\hline $\mathrm{cV}$ & 601.32 & 747.4 & 250 & 3178.14 & 2632.34 & 1.788 & 44 & 42.44 & 2.26 & 0.67 & 8.7442272 & 17.48 & 20.53 & 1.53 \\
\hline $\mathrm{CW}$ & 607.07 & 746.2 & 249 & 3178.14 & 2642.64 & 1.782 & 43.731 & 42.425 & 2.315 & 0.675 & 8.6893855 & 16.89 & 20.48 & 1.51 \\
\hline $\mathrm{cx}$ & 613.33 & 746.8 & 249 & 3178.14 & 2624.65 & 1.875 & 43.789 & 42.342 & 2.257 & 0.669 & 8.8783985 & 17.20 & 20.78 & 1.56 \\
\hline
\end{tabular}




\begin{tabular}{|c|c|c|c|c|c|c|c|c|c|c|c|c|c|c|}
\hline Pt & $\operatorname{Tos}(h \mathbf{r})$ & $P(p s i g)$ & $T(C)$ & $\begin{array}{c}\operatorname{sccm} \\
\operatorname{Vin}\end{array}$ & $\begin{array}{l}\text { sccm } \\
\text { Vout }\end{array}$ & Feed $\mathrm{CO} 2$ & H2 & $\mathbf{C M}$ & CD & N2 & $\begin{array}{c}\text { Methanol } \\
\text { L1 }\end{array}$ & $\begin{array}{c}\text { Synth. } \\
\text { Equil } \\
\text { Approach } \\
(\%)\end{array}$ & $\begin{array}{c}\text { MeOH } \\
\text { Equiv } \\
\text { rate } \\
\text { (gmol/kg-hr) }\end{array}$ & $\begin{array}{c}\text { MEOH } \\
\text { rate } \\
\text { const }\end{array}$ \\
\hline $\mathrm{CY}$ & 619.35 & 749.8 & 249 & 3178.14 & 2623.51 & 1.824 & 43.708 & 42.222 & 2.306 & 0.673 & 9.0965549 & 17.56 & 21.28 & 1.58 \\
\hline $\mathrm{CZ}$ & 625.37 & 746.6 & 250 & 3178.14 & 2627.52 & 1.8 & 43.73 & 42.63 & 2.27 & 0.67 & 8.8067039 & 17.77 & 20.63 & 1.55 \\
\hline D A & 631.12 & 745.4 & 250 & 3178.14 & 2652.26 & 1.722 & 44.36 & 42.3 & 2.15 & 0.67 & 8.472067 & 16.85 & 20.04 & 1.52 \\
\hline D B & 637 & 749.8 & 249 & 3178.14 & 2636.72 & 1.797 & 44.131 & 42.192 & 2.21 & 0.665 & 8.7957169 & 16.71 & 20.68 & 1.54 \\
\hline D C & 643.4 & 745.4 & 249 & 3178.14 & 2677.3 & 1.29 & 44.11 & 42.92 & 1.85 & 0.66 & 8.4828678 & 16.09 & 20.25 & 1.64 \\
\hline D D & 649.4 & 747.2 & 250 & 3178.14 & 2679.31 & 1.226 & 45.095 & 43.019 & 1.534 & 0.659 & 7.8678771 & 14.88 & 18.80 & 1.62 \\
\hline $\mathrm{DE}$ & 655.4 & 747.2 & 250 & 3178.14 & 2699.14 & 1.3 & 45.039 & 42.894 & 1.604 & 0.662 & 7.781378 & 14.80 & 18.73 & 1.58 \\
\hline D F & 661.95 & 750.2 & 249 & 3178.14 & 2666.07 & 1.466 & 44.414 & 43.026 & 1.819 & 0.667 & 8.1809125 & 15.08 & 19.45 & 1.55 \\
\hline$\overline{D G}$ & 667.45 & 750.4 & 249 & 3178.14 & 2661.65 & 1.5 & 44.405 & 42.776 & 1.852 & 0.664 & 8.3452514 & 15.46 & 19.81 & 1.57 \\
\hline D H & 673.2 & 750.4 & 249 & 3178.14 & 2670.75 & 1.5 & 44.49 & 42.7 & 1.93 & 0.67 & 8.3317505 & 15.41 & 19.84 & 1.54 \\
\hline
\end{tabular}




\section{Figure 1: Simplified Kingsport LPMeOH Flowsheet}

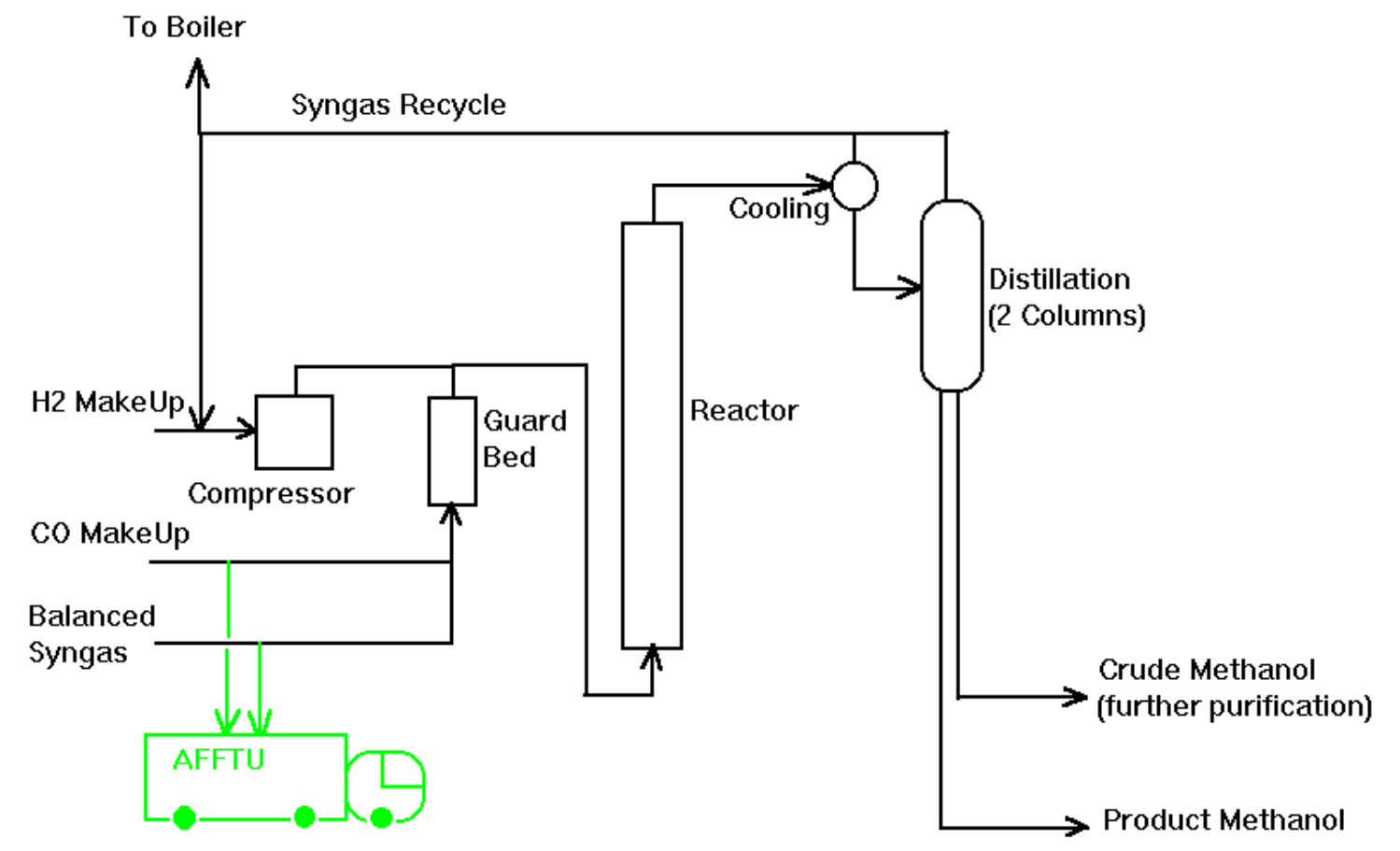

Figure 2: Simplified Overview of AFFTU Experimental Apparatus

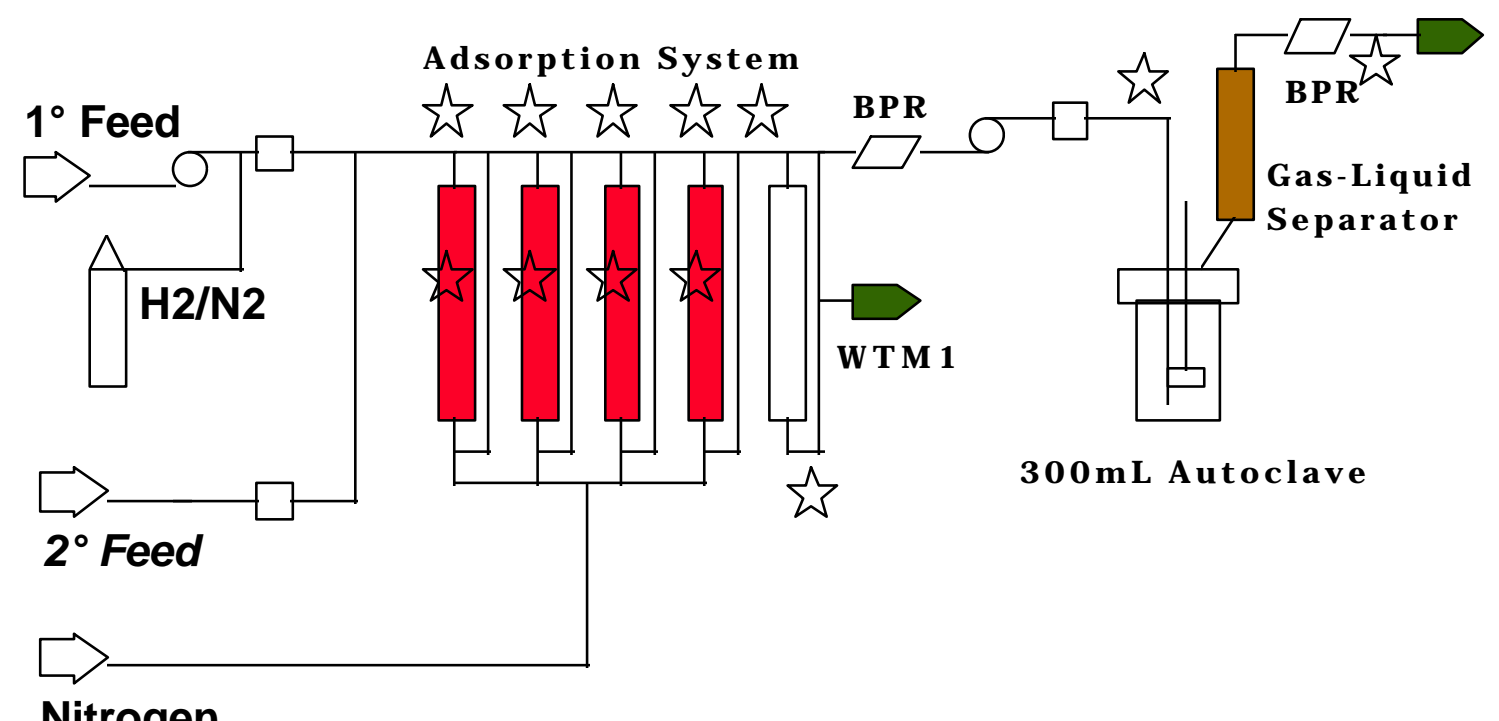

Stars represent GC sampling points; squares represent mass flow controllers 


\section{Figure 3: AFFTU Layout}

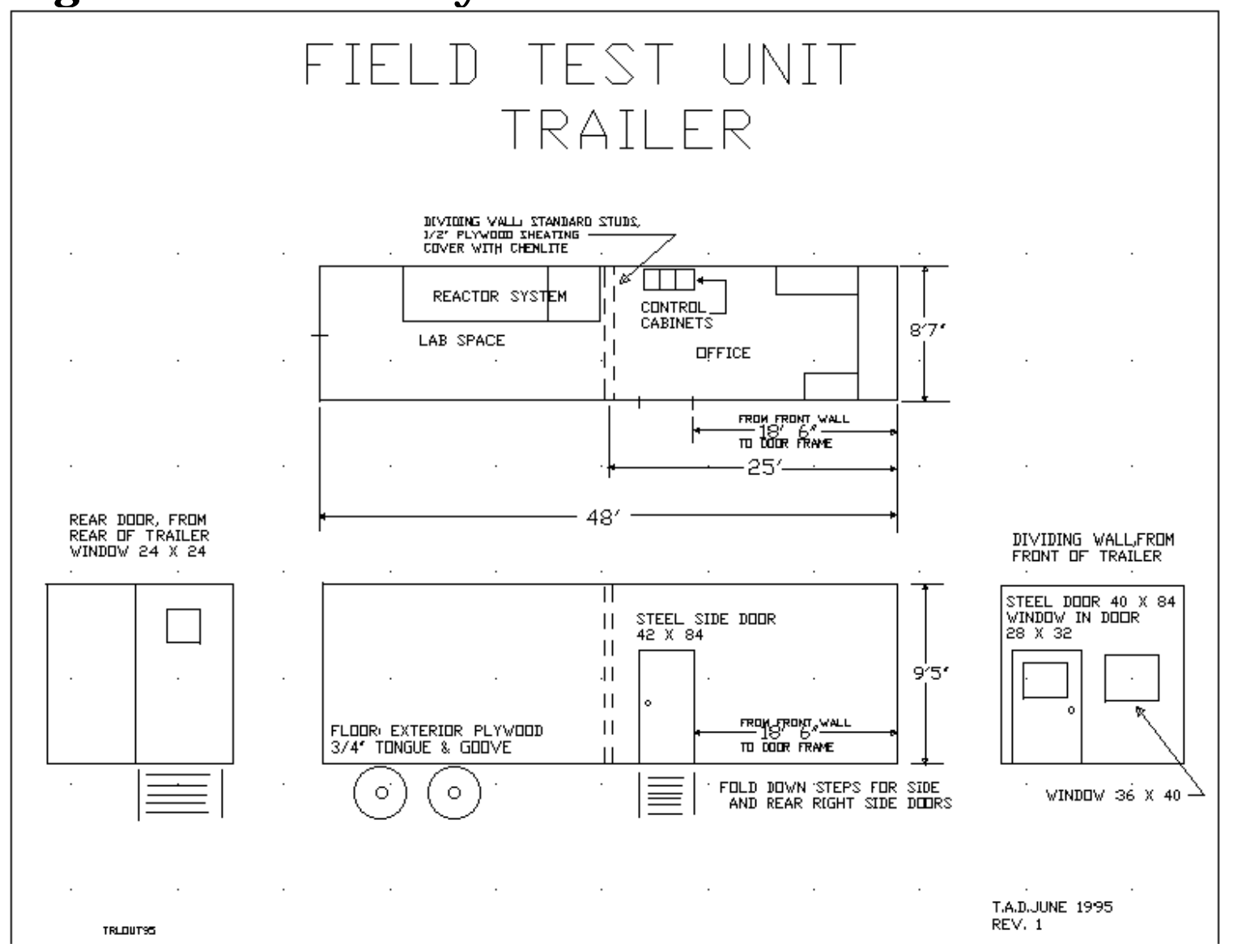




\section{Figure 4: AFFTU Office Area}

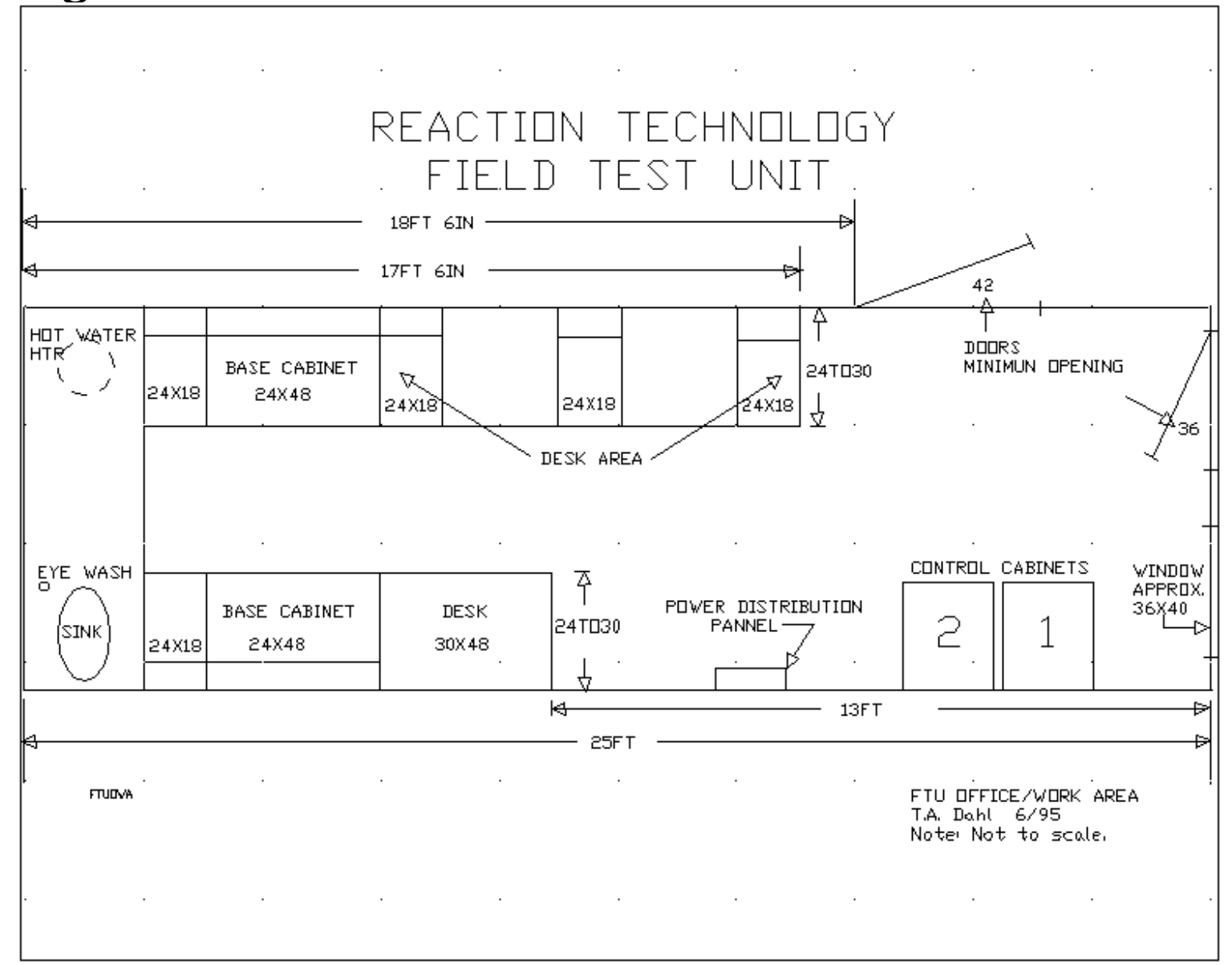




\section{Figure 5: AFFTU Gas Feed System}

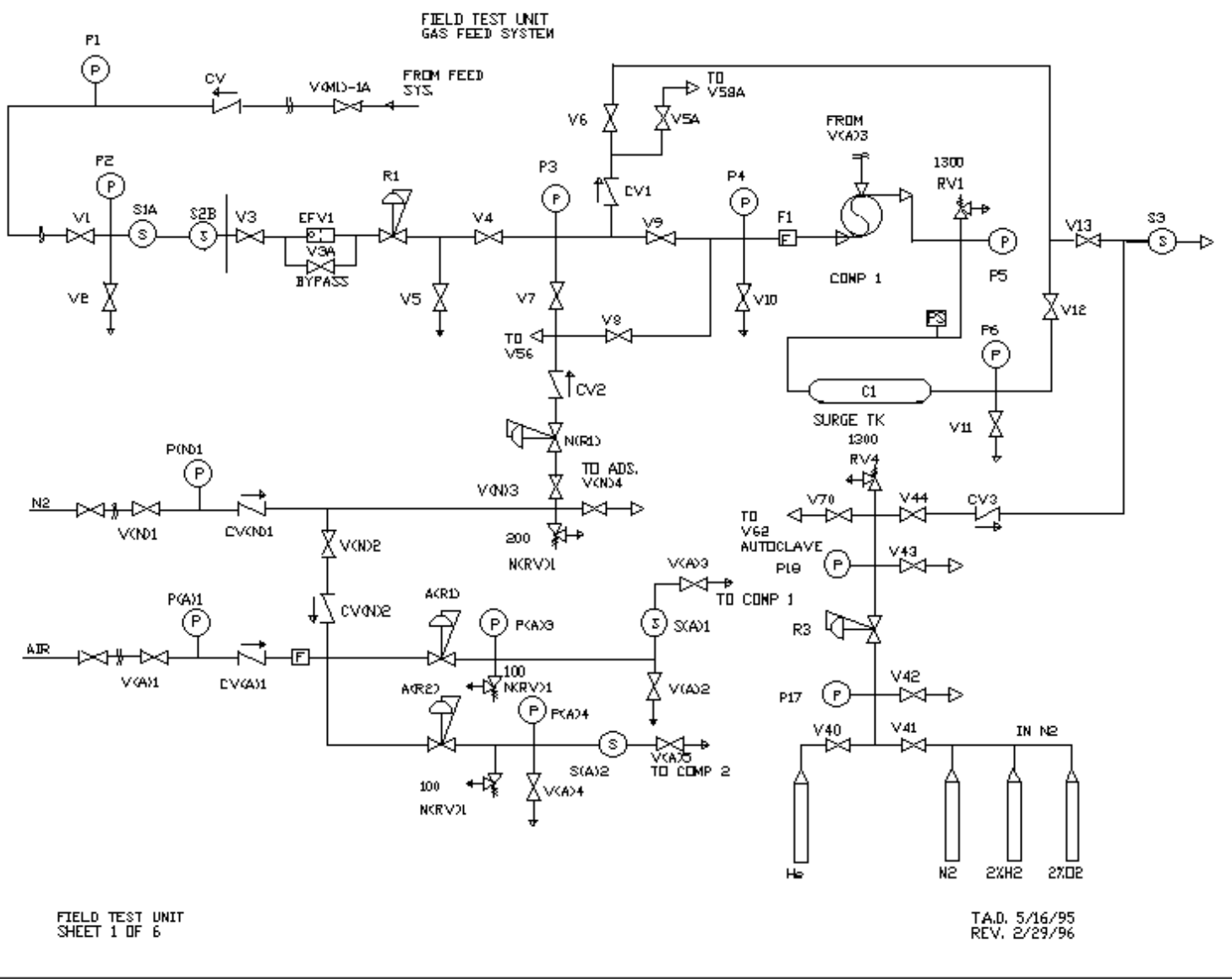




\section{Figure 6: AFFTU Adsorption System}

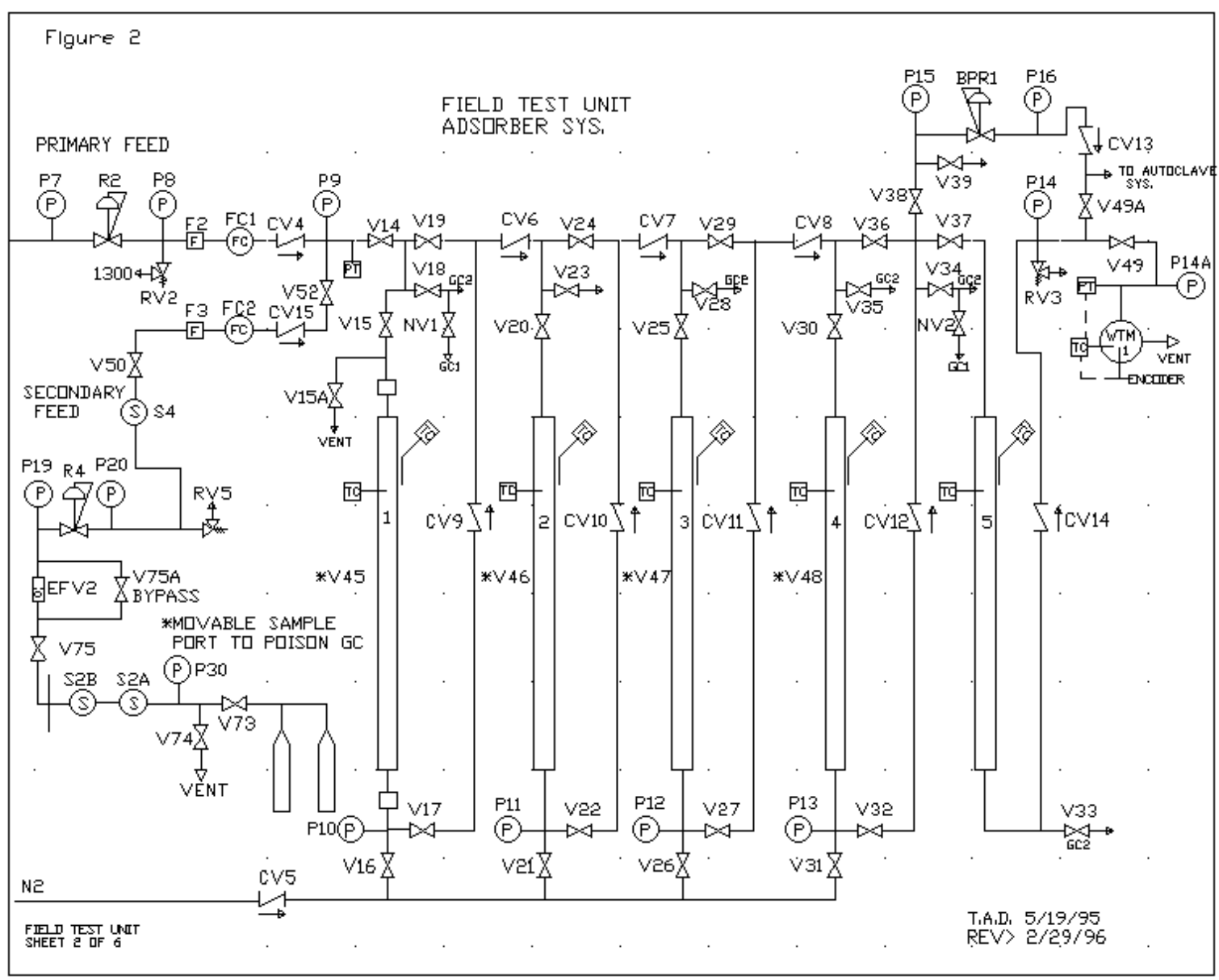




\section{Figure 7: AFFTU Autoclave System}

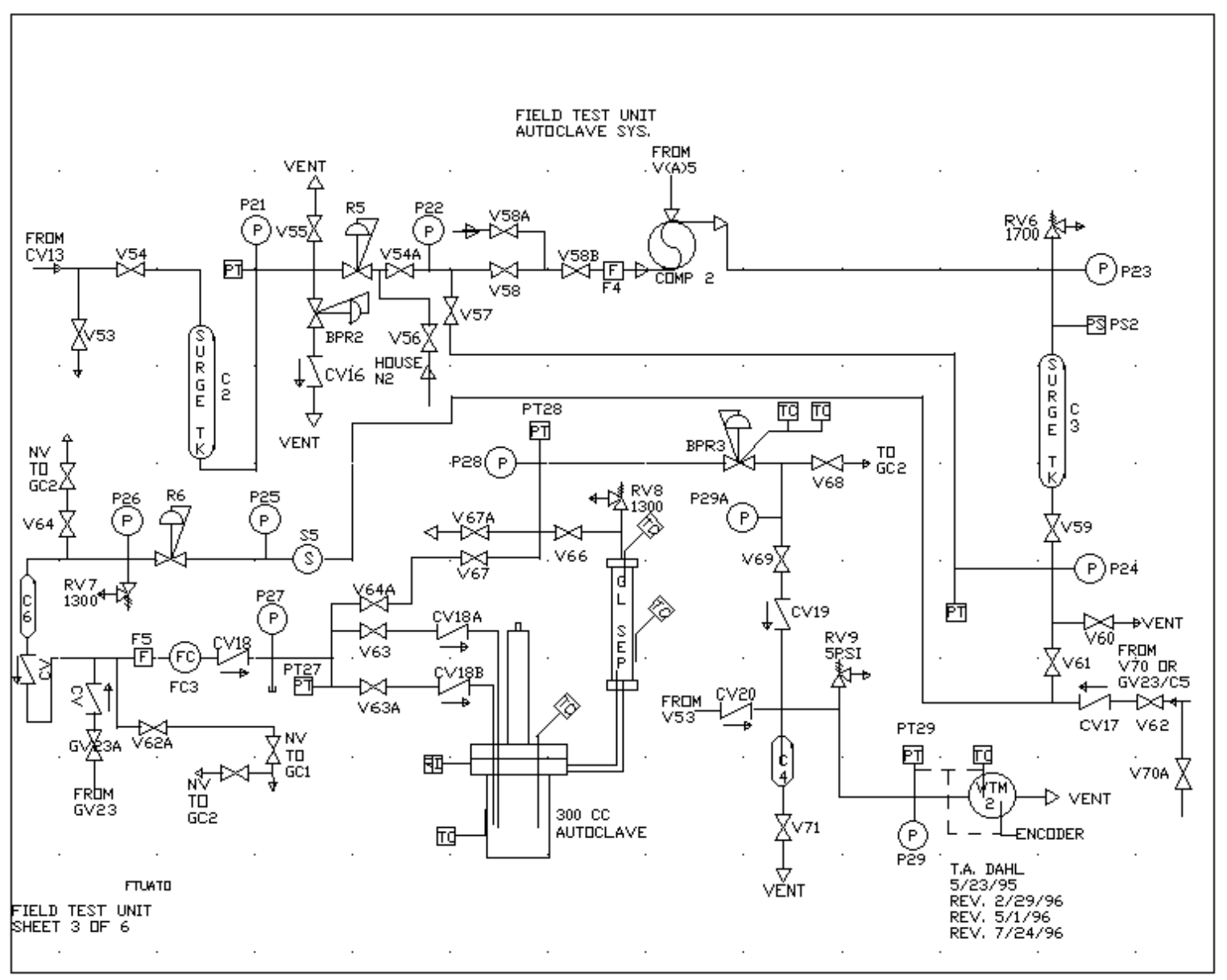


Figure 8: AFFTU GC Gas Manifold

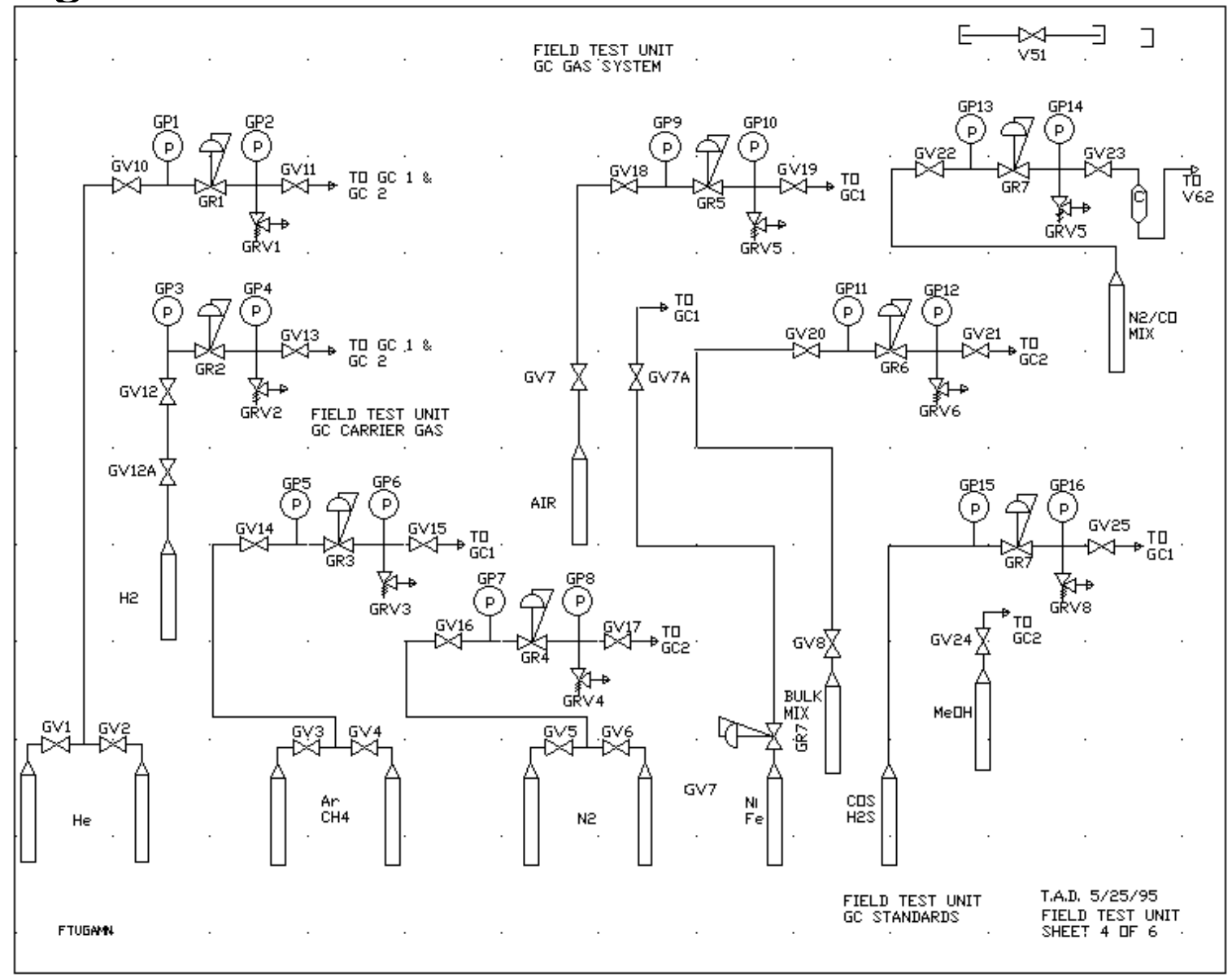




\section{Figure 9: AFFTU Poisons GC Sampling System}

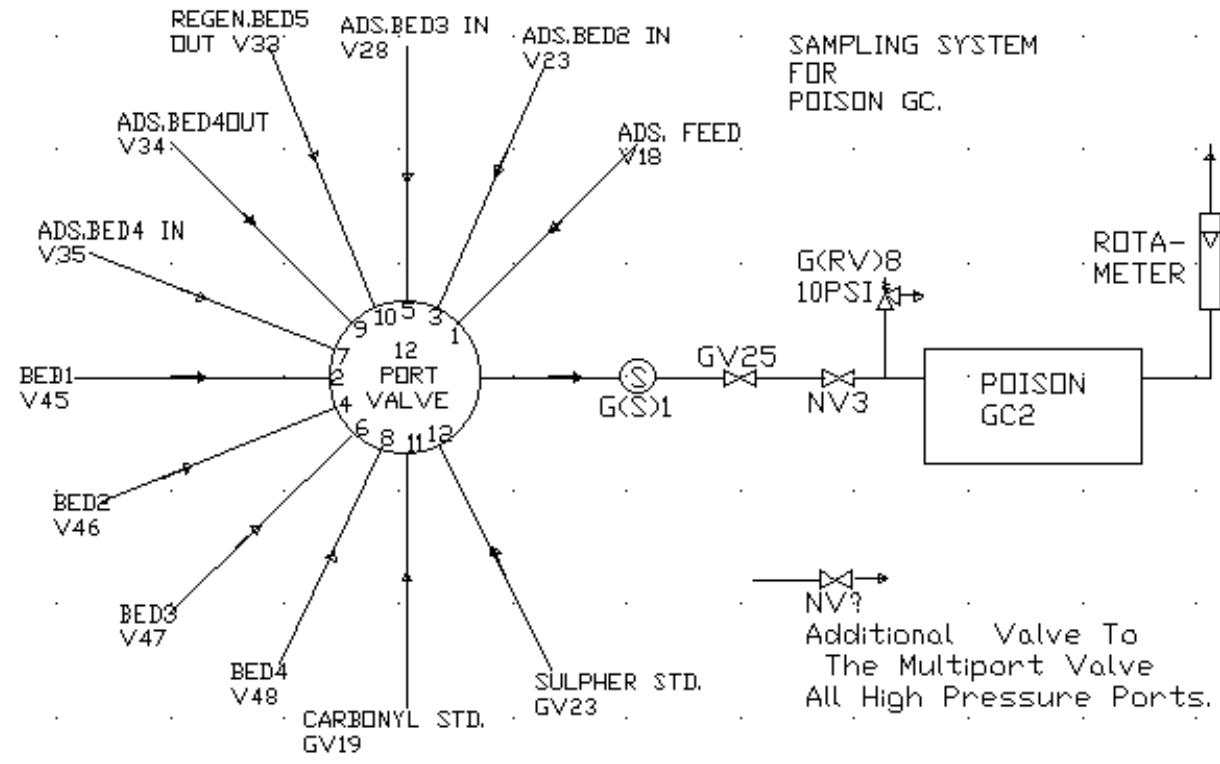

FTUPGGC

T.A.D. $4 / 11 / 96$

FIELD TEST UNIT

SHEET 5 QF 6 


\section{Figure 10: AFFTU Bulk GC Sampling System}

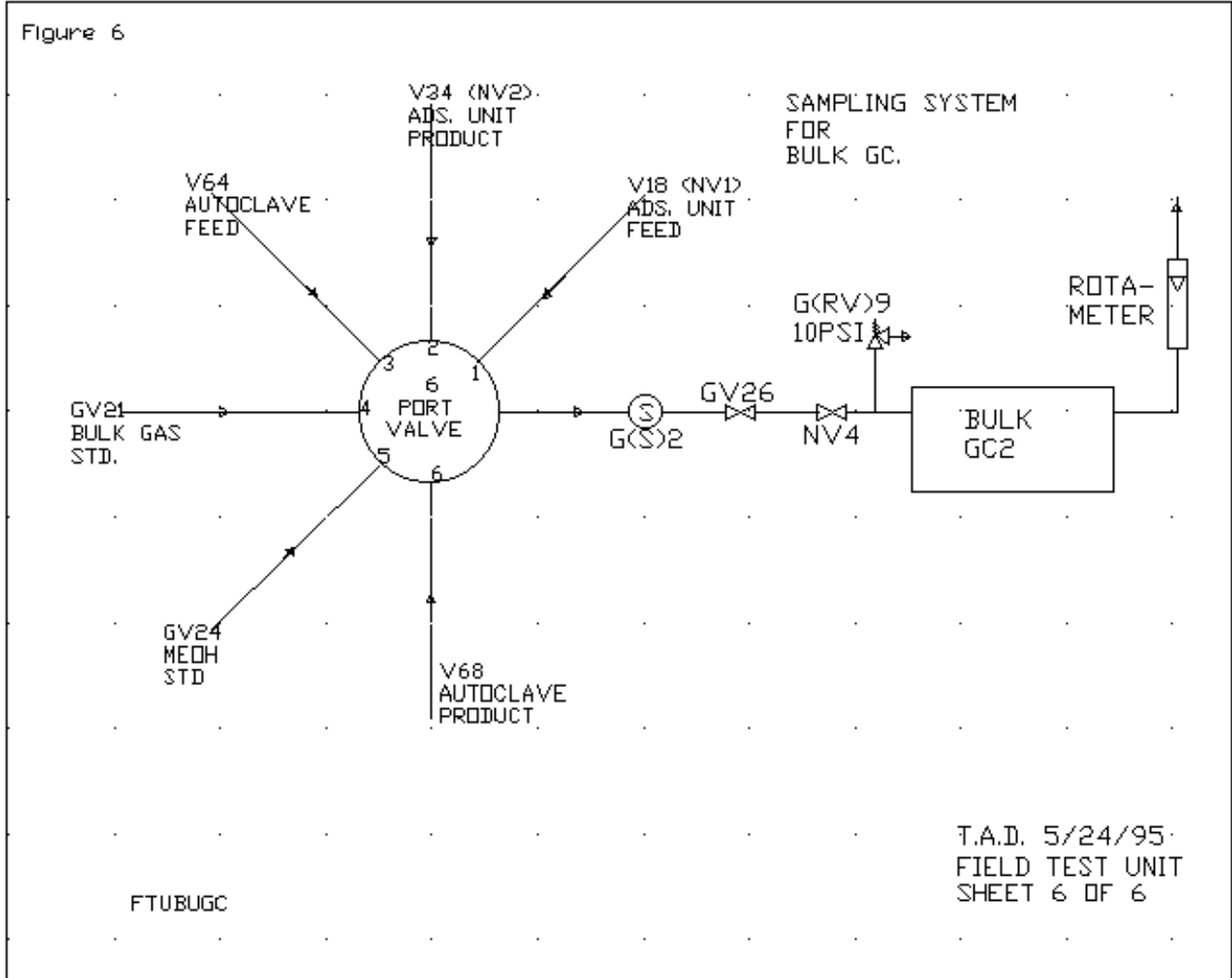

\section{Figure 11: Detail of Adsorption Bed Design}

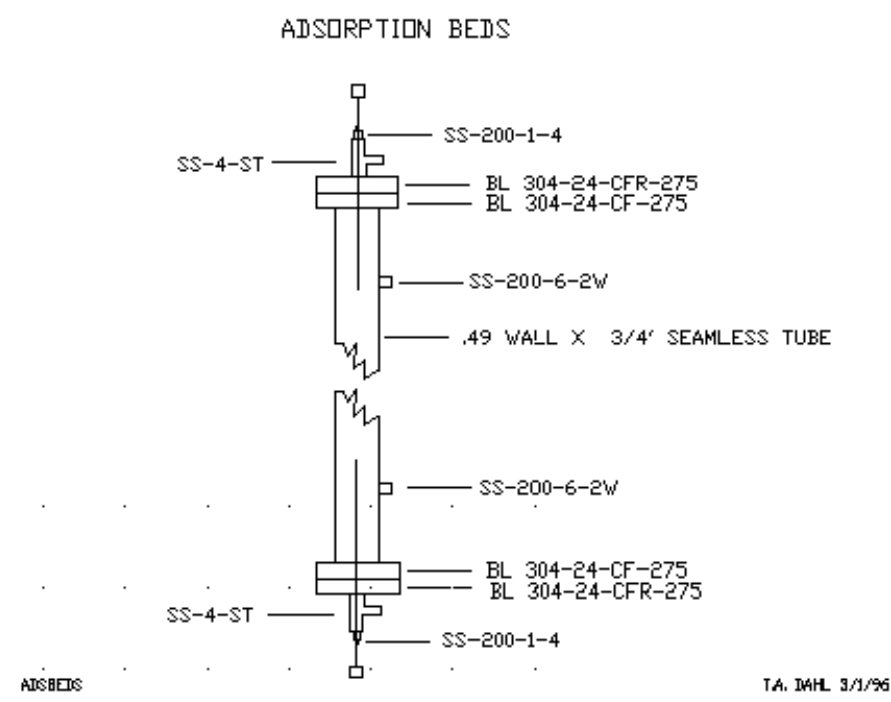




\section{Figure 12a: Bulk GC Configuration}

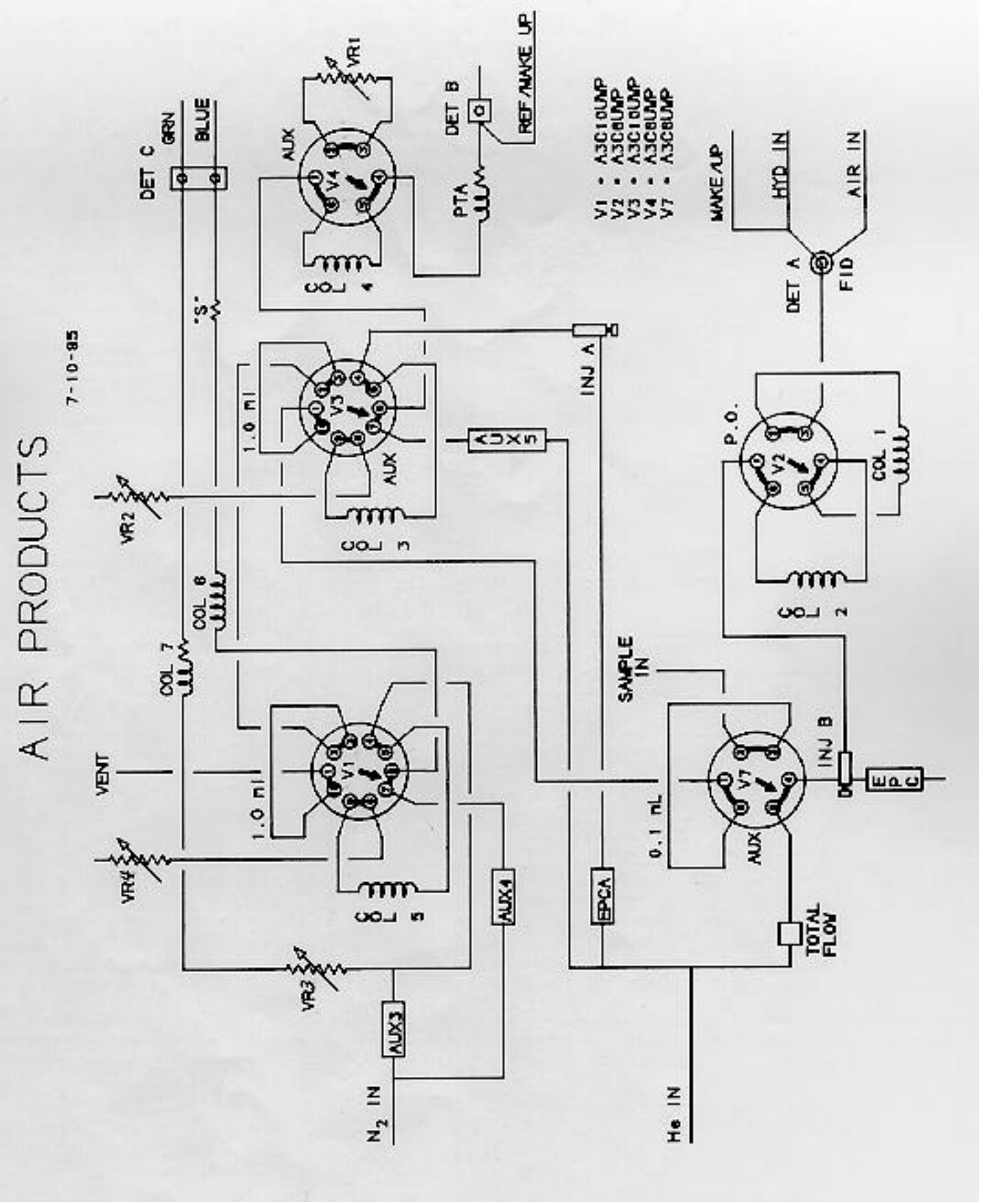


Figure 12b: Poisons GC Configuration

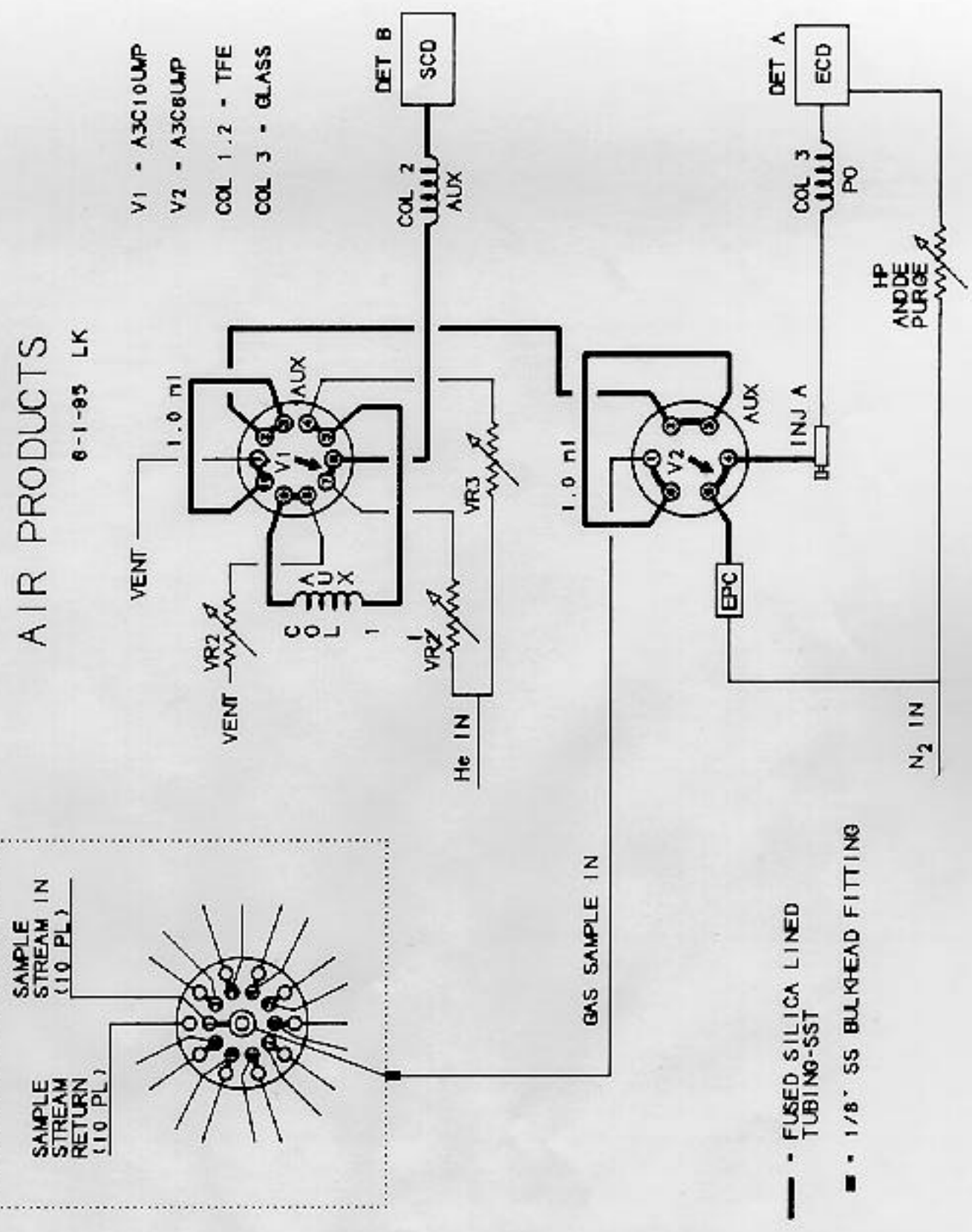


Figure 12c: Typical FID Chromatogram

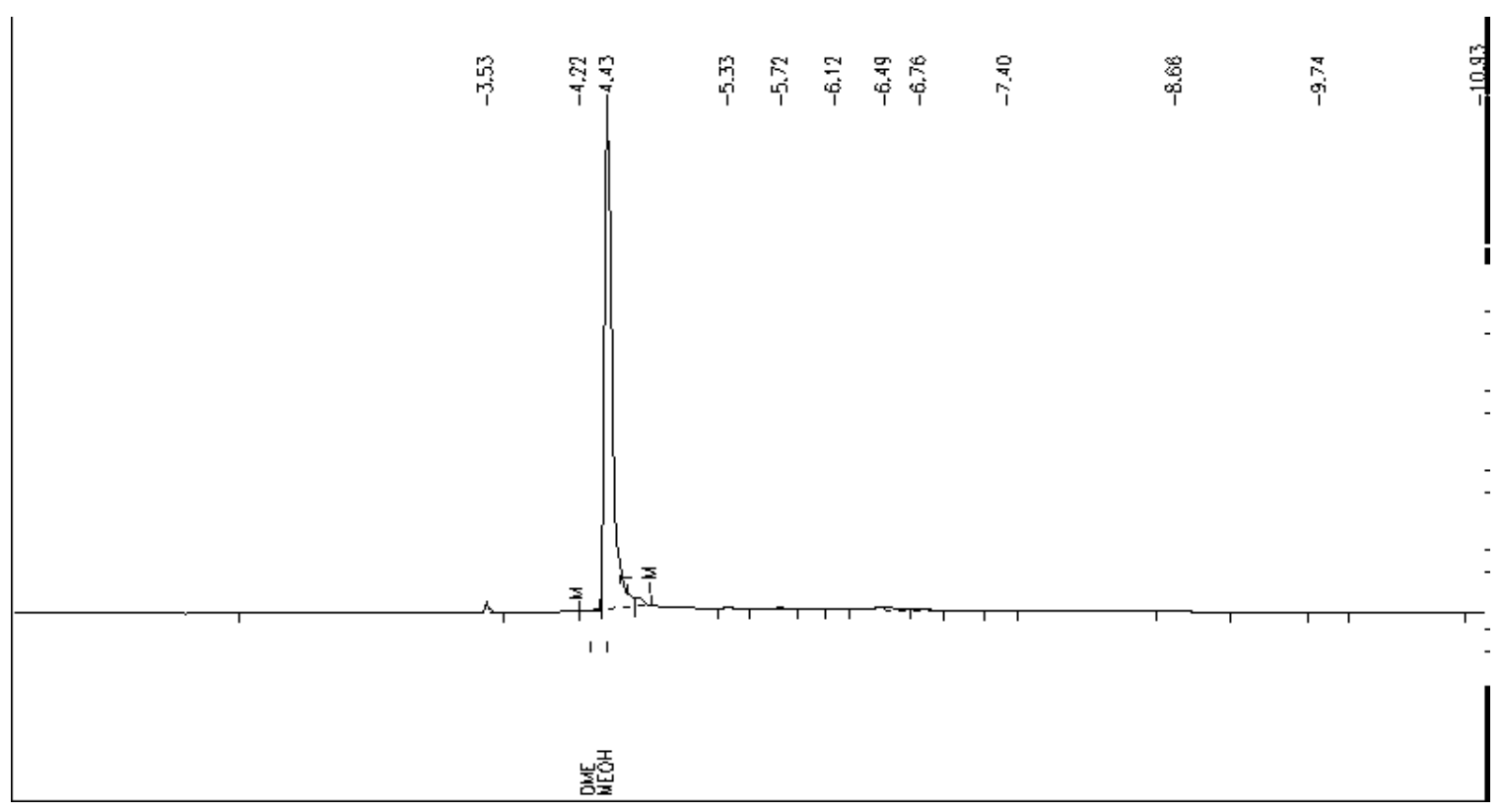

Figure 12d: Typical TCD Chromatogram

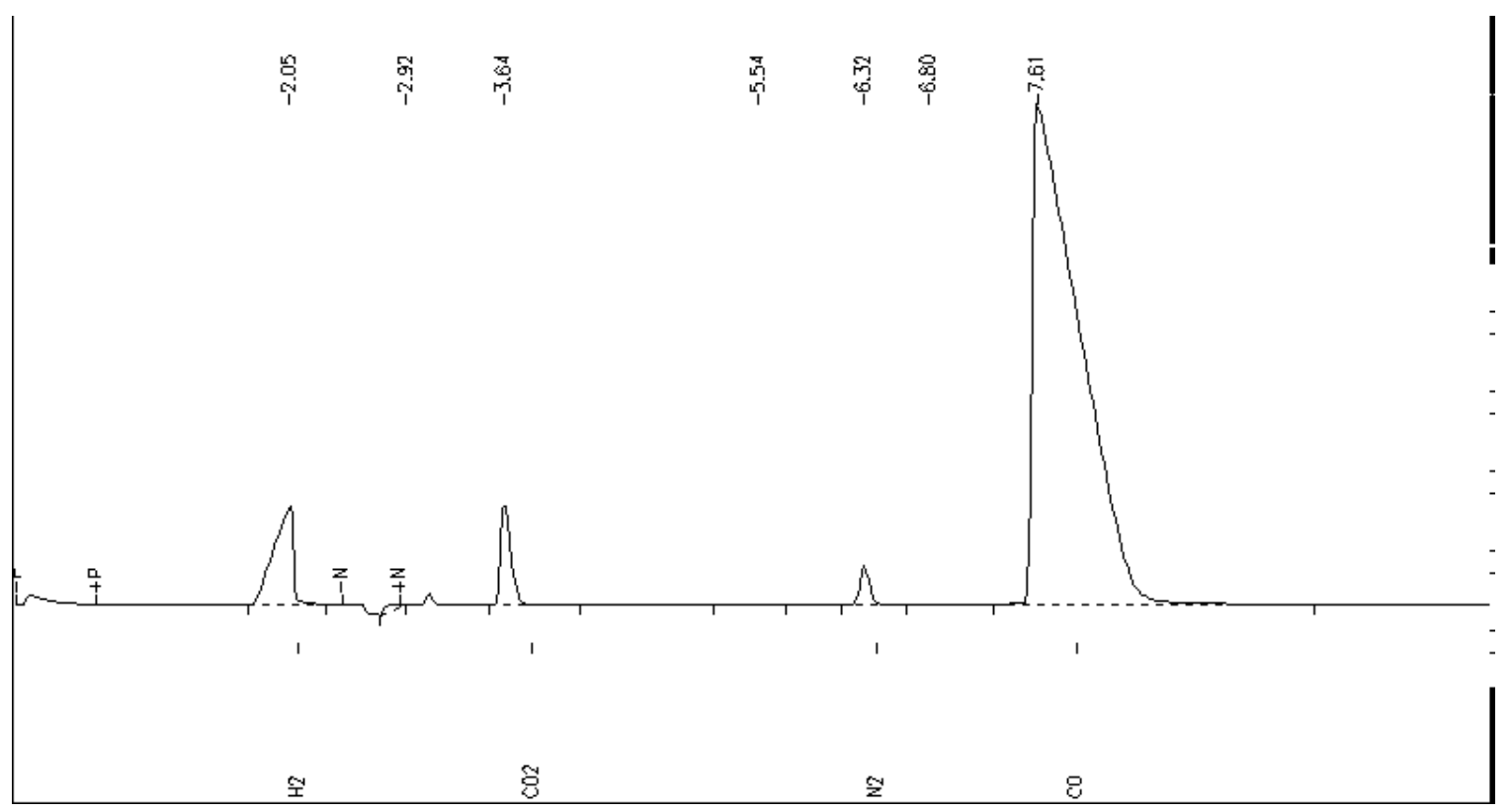


Figure 12e: Typical ECD Chromatogram

$40 \mathrm{ppb} \mathrm{Ni}(\mathrm{CO})_{4} ; 7 \mathrm{ppb} \mathrm{Fe}(\mathrm{CO})_{5}$

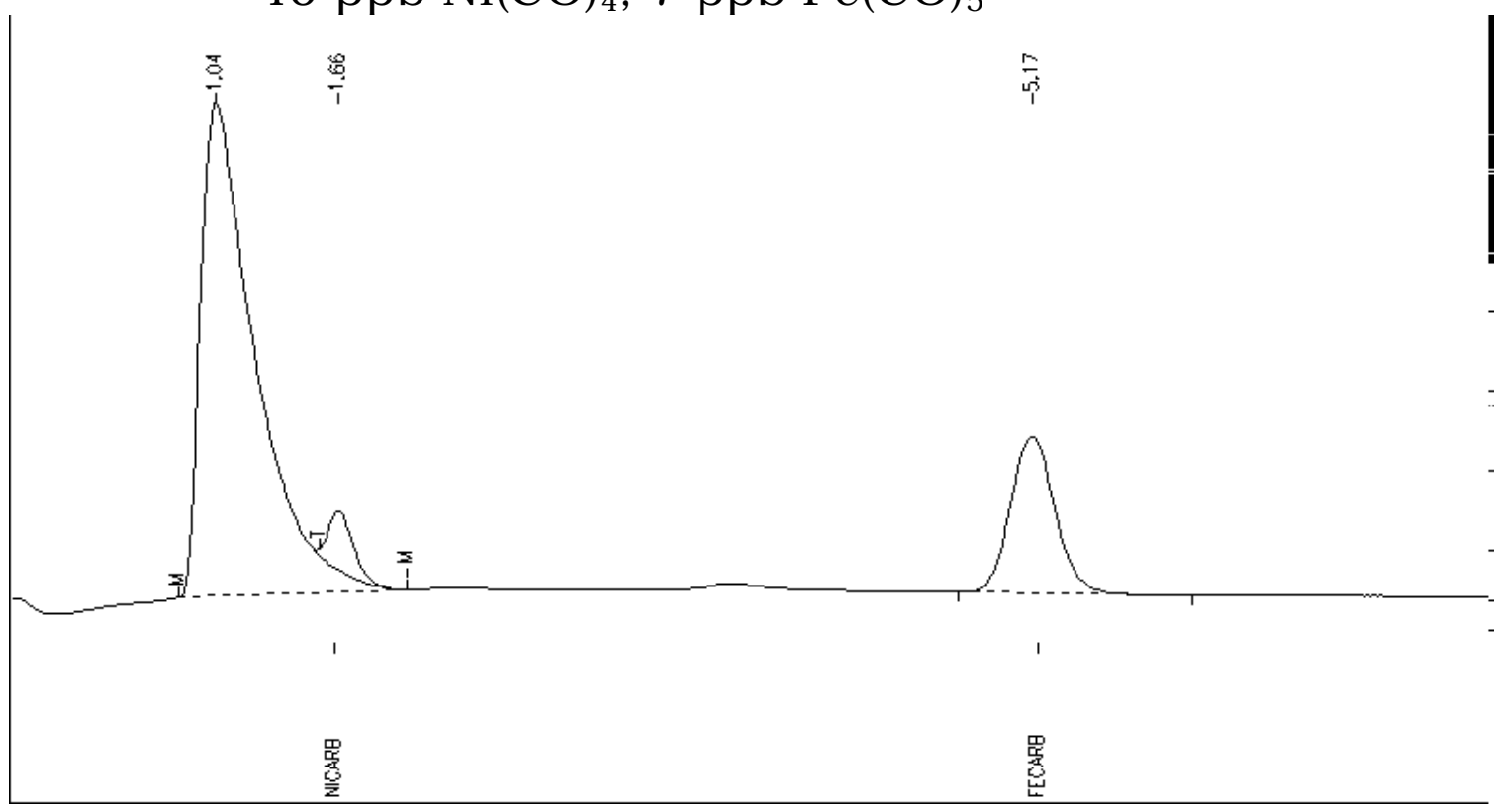

Figure 12f: Typical SCD Chromatograms $40 \mathrm{ppb}$ COS; 29 ppb $\mathrm{H}_{2} \mathrm{~S}$

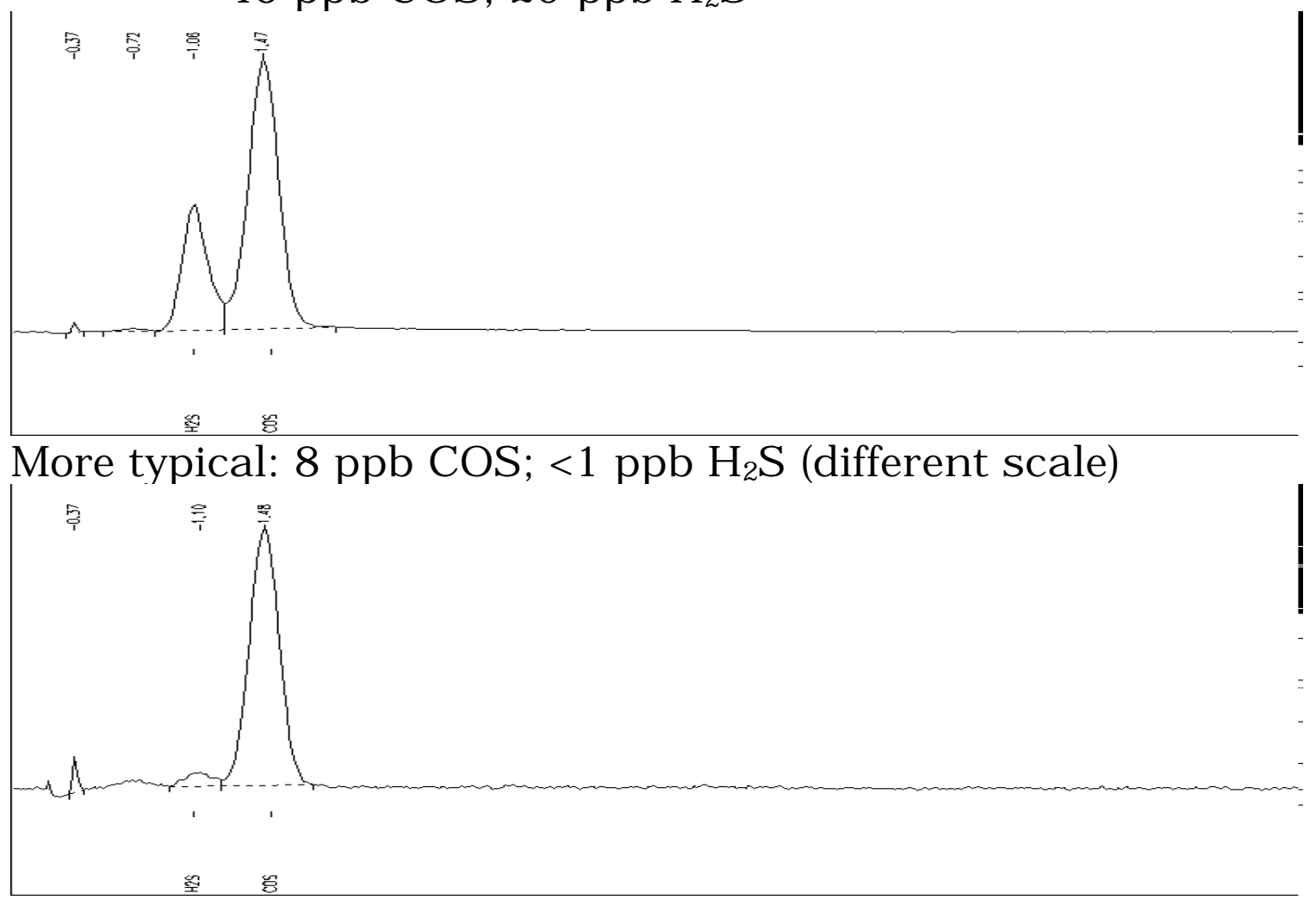




\section{Figure 13: Full Trailer Feed Poisons History}

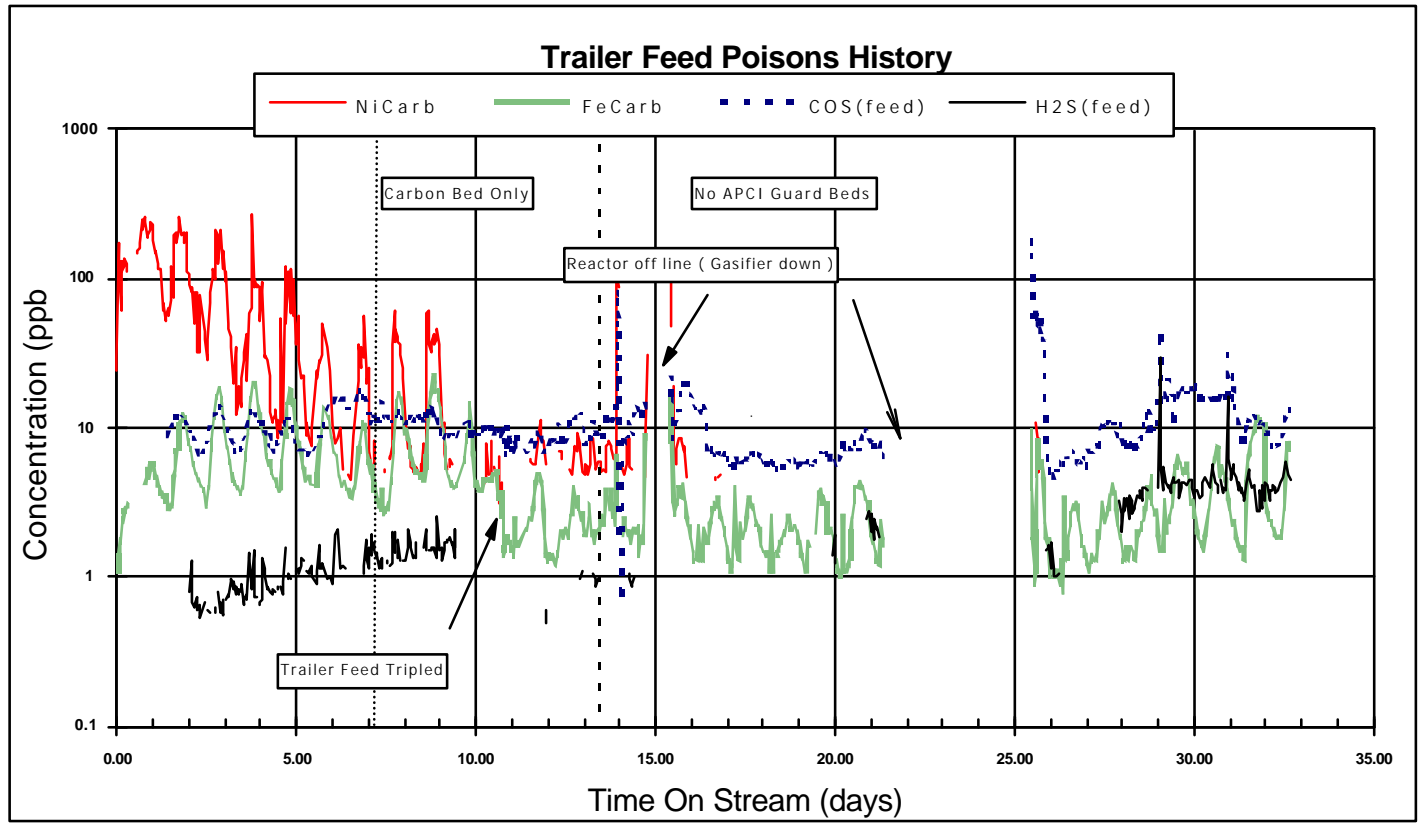

Figure 14: Trailer Feed Poisons History For First Day After Gasifier Restart

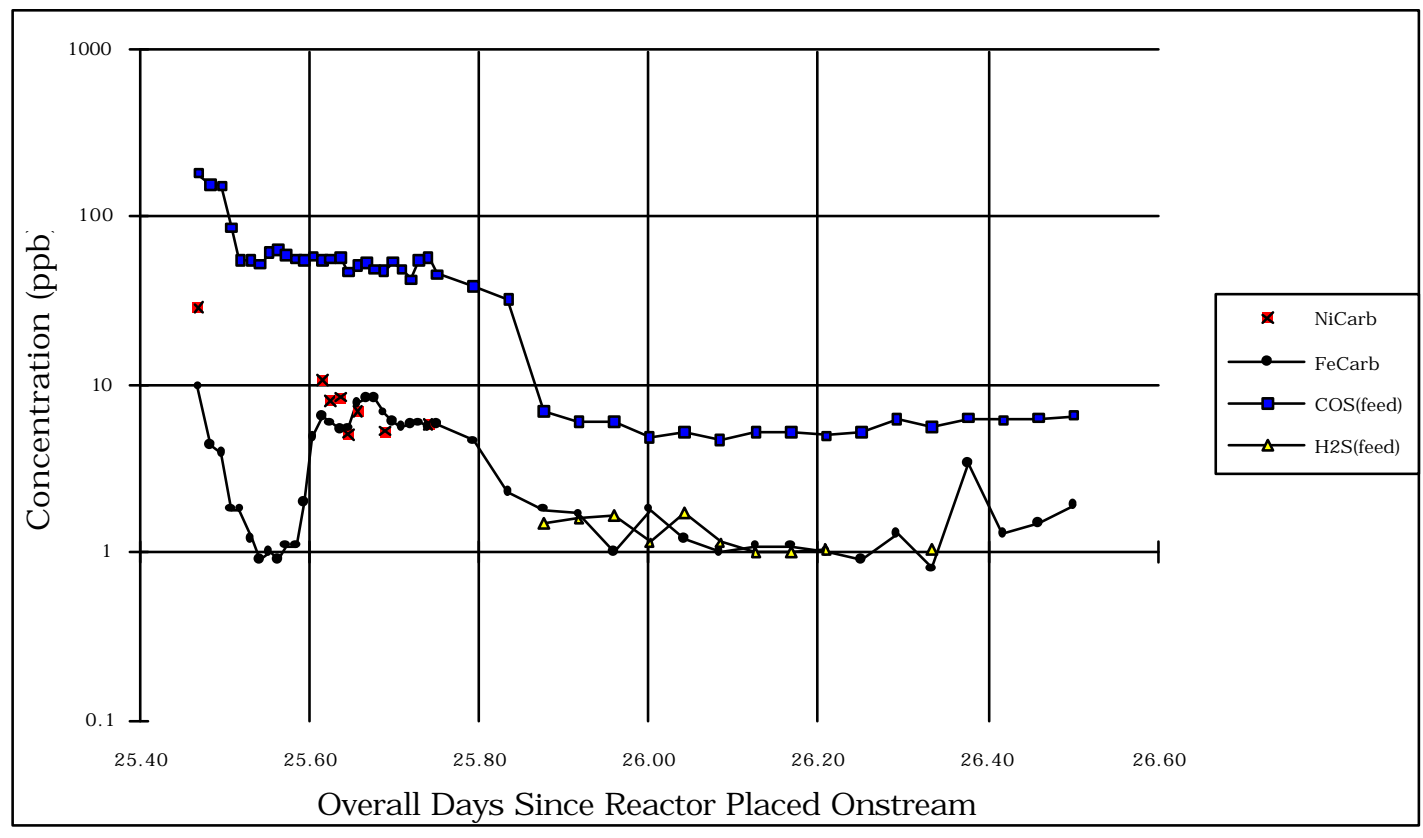




\section{Figure 15: Hydrogen Sulfide History}

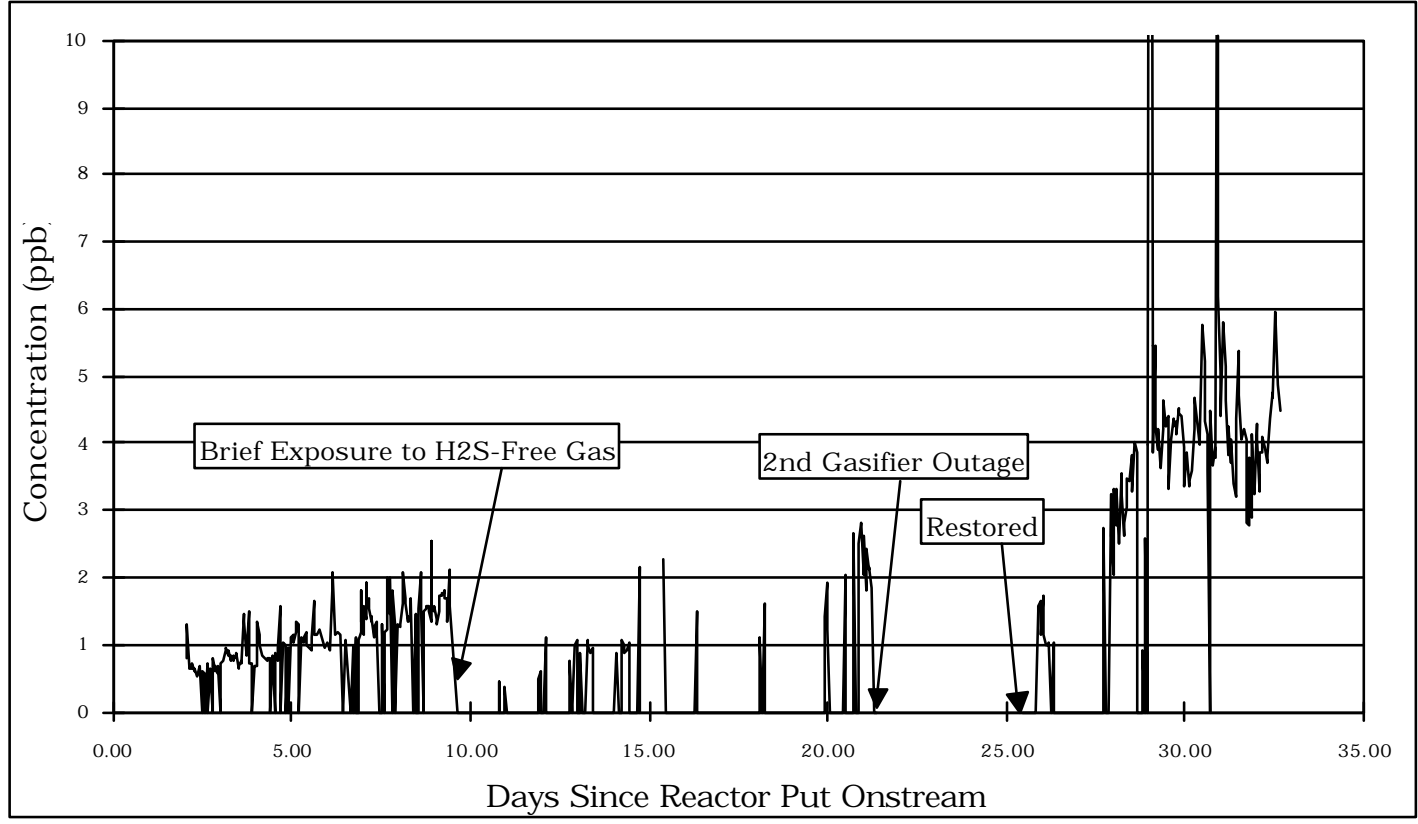




\section{Figure 16a: Concentration Fluctuations and Ambient Temperature}

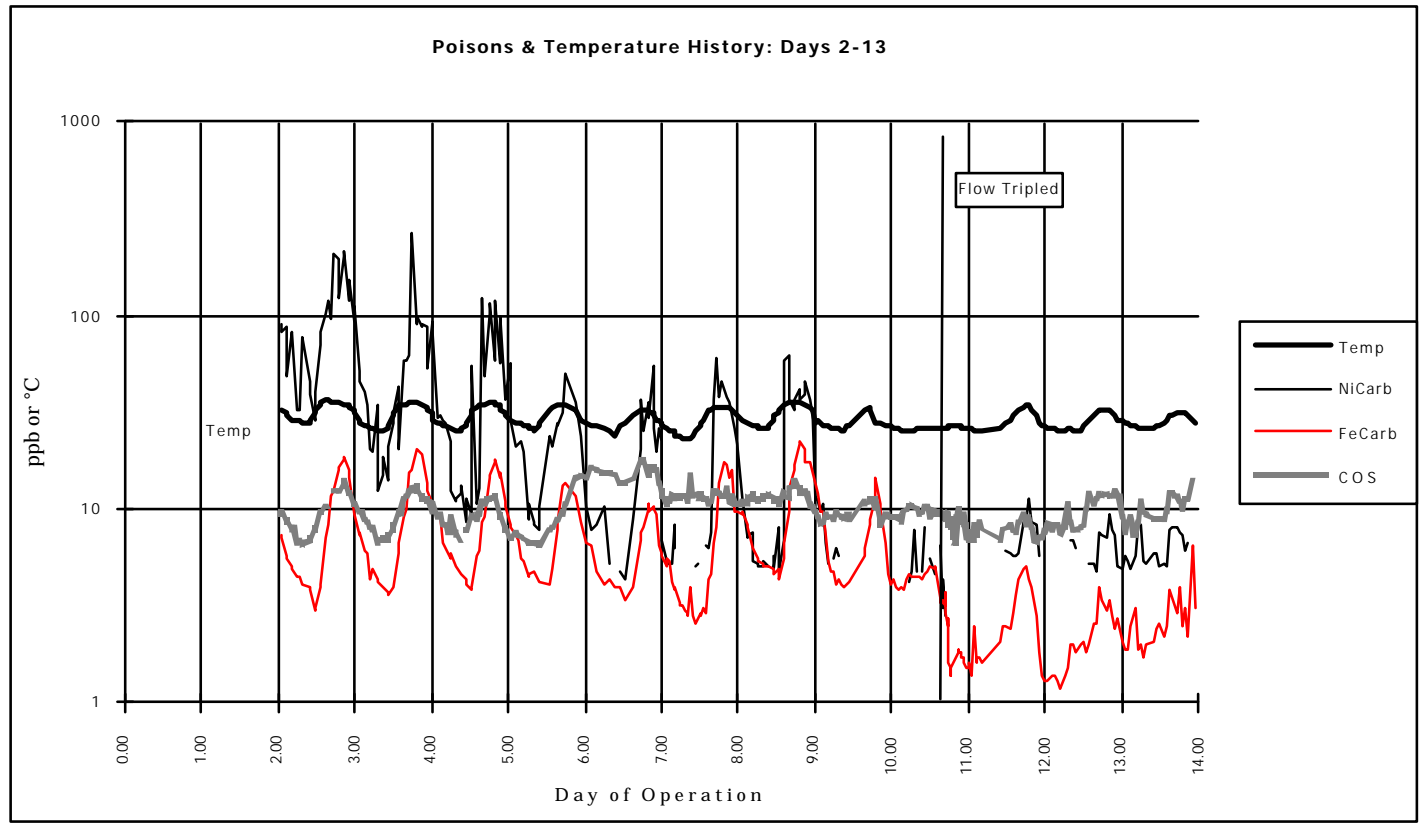

Figure 16b: Effect of Tripling Trailer Feed Flow On Poisons Concentrations

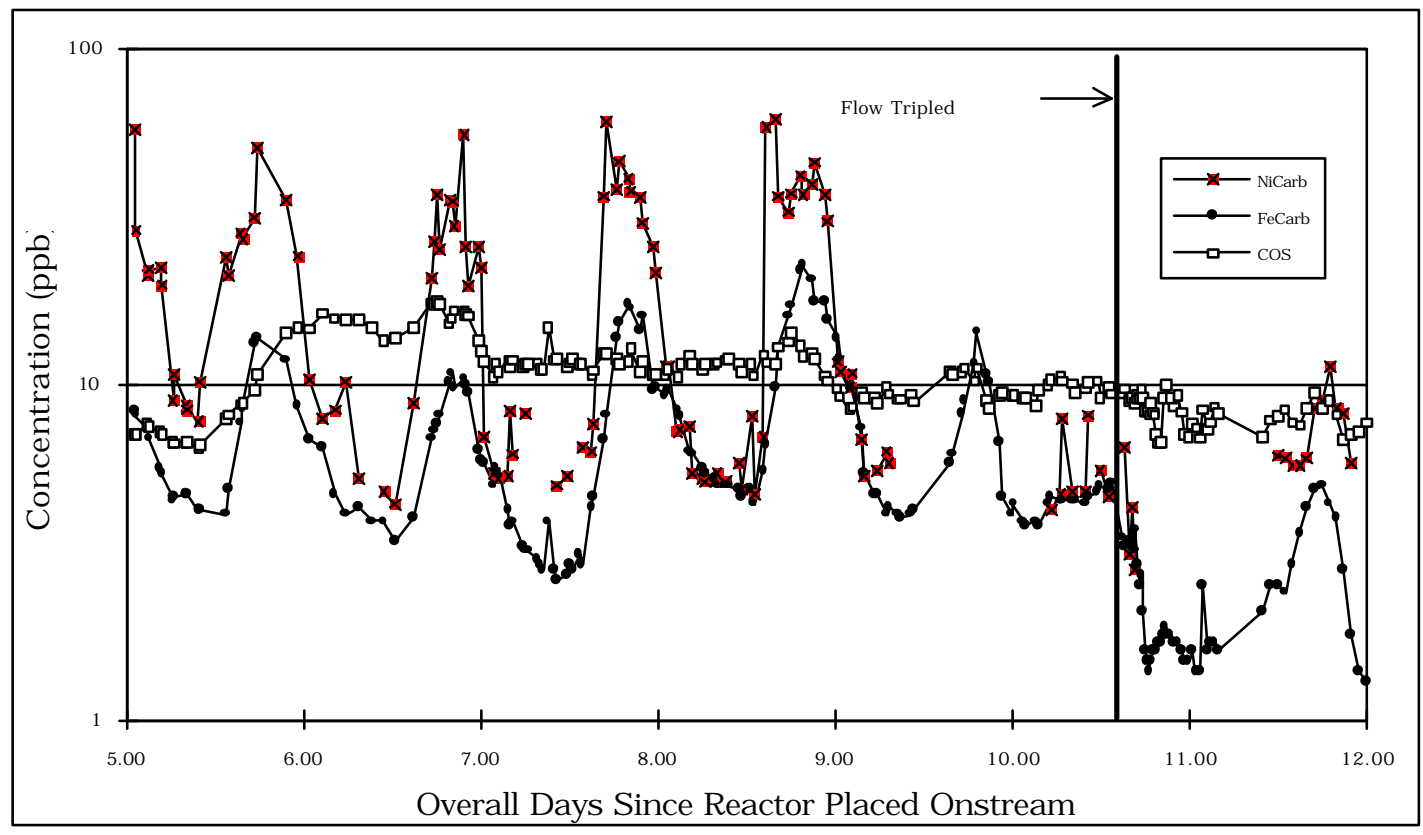


Figure 16c: Correlation of the Daily Maximum Carbonyl Concentrations with the Daily Temperature
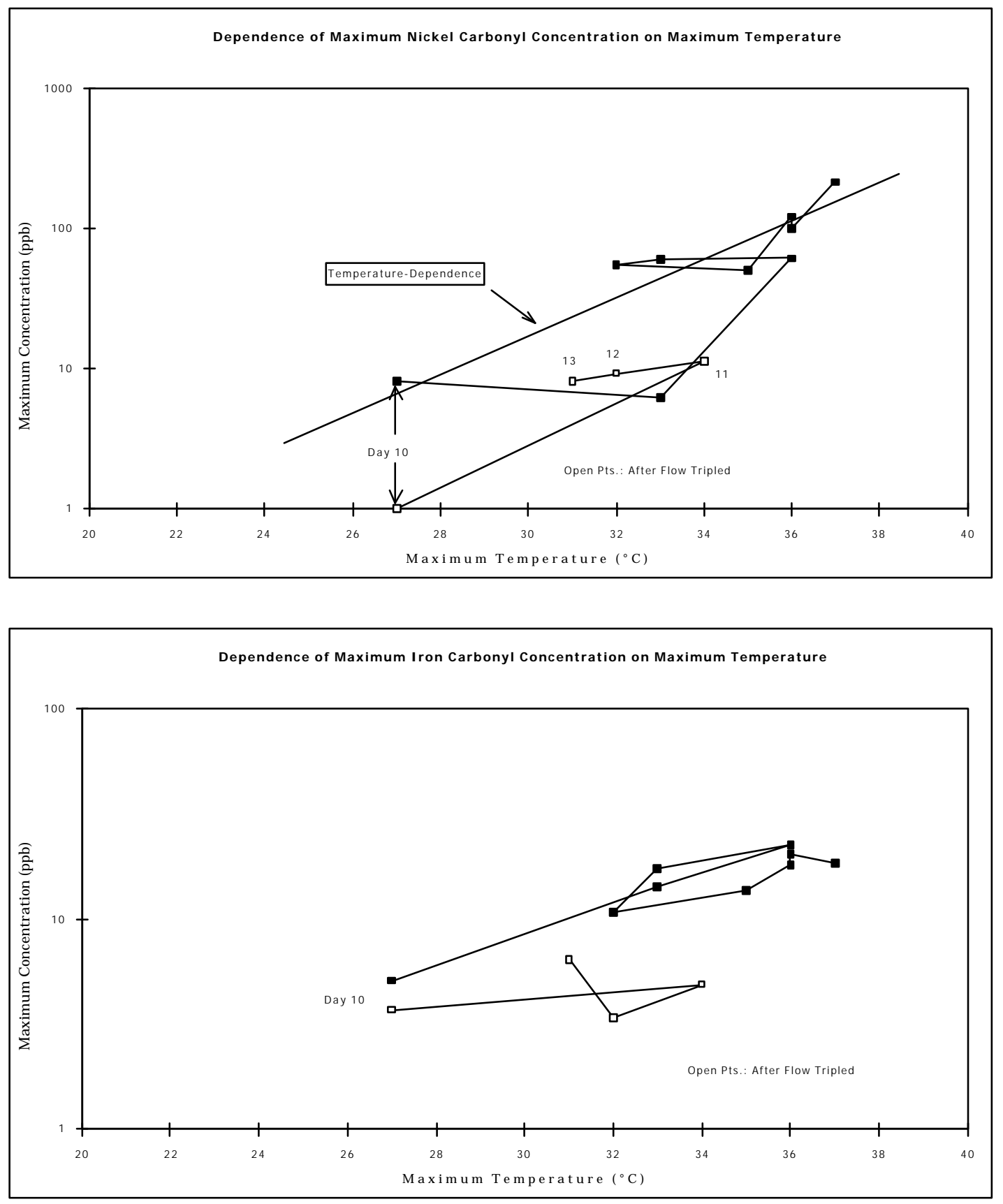


\section{Figure 17: Productivity History}

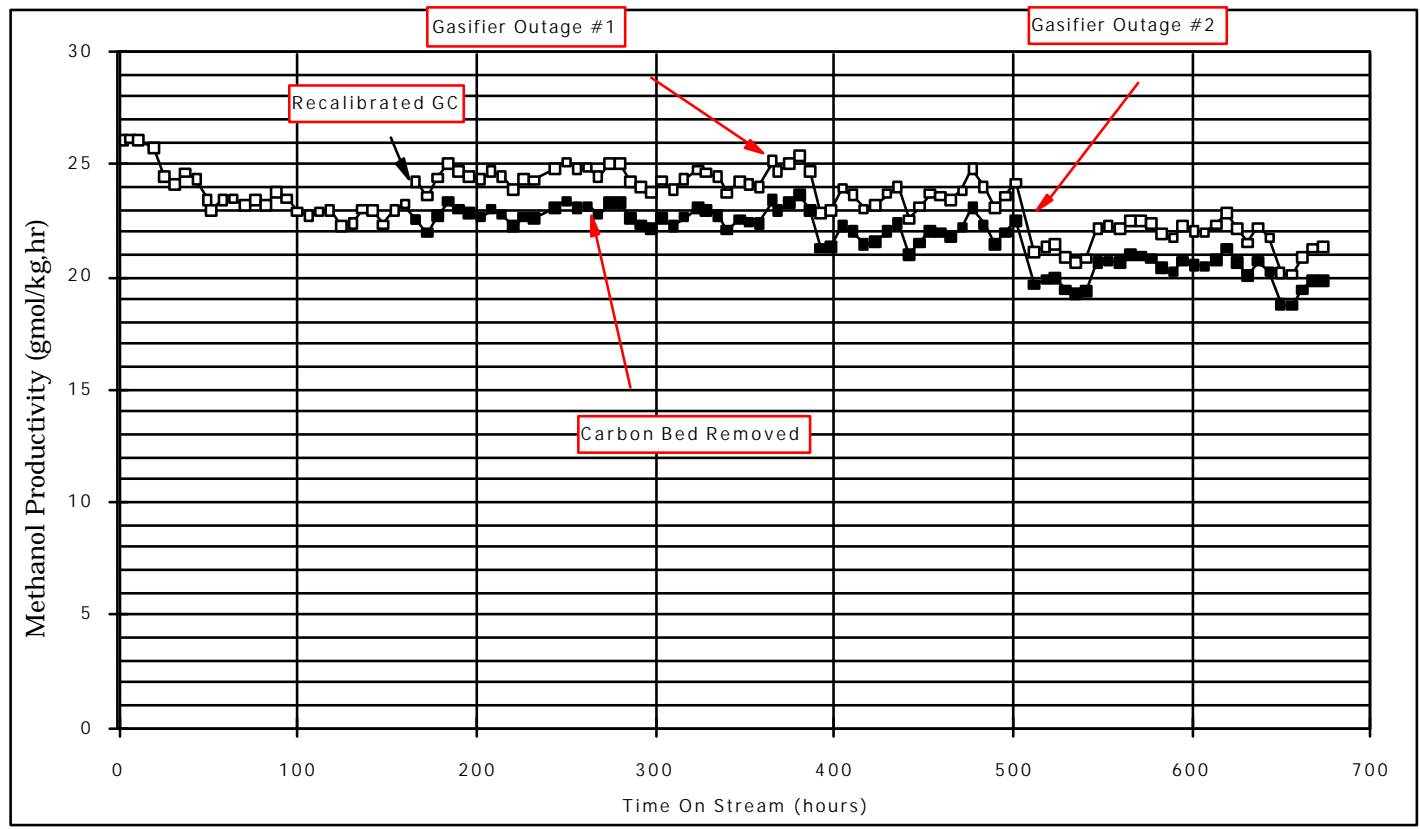

Figure 18: Comparison of $\mathbf{k}_{M}$ and Productivity Histories

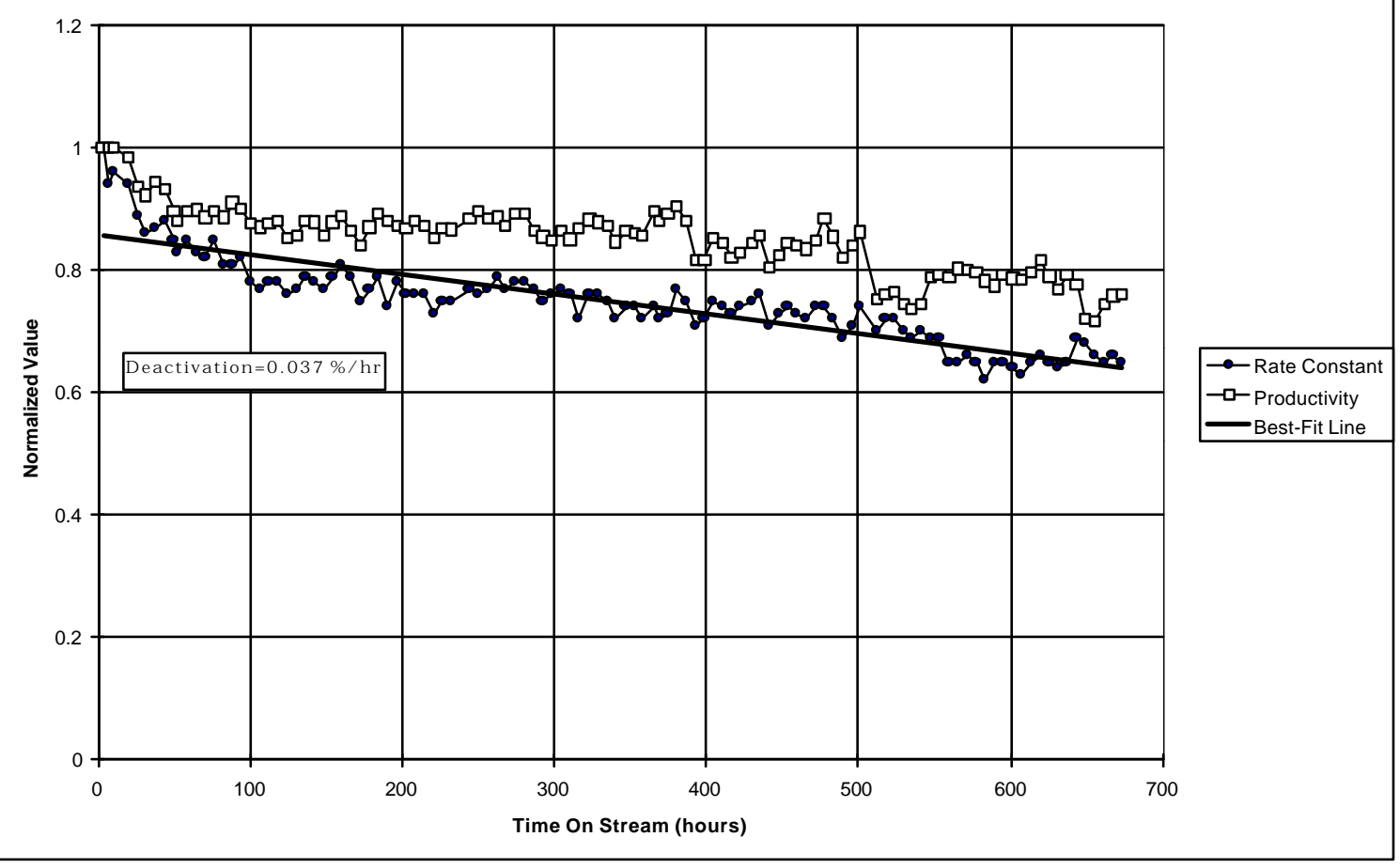




\section{Figure 19: Correlation of Productivity Deviations with Carbon Dioxide Concentrations}

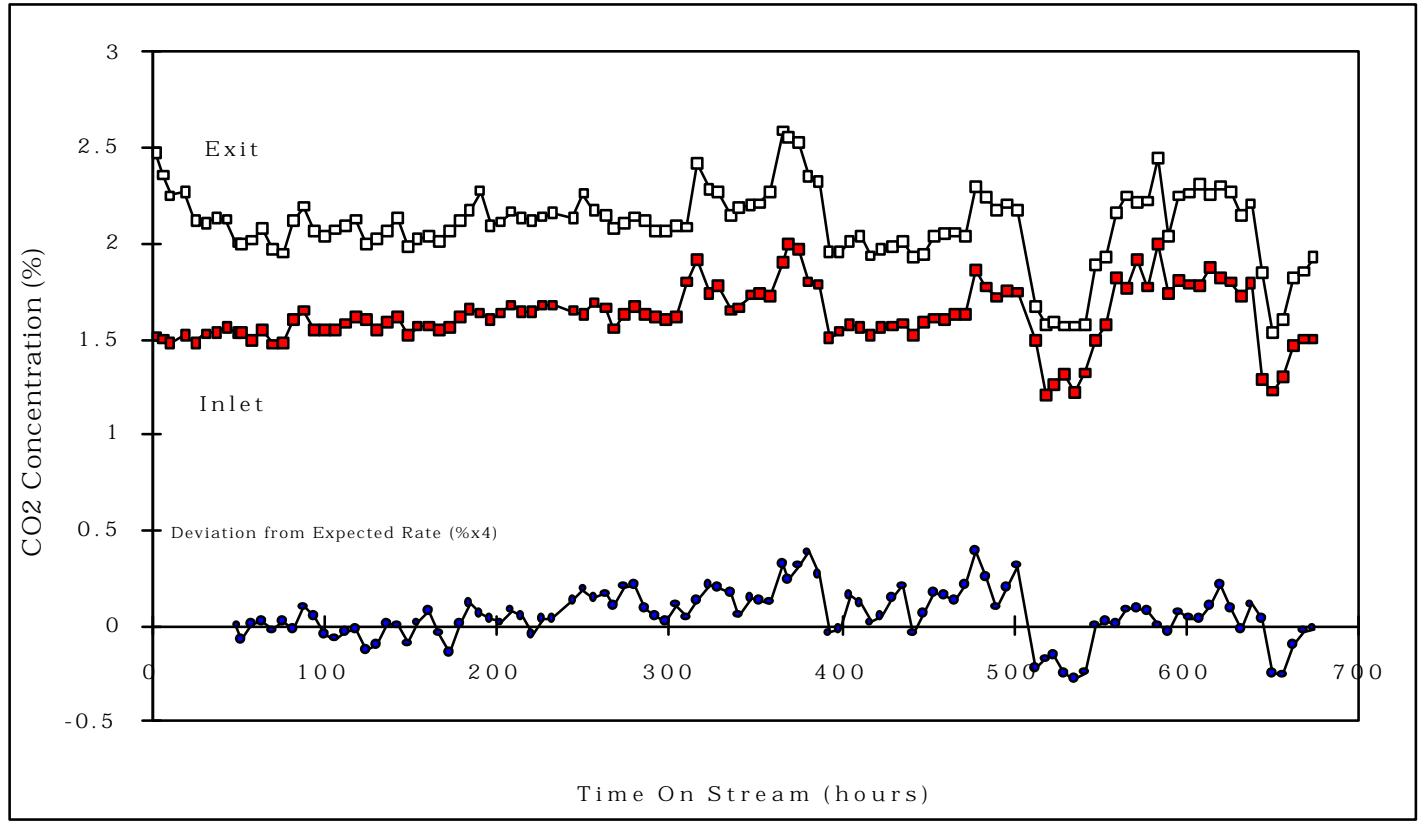

Figure 20: Analysis of Productivity Data

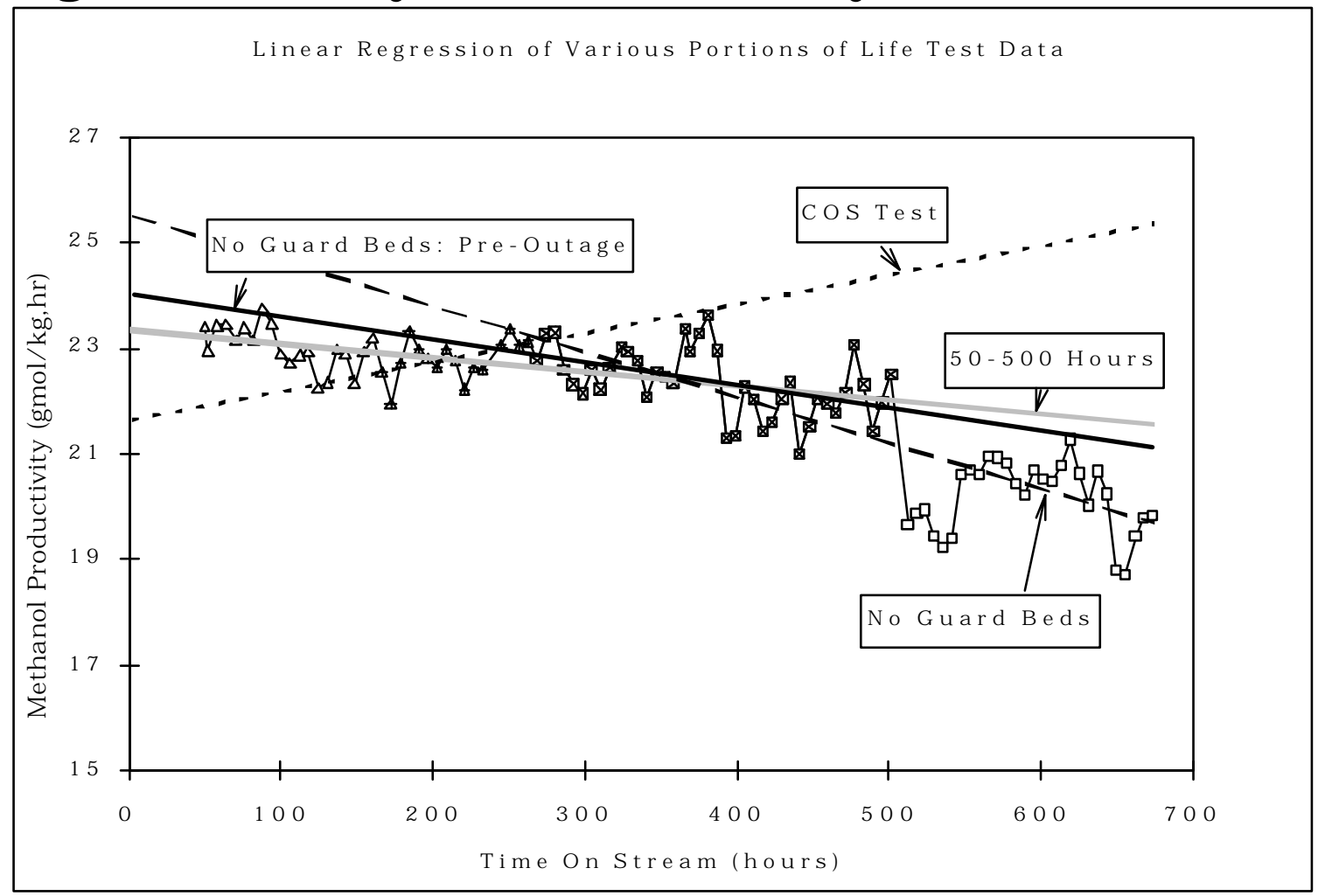




\section{Figure 21: Analysis of Rate Constant Data}

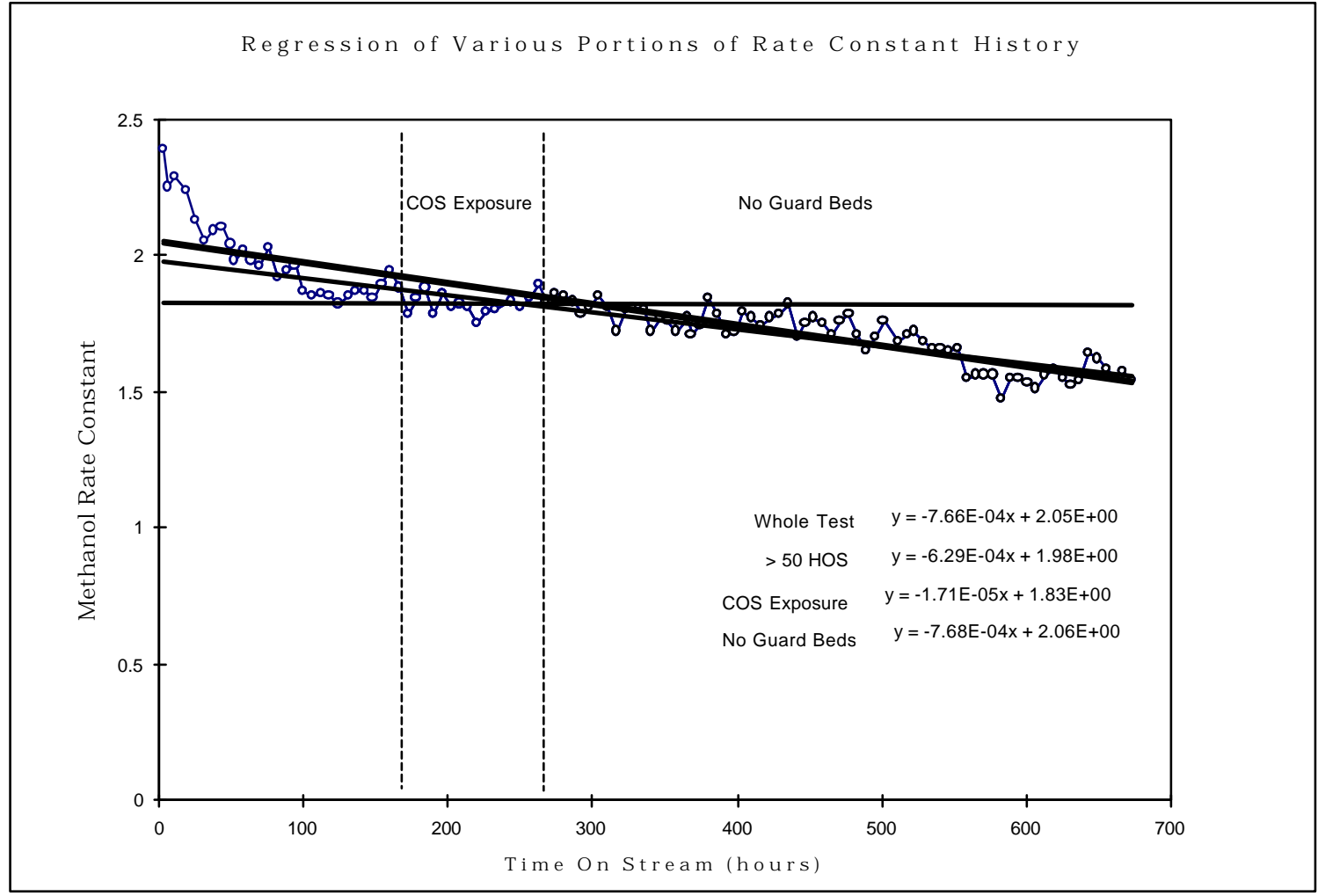


Figure 22: Infrared Spectra of Slurry Oils

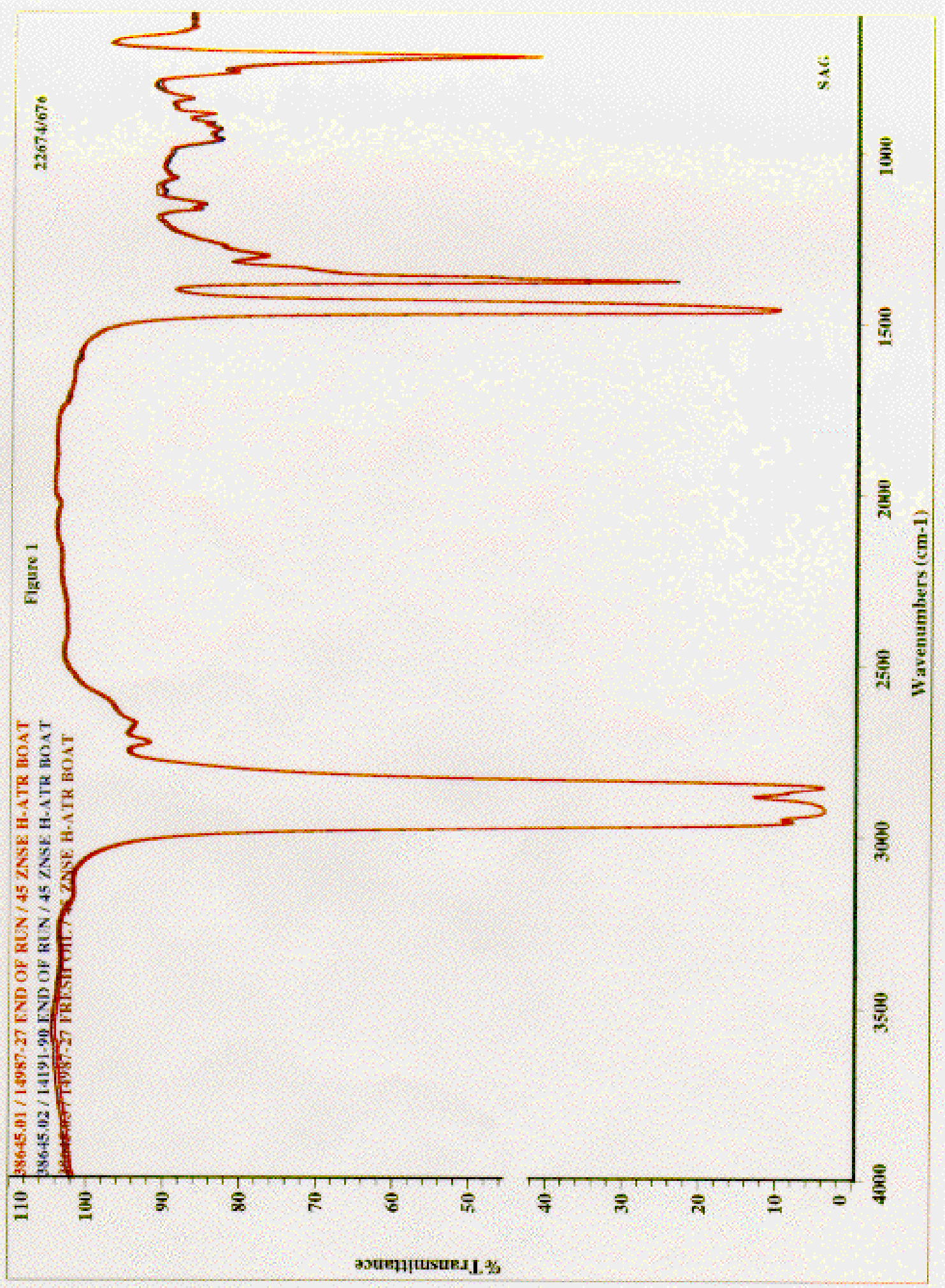


Figure 23: Raman Spectra of Slurry Oils

है

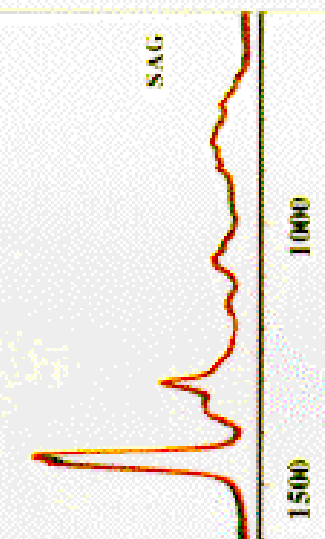

茯

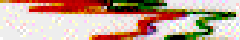

:

홀

is

푤

安合

妾

政

ivis
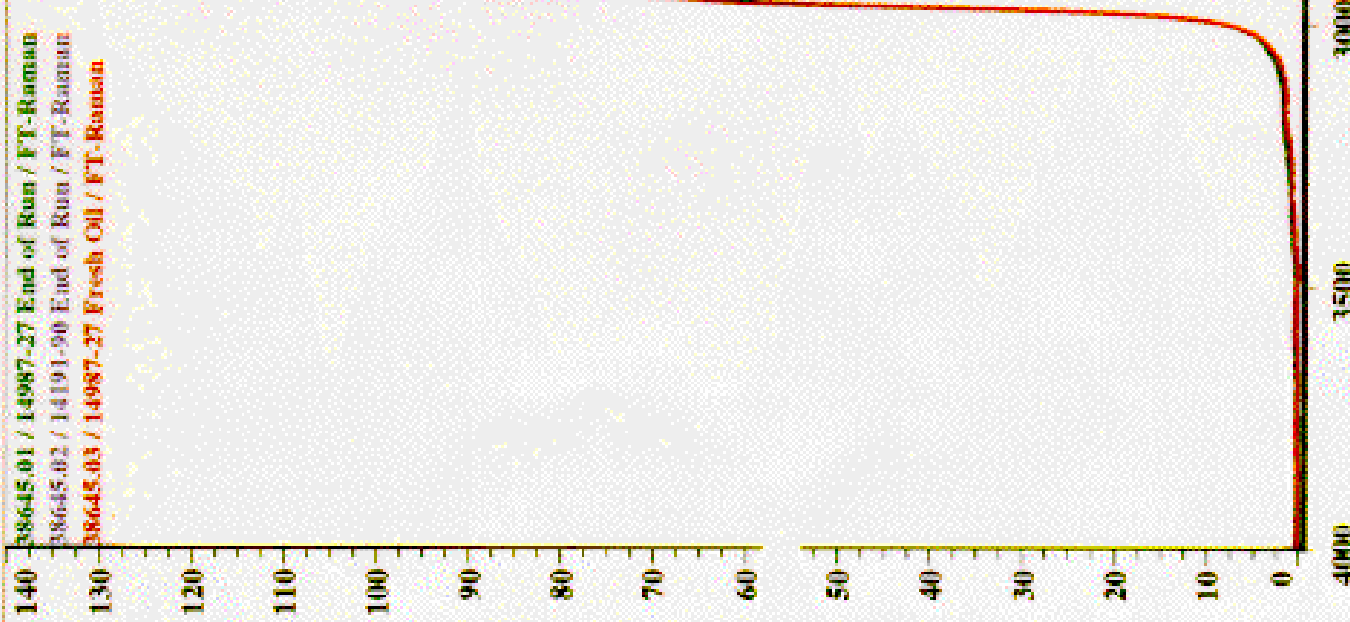


\section{Figure 24: UV/Vis Spectra of Slurry Oils}

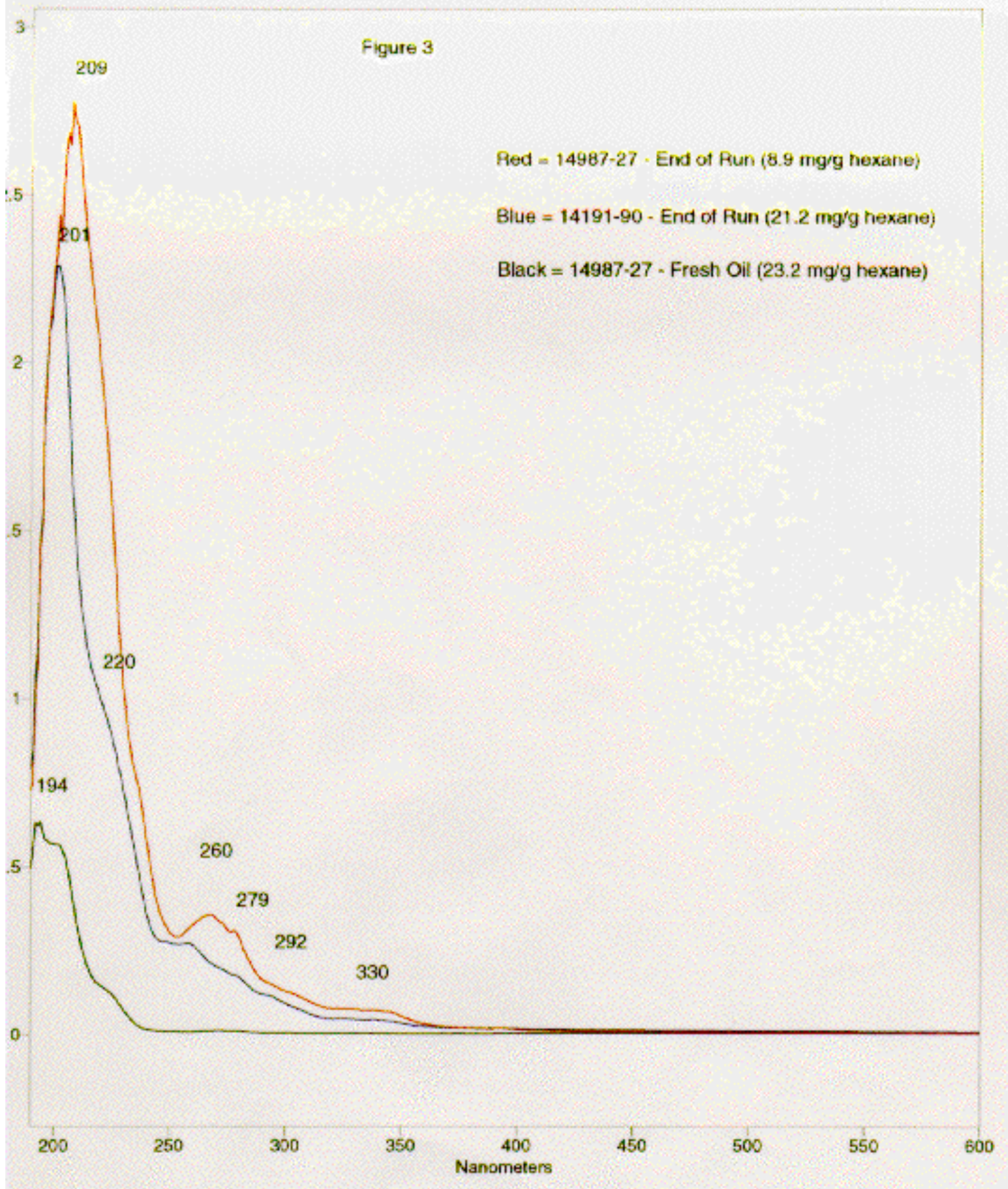




\section{Figure 25: X-Ray Diffraction Pattern of Spent Catalyst from Kingsport Test}

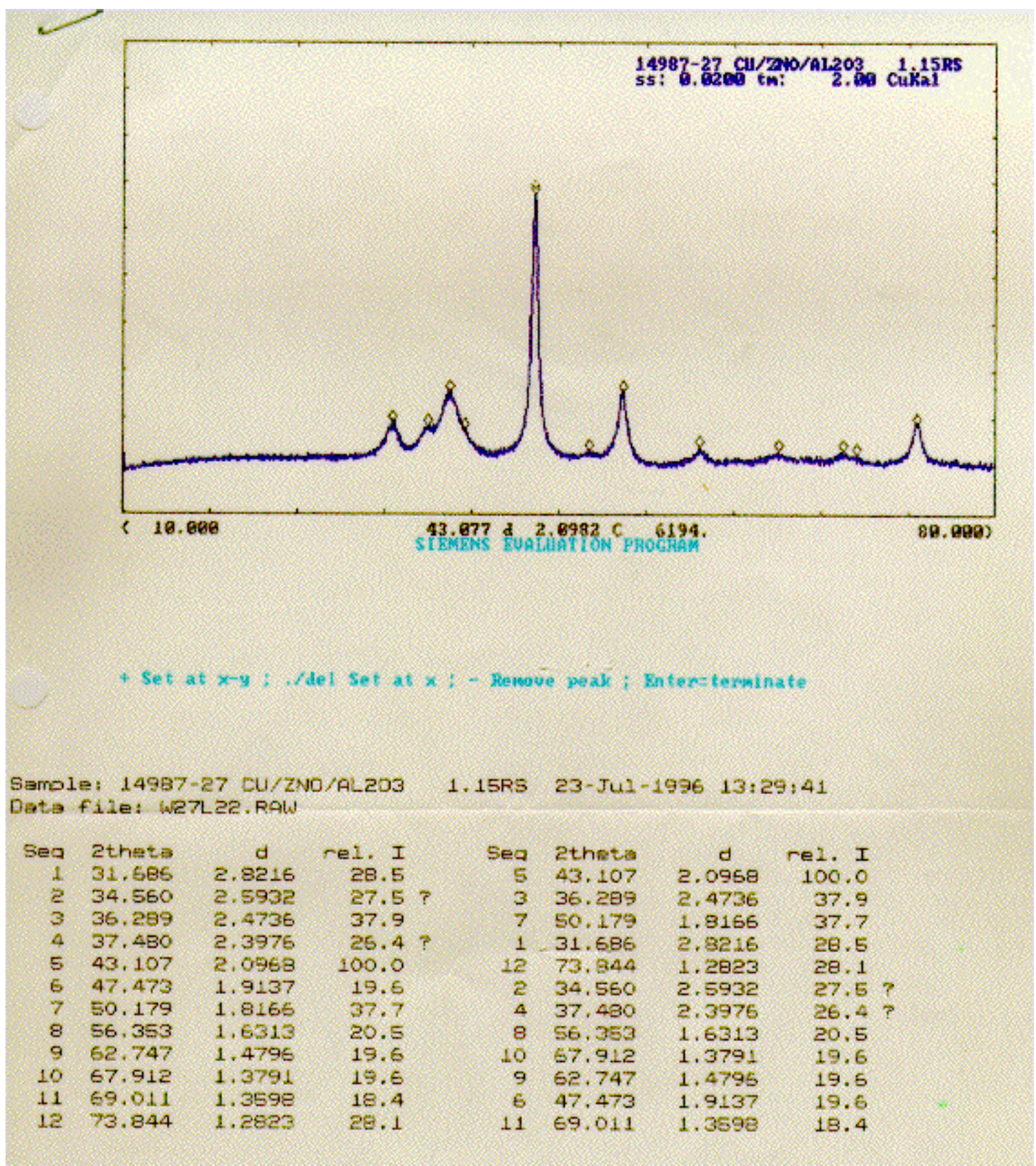

